INSTITUTO DE PESQUISAS ENERGÉTICAS E NUCLEARES Autarquia associada à Universidade de São Paulo

\title{
CARACTERIZAÇÃO DO CAMPO DE NÊUTRONS NA INSTALAÇÃO PARA ESTUDO EM BNCT NO REATOR IEA-R1
}

\section{VALDECI CARNEIRO JUNIOR}

Dissertação apresentada como parte dos requisitos para obtenção do grau de Mestre em Ciências na Área de Tecnologia Nuclear - Reatores.

Orientador:

Dr. Paulo Rogério Pinto Coelho 
INSTITUTO DE PESQUISAS ENERGÉTICAS E NUCLEARES Autarquia associada à Universidade de São Paulo

\section{CARACTERIZAÇÃO DO CAMPO DE NÊUTRONS NA INSTALAÇÃO PARA ESTUDO EM BNCT NO REATOR IEA-R1}

\section{VALDECI CARNEIRO JUNIOR}

Dissertação apresentada como parte dos requisitos para obtenção do grau de Mestre em Ciências na Área de Tecnologia Nuclear - Reatores.

Orientador:

Dr. Paulo Rogério Pinto Coelho 
Dedico este trabalho,

A minha amada esposa Camila,

pela cumplicidade, amor e compreensão,

e ao meu avô José Domingues Carneiro

(in memorian), por tudo que vivemos juntos. 


\section{AGRADECIMENTOS}

Agradeço a Deus e minha família por tudo que fizeram por mim.

Ao Dr. Paulo Rogério Pinto Coelho pela orientação sempre concisa, pelo empenho em atender-me e resolver tudo que fosse preciso para o andamento e realização deste trabalho.

Aos amigos Rafael Muniz de Souza e Jefferson Francisco do Nascimento por fazer parte fundamental deste trabalho.

Aos amigos Mestre Márcio Müller e ao Mestre Eduardo Souto pela força e colaboração neste trabalho.

A minha esposa pela ajuda e colaboração na realização deste trabalho.

Ao meu irmão Dr. Wanderley Carneiro pela ajuda e apoio na realização, deste trabalho e pela amizade de sempre.

Ao Dr. José Eduardo Manzoli, Mestre Flávio, Mestre Vicente Paulo de Campos, pela colaboração.

A Dra. Maria Carolina Cassino Carneiro pelo apoio.

Aos pesquisadores do centro de metrologia das Radiações do IPEN, laboratório de Calibração de Instrumentos (LCI).

Aos meus pais, Valdeci Carneiro, Alzira da Silva Cunha Carneiro, Minha avô Durvalina Ferreira Carneiro e Minha irmã Vera Lucia Aparecida Carneiro.

Aos meus amigos Lincoln Tadeu, Mara Rubia e Maria Luiza, pelo apoio de sempre.

A minha grande amiga quase filha Mel Bonini Carneiro.

A todos os meus sobrinhos, Amanda, Bruno, Aninha, Paola e Thiago.

A todos que diretamente ou indiretamente ajudaram-me na execução deste trabalho. 


\title{
CARACTERIZAÇÃO DO CAMPO DE NÊUTRONS NA INSTALAÇÃO PARA ESTUDO EM BNCT NO REATOR IEA-R1.
}

\author{
Valdeci Carneiro Junior
}

\begin{abstract}
RESUMO
Este trabalho tem como objetivo realizar a caracterização do campo de nêutrons e radiação gama na posição de irradiação de amostras em uma instalação para pesquisas em Terapia por Captura de Nêutrons em Boro (BNCT) no IPEN, junto ao reator IEA-R1. A técnica de BNCT vem sendo estudada como uma opção seletiva e segura de tratamento para tumores cancerígenos resistentes ou considerados não tratáveis pelas técnicas convencionais, por exemplo, o Glioblastoma Multiforme - tumor cancerígeno no cérebro.

Foram realizadas medições de fluxos de nêutrons térmicos, epitérmicos e rápidos bem como das doses devido a nêutrons, e radiação gama na posição de amostra, utilizando-se detectores de ativação tipo folha e dosímetros termoluminescente. Para determinação da intensidade e do espectro de energia de nêutrons, foi utilizado um conjunto de folhas de ativação de energias limiares distintas, irradiadas na instalação e analisadas com um detetor semicondutor de Germânio hiper puro acoplado a um sistema eletrônico adequado para espectrometria gama e os resultados processados com o código SAND-BP.

As doses devidas a radiação gama e nêutrons foram determinadas utilizando dosímetros termoluminescentes: TLD-400 (sensível a gama); TLD-600 (sensível a nêutrons) e TLD-700 (sensível a gama). Os TLDs foram selecionados e usados para a obtenção das curvas de calibração - resposta do dosímetro versus dose - de cada uma dos três tipos de TLD, as quais foram utilizadas para calcular as doses devidas a nêutrons e gama na posição de amostra.

O campo de radiação na posição de irradiação de amostra foi caracterizado fluxo para nêutrons térmicos de $1.39 .10^{8} \pm 0,12.10^{8} \mathrm{n} / \mathrm{cm}^{2} \mathrm{~s}$ a dose devido a nêutrons térmicos é três vezes maior que as devido a radiação gama, essas medidas comprovam a reprodutibilidade e consistência dos resultados experimentais obtidos. Considerando os resultados obtidos, verificou-se que o campo de nêutrons e radiação gama atende para pesquisa em BNCT.
\end{abstract}




\title{
NEUTRON FIELD CHARACTERIZATION IN THE INSTALLATION FOR BNCT STUDY IN THE IEA R1 REACTOR.
}

\author{
Valdeci Carneiro Junior
}

\begin{abstract}
This work aims to characterize the mixed neutron and gamma field, in the sample irradiation position, in a research installation for Boron Neutron Capture Therapy (BNCT), in the IPEN IEA-R1 reactor. The BNCT technique has been studied as a safe and selective option in the treatment of resistant cancerigenous tumors or considered non-curable by the conventional techniques, for example, the Glioblastoma Multiform - a brain cancerigenous tumor.

Neutron flux measurements were carried out: thermal, ressonance and fast, as well as neutron and gamma rays doses, in the sample position, using activation foils detectors and thermoluminescent dosimeters. For the determination of the neutron spectrum and intensity, a set of different threshold activation foils and gold foils covered and uncovered with cadmium irradiated in the installation was used, analyzed by a high Pure Germanium semiconductor detector, coupled to an electronic system suitable for gamma spectrometry. The results were processed with the SAND-BP code.

The doses due to gamma and neutron rays were determined using thermoluminescent dosimeters TLD 400 and TLD 700 sensitive to gamma and TLD 600, sensitive to neutrons. The TLDs were selected and used for obtaining the calibration curves - dosimeter answer versus dose - from each of the TLD three types, which were necessary to calculate the doses due to neutron and gamma, in the sample position.

The radiation field, in the sample irradiation position, was characterized flux for thermal neutrons of $1.39 .10^{8} \pm 0,12.10^{8} \mathrm{n} / \mathrm{cm}^{2} \mathrm{~s}$ the doses due to thermal neutrons are three times higher than those due to gamma radiation and confirm the reproducibility and consistency of the experimental findings obtained. Considering these results, the neutron field and gamma radiation showed to be appropriated for research in BNCT.
\end{abstract}




\section{LISTA DE FIGURAS}

Figura 1 - Instalação para Pesquisa em BNCT no Reator IEA-R1.

Figura 2 - Níveis de transição envolvidos na produção de fluorescência (a) e de

fosforescência (b).

Figura 3 - Espectro eletromagnético.

Figura 4 - Curva Termoluminescente do TLD-400 para uma taxa de aquecimento de $1{ }^{\circ} \mathrm{C} / \mathrm{s} .20$

Figura 5 - Curva Termoluminescente do TLD-600 para uma taxa de aquecimento de $1{ }^{\circ} \mathrm{C} / \mathrm{s} .21$

Figura 6 - Curva Termoluminescente do TLD-700 para uma taxa de aquecimento de $1{ }^{\circ} \mathrm{C} / \mathrm{s} .22$

Figura 7 - Níveis de energia na banda proibida de um sólido. ............................................24

Figura 8 - Curva da resposta termoluminescente, em função da dose absorvida para $0{ }^{60} \mathrm{Co}$, para diferentes materiais termoluminescentes.A: $\mathrm{SiO}_{2}$; B: LiF:Mg,Ti; C: TLD-400 $\left(\mathrm{CaF}_{2}: \mathrm{Mn}\right)^{[22]}$.

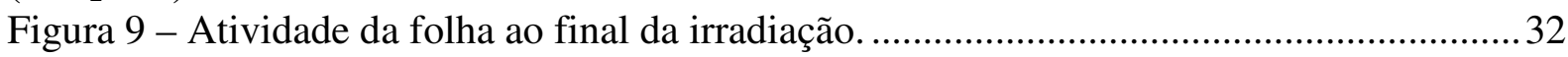

Figura 10 - Definição de Energia Limiar Efetiva. .................................................................. 35

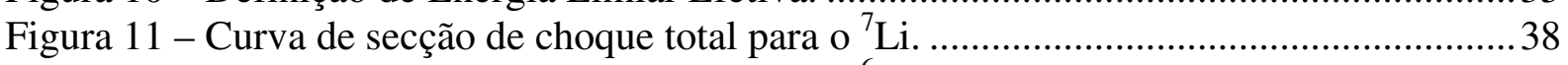

Figura 12 - Curva de secção de choque total para o ${ }^{6} \mathrm{Li}$.........................................................39

Figura 13 - Vista externa da instalação para pesquisa em BNCT, lado direito. ...................... 40

Figura 14 - Vista externa da instalação para pesquisa em BNCT, lado esquerdo. ...................41

Figura 15 - (a) câmeras dentro da instalação para a visualização da inserção e retirada de amostras; (b) monitor que projeta as imagens das câmeras dentro da instalação. ...................41 Figura 16 - (a) Amostra presa à garra fora da instalação; (b) Garra com a amostra descendo pelo trilho; (c) Amostra na calha para inserção no BH-3; (d) calha inserida no BH-3 para

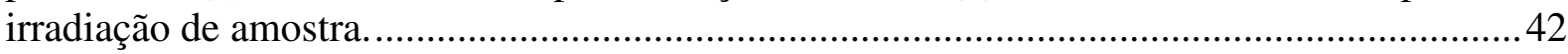

Figura 17 - Placa para acomodação dos dosímetros. ......................................................... 44

Figura 18 - Suporte para irradiação e transporte dos dosímetros.......................................... 44

Figura 19 - Esquema do suporte para irradiação e transporte dos dosímetros. ..........................45

Figura 20 - Forno utilizado para o tratamento térmico........................................................ 45

Figura 21 - Fonte pertencente ao LDT, suportes contendo nove TLDs colocados a uma

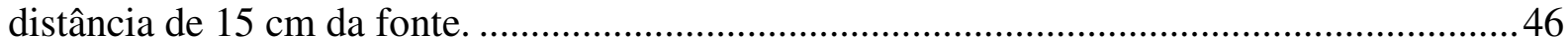

Figura 22 - Posicionamento do suporte para ser irradiado. A posição da seta no bastão de alumínio indica o local onde está a fonte.

Figura 23 - Leitora Harshaw modelo 2000 pertencente ao LDT/IPEN, os dois módulos

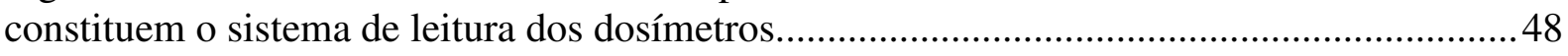

Figura 24 - Leitora de TLDs com a gaveta aberta. ..............................................................50

Figura 25 - Chapa de aço utilizada para o tratamento térmico dos dosímetros. Ela é perfurada

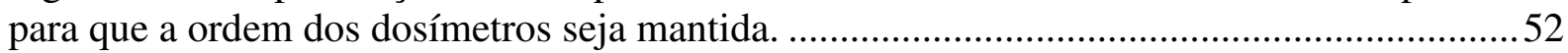

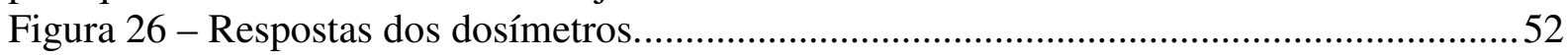

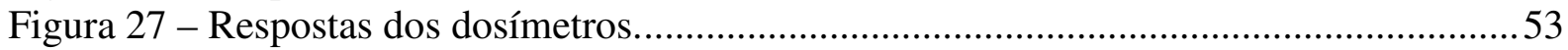

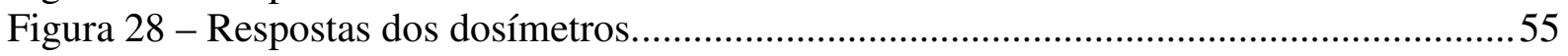

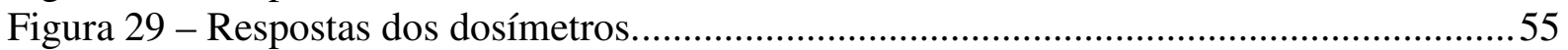

Figura 30 - Fonte pertencente ao (CTR/IPEN), suportes contendo três TLDs-400 na linha

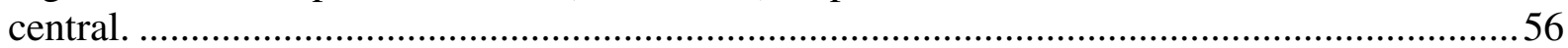

Figura 31 - Suporte de acrílico utilizado para colocar os dosímetros na posição onde as

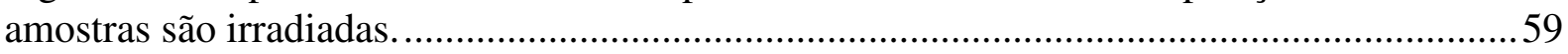

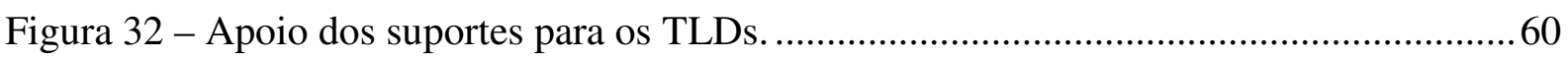

Figura 33 - Calha onde estão os discos de chumbo (blindagem) e o local onde as amostras são posicionadas para serem irradiadas. Suporte fixo a calha metálica e cestinha posicionada em

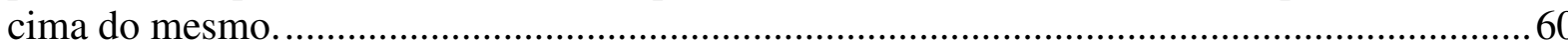


Figura 34 - Mesa com o conjunto calha mais esteira está em cima de uma mesa..................61

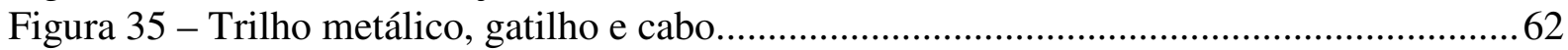

Figura 36 - (a) Laboratório do reator IPEN/MB01 e (b) Detalhe das gavetas a onde são

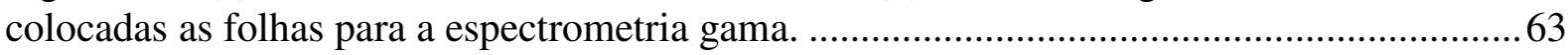

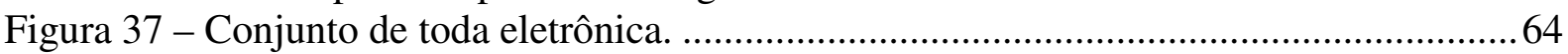

Figura 38 - Curvas de eficiência das gavetas: 3 (a), 5 (b) e 7 (c)........................................ 66

Figura 39 - Tela do software Maestro para a folha de ouro nua irradiada no dia 20/12/05....67

Figura 40 - Curva de calibração para os TLDs-400 para o intervalo de dose de 0,5 até 90Gy.

Figura 41 - Curva de calibração para os TLDs-400 para o intervalo de dose de 100 até 500Gy.

Figura 42 - Pontos experimentais obtidos para os TLDs-400 para o intervalo de dose de 0,5

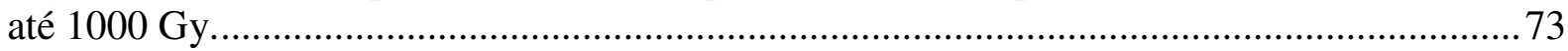

Figura 43 - Curva de calibração para os TLDs-700 para o intervalo de dose de 0,5 até 20 Gy. 74

Figura 44 - Curva de calibração para os TLDs-700 para o intervalo de dose de 30 até 600Gy. 75

Figura 45 - Pontos experimentais obtidos para os TLDs-700 para o intervalo de dose de 0,5

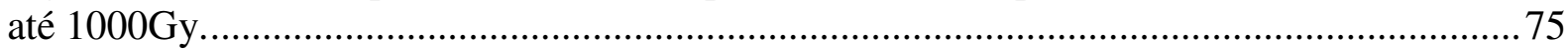

Figura 46 - Curva de calibração para os TLDs-600 para o intervalo de dose de 0,5 até 100m

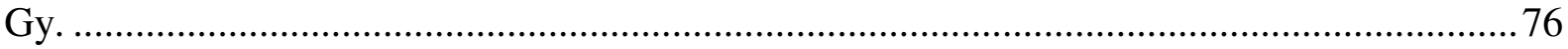

Figura 47 - Espectro de energia de nêutrons utilizado como dado de entrada para o programa

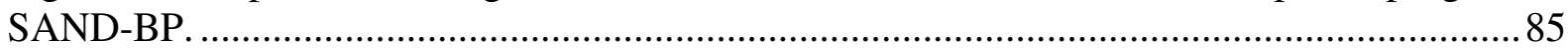

Figura 48 - Espectro de saída do programa SAND-BP após 5 interações............................... 86 


\section{SUMÁRIO}

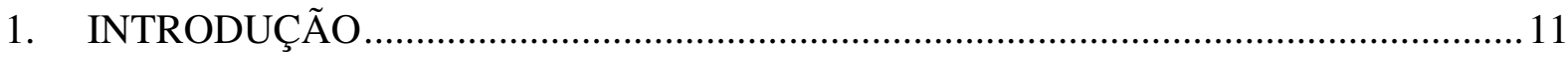

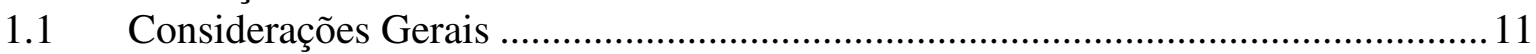

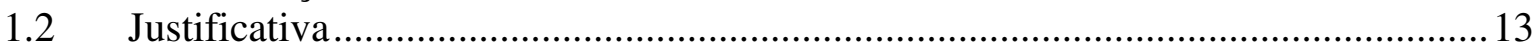

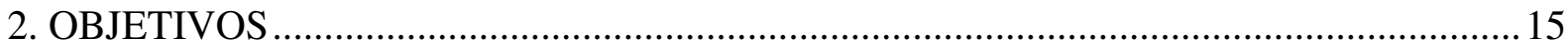

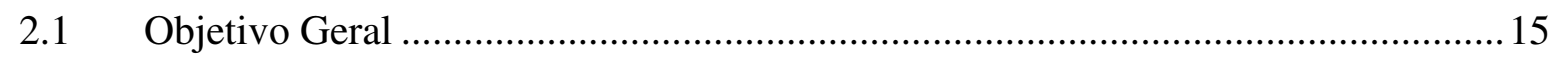

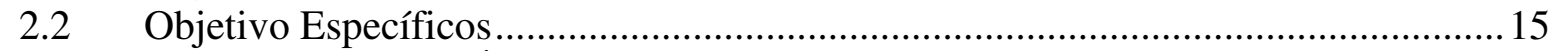

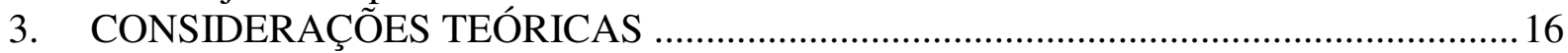

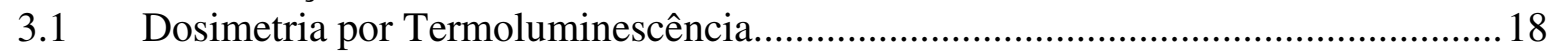

3.1.1 Termoluminescência: Processo e Propriedades.............................................. 18

3.2 Teoria de Adirovitch para a Fosforescência ............................................................ 23

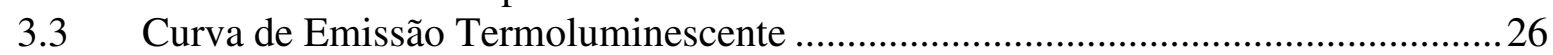

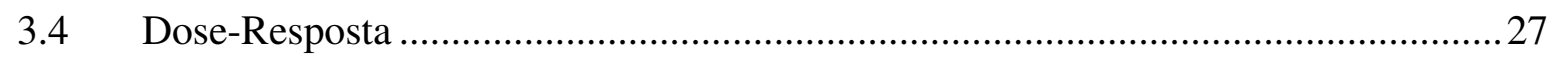

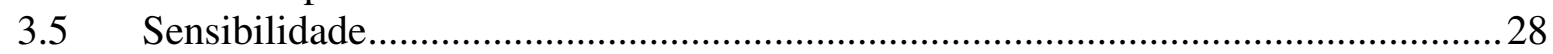

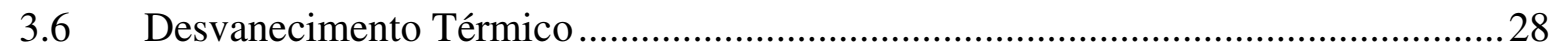

3.7 Tratamento Térmico de Reutilização ...................................................................29

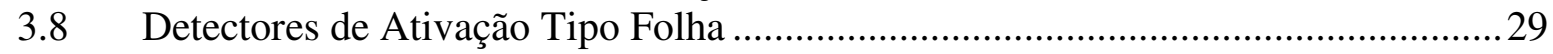

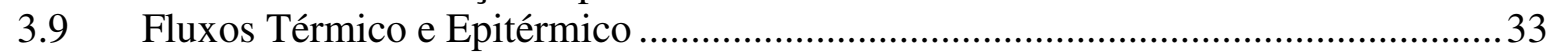

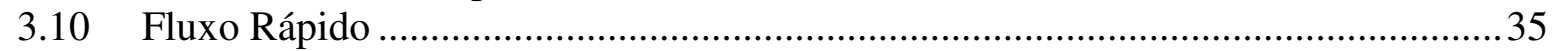

3.11 Determinação do Espectro de Nêutrons por Detectores de Ativação........................36

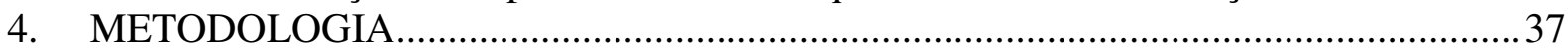

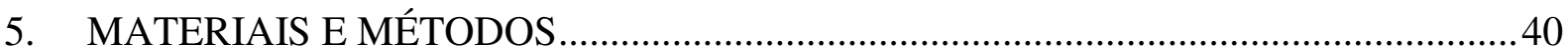

5.1 DESCRIÇÃO DA INSTALAÇÃO PARA PESQUISA EM BNCT ........................... 40

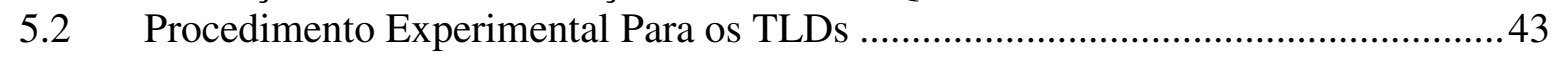

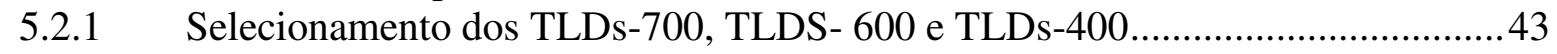

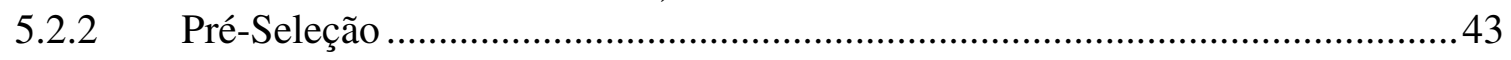

5.2.3 Tratamento térmico nos TLDs-700, TLDS- 600 e TLDs-400............................45

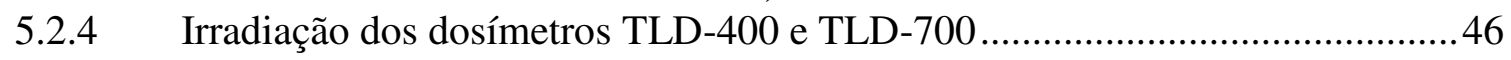

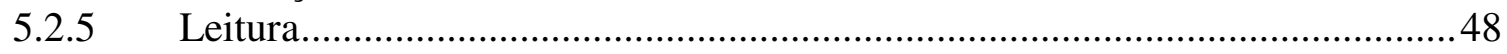

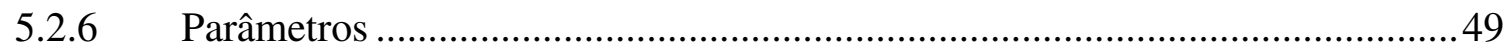

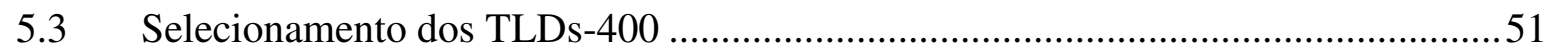

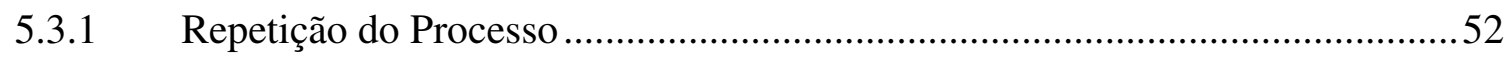

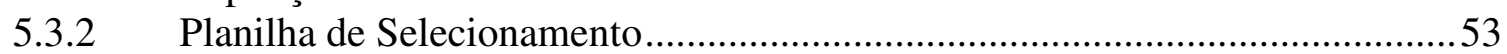

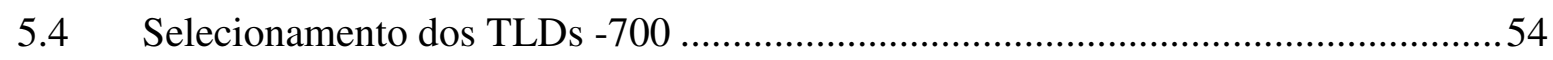

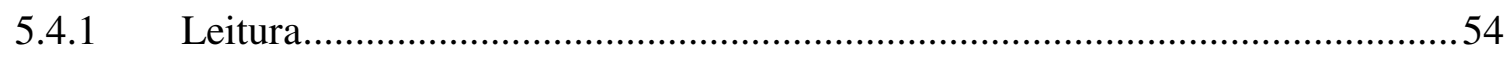

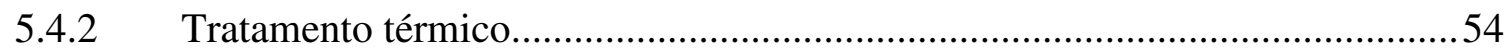

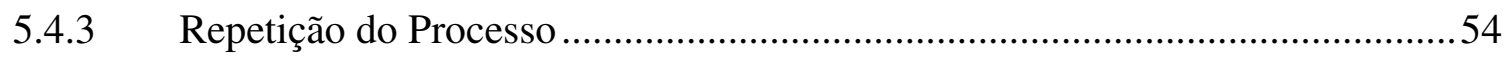

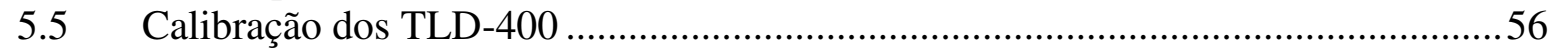

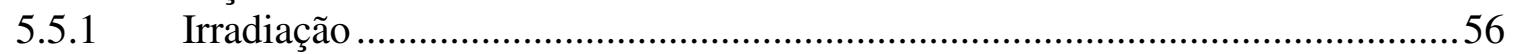

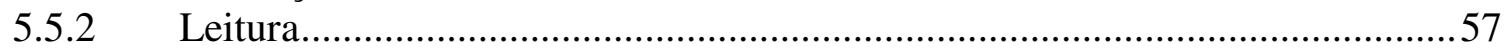

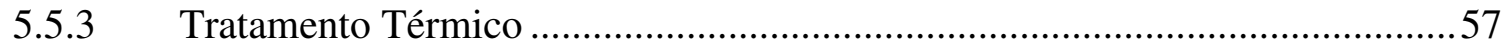

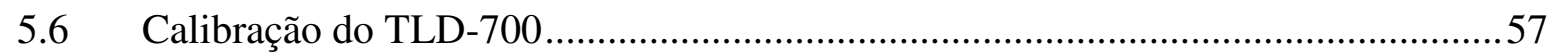

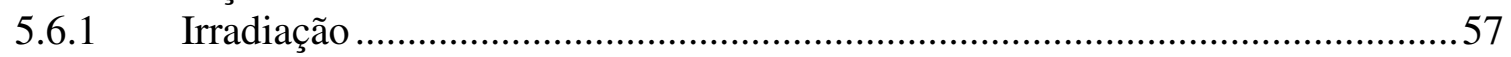

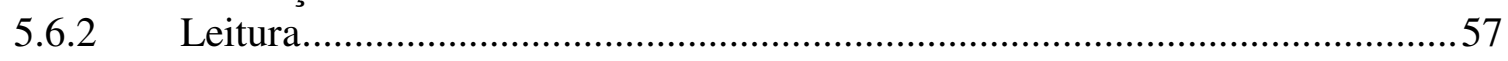

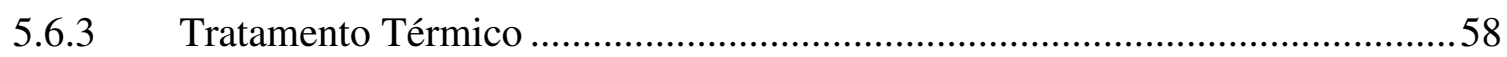

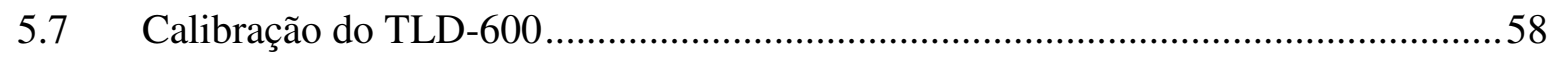

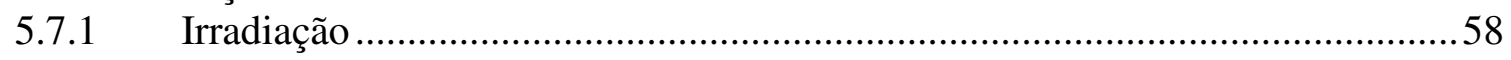

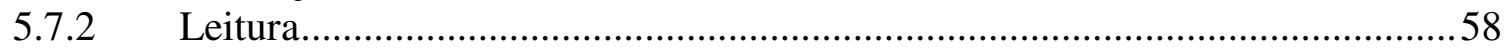




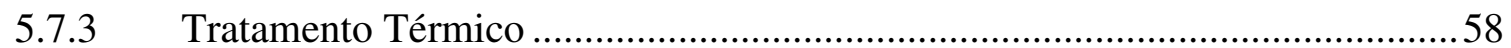

5.8 Medidas na Instalação para Pesquisas em BNCT .................................................58

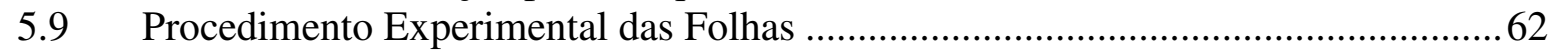

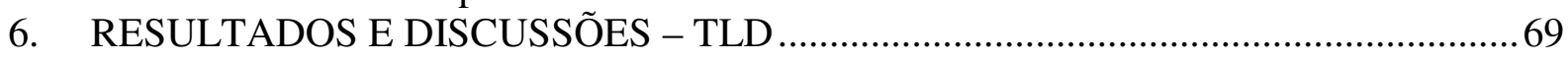

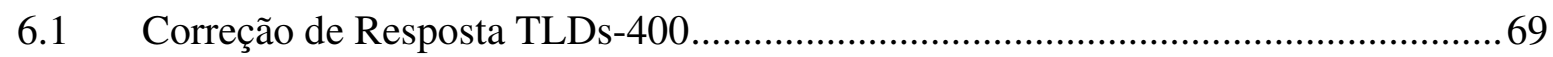

6.2 Tabela de Estudo da Janela Aberta e Fechada.......................................................69

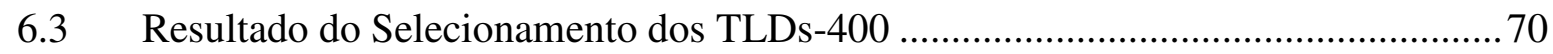

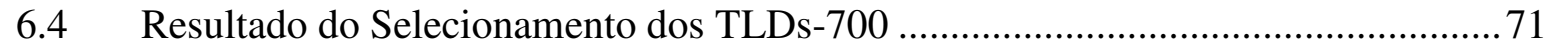

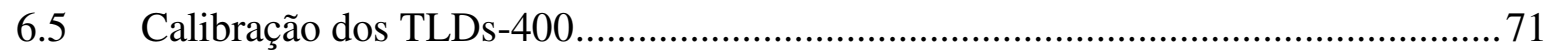

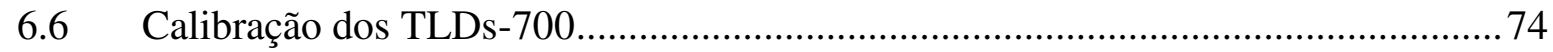

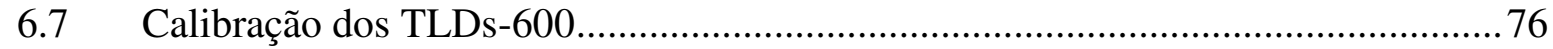

6.8 Medidas na Instalação para Pesquisas em BNCT ...............................................76

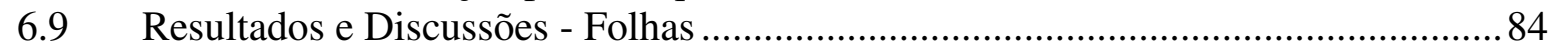

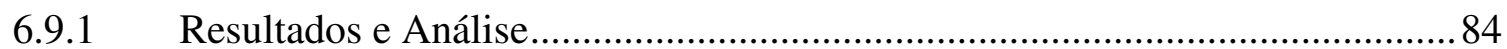

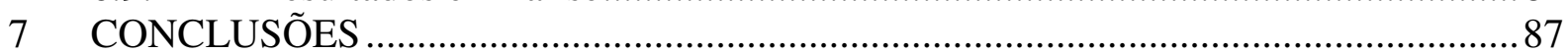

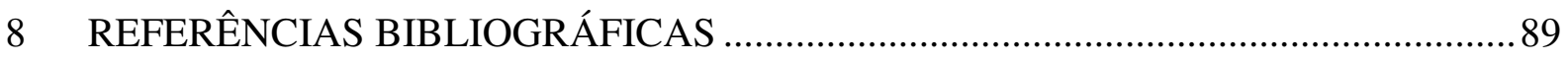

ANEXO 1 - RESULTADO DO SELECIONAMENTO DOS TLDS - 400 E TLDS - 700...91

ANEXO 2 - CALIBRAÇÃO TLD-400 e TLD-700 CTR CALIBRAÇÃO TLD-600 IRD.....98 


\section{INTRODUÇÃO}

\subsection{Considerações Gerais}

Um tratamento em que todas as células do tumor pudessem ser destruídas seletivamente sem causar danos aos tecidos normais é considerado uma técnica de terapia ideal contra o câncer.

Quatro anos após a descoberta dos nêutrons em 1932 por J. Chadwick da Universidade de Cambridge, o biofísico, G.L. Locher, do Instituto Franklin na Pensilvânia introduziu o conceito de terapia por captura do nêutron (NCT): - "ligação de um nuclídeo com alta seção de choque microscópica de captura para nêutrons a um tumor" e posterior irradiação do mesmo com nêutrons.

A Terapia por Captura de Nêutrons em Boro $(\mathrm{BNCT})^{[1,2,3]}$, vem sendo estudada como uma opção seletiva e segura de tratamento para os tumores cancerígenos resistentes ou considerados não tratáveis pelas técnicas convencionais (cirurgia, radioterapia por raios gama e quimioterapia), como por exemplo, o Glioblastoma Multiforme - tumor cancerígeno no cérebro.

Os primeiros testes clínicos de $\mathrm{BNCT}^{[4]}$ foram realizados nos reatores nucleares do Brookhaven National Laboratoy (BNL) e do Massachussetts Institute of Tecnology (MIT) na década de 50 e início dos anos 60. Estes testes utilizavam feixes de nêutrons térmicos, contudo, não obtiveram bons resultados, pois o composto de boro não era seletivo ou seja, era absorvido igualmente pelas células sadias e pelas cancerígenas. Com isso os pacientes não tinham uma sobrevida melhor se comparada com as técnicas convencionais da época.

No Japão, no final dos anos 60 o tratamento com BNCT começou obter bons resultados, no Musashi (MITRR), com Hatanaka que utilizou um composto seletivo $\left(\mathrm{Na}_{2} \mathrm{~B}_{12} \mathrm{H}_{11} \mathrm{SH}\right.$, identificado como BSH), desenvolvido por um grupo de químicos. ${ }^{[5]}$ Em seguida, o tratamento com BNCT também começou a ser aplicado no Kyoto Universitty Reactor (KUR), e no Japan Atomic Energy Research (JRR-2) todos estes reatores fornecem feixe de nêutrons térmicos ${ }^{[2]}$. 
Entre estes reatores, somente o JRR4 e o KUR estão atualmente disponíveis para o tratamento contra o câncer cerebral. O KUR foi remodelado para o tratamento com BNCT, fornecendo agora dois feixes de nêutrons, um feixe epitérmico e outro térmico. Os participantes do "Europeam Collaboration" para BNCT modificaram o reator de alto fluxo (HFR) de Petten, na Holanda, para obter um feixe epitérmico com o objetivo de realizar testes clínicos em animais e estudos em humanos ${ }^{[2]}$.

Nos Estados Unidos, dois reatores estão atualmente sendo usados para testes clínicos de BNCT com feixes epitérmicos: o Brookhaven Medical Research Reator (BMRR) e o Massachusetts Institute of Technology Reactor (MITTR) ${ }^{[4]}$.

A técnica de BNCT é realizada em dois estágios: no primeiro estágio, aplica-se no paciente, um composto especial contendo boro $\left({ }^{10} \mathrm{~B}\right)$, que é absorvido preferencialmente pelas células cancerígenas. $\mathrm{O}{ }^{10} \mathrm{~B}$ é um isótopo não tóxico, não radioativo, com abundância isotópica natural de $20 \%$ e com alta secção de choque para nêutrons térmicos. No segundo estágio, o órgão do paciente que contém o tumor cancerígeno, é submetido à irradiação com um fluxo de nêutrons térmicos, induzindo a seguinte reação:

$$
{ }_{0}^{1} n+{ }_{5}^{10} B \rightarrow \begin{cases}{ }_{3}^{7} \mathrm{Li}^{*}+{ }_{2}^{4} \mathrm{He} & \mathrm{Q}=2,310 \mathrm{MeV} \text { (estado excitado) } \\ { }_{3}^{7} \mathrm{Li}+{ }_{2}^{4} \mathrm{He} & \mathrm{Q}=2,792 \mathrm{MeV} \text { (estado fundamental) }\end{cases}
$$

onde as partículas produzidas na reação, partículas alfa $(\alpha)$ e os íons de Lítio $\left({ }^{7} \mathrm{Li}\right)$, possuem uma alta energia cinética. Estas partículas possuem uma alta transferência linear de energia (LET), o que faz com que transfiram sua energia para o tecido na distância de aproximadamente $9 \mu \mathrm{m}^{[7,8]}$, que é da ordem do diâmetro da célula, induzindo assim uma grande probabilidade de destruição das células cancerígenas sem causar grandes danos às células sadias do entorno.

O feixe de radiação para uso em BNCT deve ter a característica de que a dose no tecido sadio seja a menor possível, enquanto que a penetração dos nêutrons deve ser otimizada para permitir o tratamento de tumores superficiais ou profundos. 
Os raios gama e os nêutrons rápidos (altamente energéticos) são indesejáveis, pois, apresentam intenso efeito biológico, além de possuírem um alto poder de penetração. Assim sendo, não depositam sua energia apenas no interior das células cancerígenas e, portanto, também prejudicam o tecido sadio. Por este motivo, é necessário irradiar o tumor com um feixe de nêutrons térmicos de alta intensidade e com o mínimo de contaminantes como nêutrons rápidos e radiação gama.

Para os tumores mais profundos, da ordem de 2 a $3 \mathrm{~cm}$, utiliza-se um feixe de nêutrons epitérmicos, que são moderados por reações de espalhamento e chegam ao tumor como nêutrons térmicos.

Para o sucesso de uma irradiação em BNCT, recomenda-se que a fluência de nêutrons térmicos deva ser de aproximadamente $4 \times 10^{12} \mathrm{n} / \mathrm{cm}^{2}$, e que se tenha uma concentração de $30 \mu \mathrm{g}$ de ${ }^{10} \mathrm{~B}$ por grama de tecido tumoral, para que a sessão de irradiação no tumor do paciente seja limitada a pouco mais de uma hora de duração ${ }^{[9]}$.

As pesquisas na área de BNCT têm apresentado grande ímpeto nos últimos anos por causa de resultados promissores obtidos até agora. O Japão possui mais de 300 pacientes já submetidos a essa terapia enquanto que, nos Estados Unidos e na Europa este número já atinge a dezenas ${ }^{[10,11]}$. Devido a perspectiva promissora em BNCT, no Brasil muitos estudos estão sendo realizados inclusive no IPEN.

\subsection{Justificativa}

Foi projetada e construída uma instalação experimental junto ao reator IEA-R1 (figura 1) do IPEN-CNEN/SP (Instituto de Pesquisas Energéticas e Nucleares), para a realização de pesquisas na área de BNCT. A instalação consiste na utilização do tubo de irradiação radial número 3 (BH-3 -"beam hole" número 3) do reator IEA-R1. O tubo do BH3 tem 20,3 cm de diâmetro interno e a posição de irradiação de amostras é no seu interior. O local para o posicionamento das amostras é uma região cilíndrica com 12,8 cm de diâmetro e $30 \mathrm{~cm}$ de altura.

A construção desta instalação tem como principal objetivo à realização de pesquisas na área de Física das Radiações e Radiobiologia, que utilizam feixes de nêutrons. 
Estas pesquisas irão permitir a caracterização dos campos de radiação (nêutrons e gamas) mais adequados para a aplicação da técnica de BNCT, além do desenvolvimento de estudos de filtros para aumentar a eficiência da técnica , avaliar as simulações realizadas pelo grupo de BNCT do IPEN estudos de níveis de dose utilizando "phantons", e também de estudos biológicos "in vitro" e "in vivo". Um esquema da Instalação para pesquisa em BNCT pode ser visto na figura1.

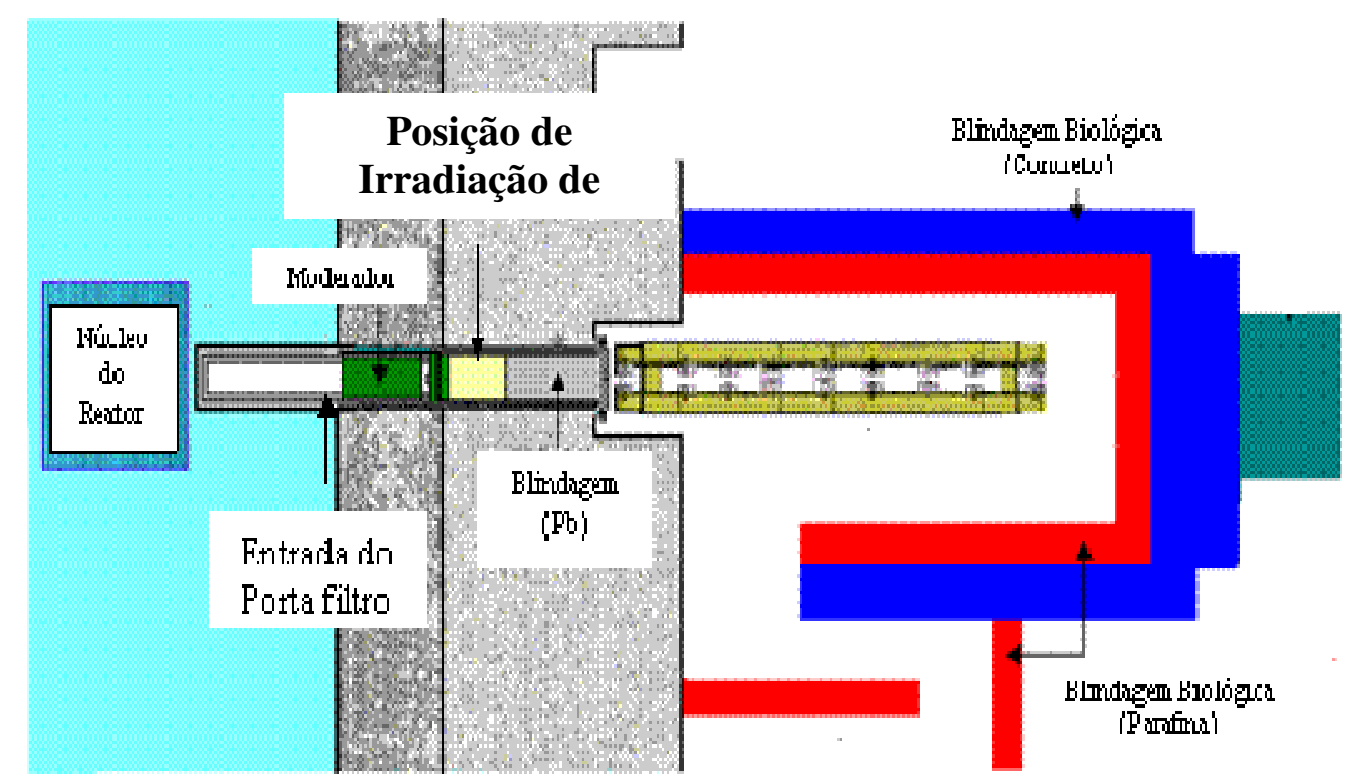

Figura 1 - Instalação para Pesquisa em BNCT no Reator IEA-R1. 


\section{OBJETIVOS}

\subsection{Objetivo Geral}

Caracterizar o campo de nêutrons e de radiação gama na posição de irradiação de amostras da instalação, além de verificar se este campo de radiação é adequado para pesquisa em BNCT.

\subsection{Objetivo Específicos}

- Avaliar os cálculos já realizados para a tomada de possíveis atitudes corretivas, propiciando melhor base técnica para a determinação do conjunto de materiais - moderadores, filtros e blindagem - a serem utilizados nos experimentos futuros.

- Adquirir e ampliar conhecimentos tecnológicos em relação ao uso das radiações em aplicações médicas para a sociedade. 


\section{CONSIDERAÇÕES TEÓRICAS}

Em 28 de outubro de 1663, Sir Robert Boyle, um dos fundadores da Química moderna, descreveu pela primeira vez o fenômeno da termoluminescência (TL) à "Royal Society" de Londres. Ele descreveu a observação de luz emitida por um diamante durante seu aquecimento, conforme reportado na Royal Society de Londres ${ }^{[13]}$. O uso do termo "termoluminescëncia" (TL) na literatura começa no século XIX, com Wiedemann e Schmidt $^{[14]}$, que foram os primeiros a sintetizar fósforo CaSO4:Mn. Somente em 1904, com Marie Curie, soube-se que era possível provocar propriedades TL em cristais expondo-os à radiação ionizante ${ }^{[15]}$. Dessa forma, explicou a capacidade de um material tornar-se luminoso por meio de aquecimento, sendo a capacidade de emitir luz readquirida pela ação da radiação.

Embora o fenômeno da termoluminescência seja conhecido por mais de três séculos, a primeira compreensão matemática foi dada por Randal e Wilkins em 1945 e sua aplicação como ferramenta de pesquisa e na dosimetria da radiação foi proposta subseqüentemente, em 1953, por Daniels que com seu grupo de pesquisa desenvolveu instrumentos para este propósito $^{[16]}$.

Houve uma longa série de pesquisas neste campo desde o surgimento do LiF TLD100, em 1963. Atualmente, a literatura encontra-se repleta tanto dos aspectos teóricos como das aplicações da termoluminescência. De fato, o sistema de TLD se tornou parte integrante de laboratórios de dosimetria e departamentos de física médica. A maneira mais fácil de analisar o progresso dessa área é através das séries de anais das Conferências Internacionais sobre Dosimetria por Luminescência - chamadas a partir de 1980 de Conferências Internacionais sobre Dosimetria no Estado Sólido - que acontecem a cada três anos desde 1965.

Já há décadas existem bons livros sobre TL. ${ }^{[15,16]}$ Aqui é apresentada uma consideração teórica simplificada, um modelo suficiente para a compreensão dos resultados e que permitirá atingir os objetivos desta Dissertação. 
Os átomos de um corpo sólido podem ser excitados fornecendo energia térmica a este corpo, no processo de desexcitação há a possibilidade de emissão de luz visível.

Existem dois processos básicos de emissão de luz: incandescência e luminescência. A incandescência é caracterizada pela mudança de coloração do sólido, este só se torna luminoso a partir de certa temperatura. Esta luminosidade pode ser reproduzida se a temperatura for mantida ou se o sólido for reaquecido.

A luminescência engloba diversos processos de emissão de luz, inclusive aqueles nos quais a excitação é produzida mediante o aquecimento. Para cada método de excitação existe uma classificação da luminescência, essas classificações estão resumidas na tabela 1 .

Tabela 1 - Processos de luminescência.

\begin{tabular}{c|c}
\hline \hline \multicolumn{2}{c}{ LUMINESCÊNCIA } \\
\hline \hline Fenômeno & Método de excitação \\
\hline Termoluminescência & Aquecimento \\
\hline Quimioluminescência & Reações químicas \\
\hline Eletroluminescência & Campo elétrico \\
\hline Triboluminescência & Atrito \\
\hline Radioluminescência & Radiação ionizante \\
\hline Bioluminescência & Reações bioquímicas \\
\hline \hline
\end{tabular}

Em 1960 Curie explicou a luminescência utilizando um esquema de níveis de energia $^{[17]}$. Neste, a emissão de luz pode ocorrer de duas formas: na primeira, ocorre uma transição do estado fundamental para o estado excitado, seguida por um retorno espontâneo ao estado fundamental. Essa emissão de luz espontânea é denominada fluorescência.

$\mathrm{Na}$ segunda forma, durante a passagem do estado fundamental para o estado excitado, pode ocorrer uma transição para um estado metaestável, que é denominado atualmente como armadilha, de onde não é possível haver uma transição espontânea para o estado fundamental, ou seja, torna-se necessário fornecer energia ao sistema para que haja um retorno ao estado fundamental; essa energia é denominada atualmente de profundidade da armadilha. Ao fornecer energia há um retorno ao estado fundamental com emissão de luz, este processo é denominado fosforescência. Pode haver também um retorno ao estado metaestável. 
A figura 2 ilustra os fenômenos de fluorescência e de fosforescência, bem como os intervalos de tempo nos quais cada um destes fenômenos é definido. A emissão de luz de interesse deste trabalho é a fosforescência por termoluminescência.

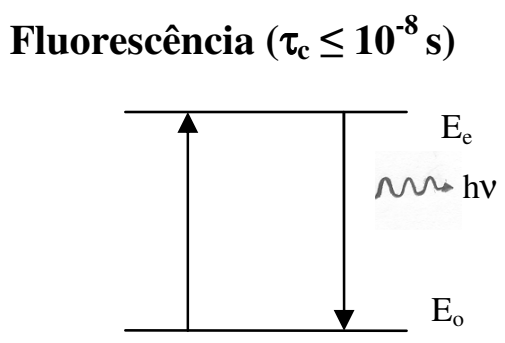

(a)

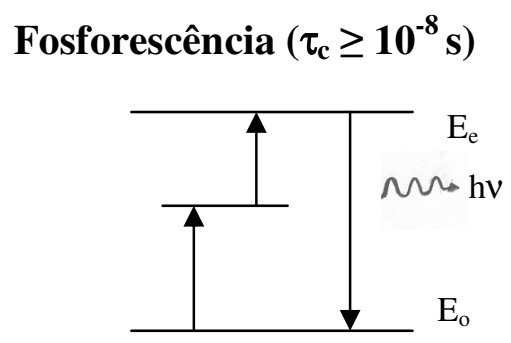

(b)

Onde: $\mathrm{E}_{\mathrm{o}}$ representa o estado fundamental; $\mathrm{E}_{\mathrm{e}}$ representa o estado excitado; $h v$ é a energia do fóton de luz emitido e $\tau_{c}$ representa o tempo entre a absorção da radiação e a emissão do fóton.

Figura 2 - Níveis de transição envolvidos na produção de fluorescência (a) e de fosforescência (b).

\subsection{Dosimetria por Termoluminescência}

\subsubsection{Termoluminescência: Processo e Propriedades}

A Termoluminescência (TL) é uma abreviação de Luminescência Estimulada Termicamente ${ }^{[18]}$. Como o nome sugere, é a emissão de luz devido à estimulação térmica de um material que foi previamente irradiado, onde o aquecimento induz o desprendimento de cargas elétricas resultando em recombinações que causam luminescência. Os materiais geralmente utilizados são inorgânico cristalino ou cristais de fósforos policristralinos, que apresentam defeitos produzidos durante a síntese, inclusive devido a impurezas adicionadas intencionalmente $^{[19]}$.

Ao aquecer um cristal previamente excitado por meio de radiação ionizante, o mesmo libera uma quantidade de luz que é proporcional a energia da radiação incidente ${ }^{[18]}$. Durante o processo de aquecimento, monitora-se a intensidade de luz emitida pelo cristal; esta recebe o nome de intensidade termoluminescente ou intensidade TL.

A luz emitida pelo cristal tem comprimento de onda da ordem do espectro visível $\left(10^{3}\right.$ a $10^{4} \AA$ Á), como pode ser verificado na figura 3 , portanto, pode ser medida por meio de uma 
fotomultiplicadora, desde que a intensidade de luz emitida seja menor que o limite de saturação da mesma ${ }^{[19]}$. A fotomultiplicadora transforma o sinal luminoso em um sinal elétrico, este por sua vez pode ser quantificado mediante um circuito que converte o sinal em um valor de carga.

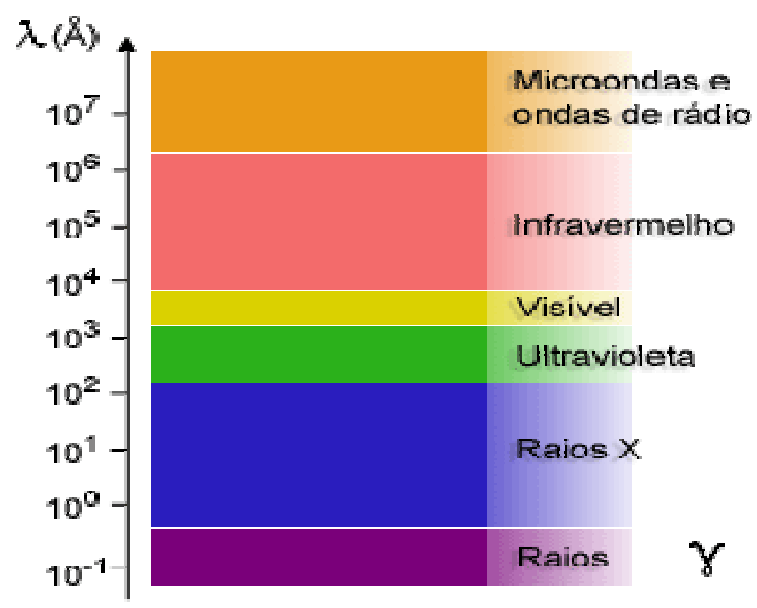

Fonte: http://www.cepa.if.usp.br/e-fisica/imagens/otica/universitario/cap01/figura1_3.gif Acessado em 28-04-2008.

Figura 3 - Espectro eletromagnético.

Em dosimetria utilizam-se duas formas de medir a intensidade luminosa emitida pelo cristal. Na primeira um circuito eletrônico converte o sinal luminoso em uma quantidade de carga, assim sendo, a quantidade de carga que os fótons emitidos pelo cristal foram capazes de gerar é proporcional a dose a qual o cristal foi exposto, essa quantidade de carga é dado o nome de resposta do cristal ou resposta $T L$. Na segunda, a luz emitida é medida por um fotômetro e a resposta do cristal é dada em unidades de absorbância. Neste trabalho foi utilizada a primeira forma de quantificar a luz, devido ao equipamento utilizado (Harshaw modelo 2000). As faixas de comprimento de onda emitidos pelos cristais e o comprimento de onda no qual a intensidade de luz é máxima estão relacionados na tabela 2. Estes dados são fornecidos pelo fabricante dos mesmos.

Tabela 2 - Faixa de comprimentos de onda e comprimento de onda máximos.

\begin{tabular}{c|c|c}
\hline \hline TLD & $\Delta \lambda(\AA)$ & $\lambda$ \\
\hline \hline 400 & $4600-6000$ & 5000 \\
\hline 600 & $2000-6000$ & 4000 \\
\hline 700 & $3500-6000$ & 4000 \\
\hline \hline
\end{tabular}


O gráfico da resposta TL em função da temperatura de aquecimento é chamado de curva de emissão ou simplesmente de curva TL. As figuras 4, 5 e 6 mostram exemplos típicos de curvas TL para: TLD-400, TLD-600 e TLD-700. Essas curvas apresentam picos de intensidade luminosa para uma dada temperatura. Isso significa que para a temperatura onde se observa o pico, a probabilidade dos elétrons escaparem de suas respectivas armadilhas, e conseqüentemente liberarem um fóton, é máxima e é dada pela equação 3.2.1.

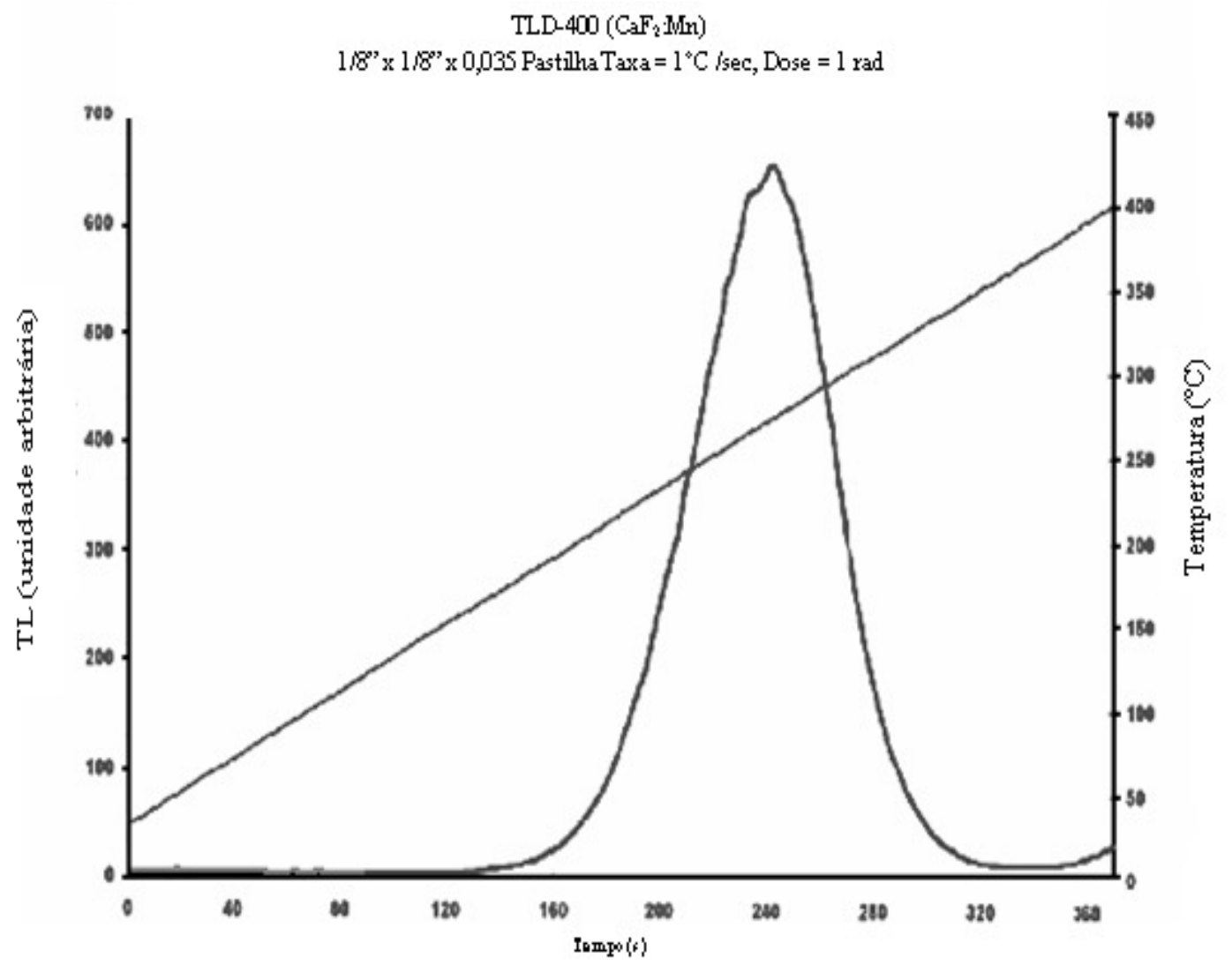

Figura 4 - Curva Termoluminescente do TLD-400 para uma taxa de aquecimento de $1^{\circ} \mathrm{C} / \mathrm{s}$. 


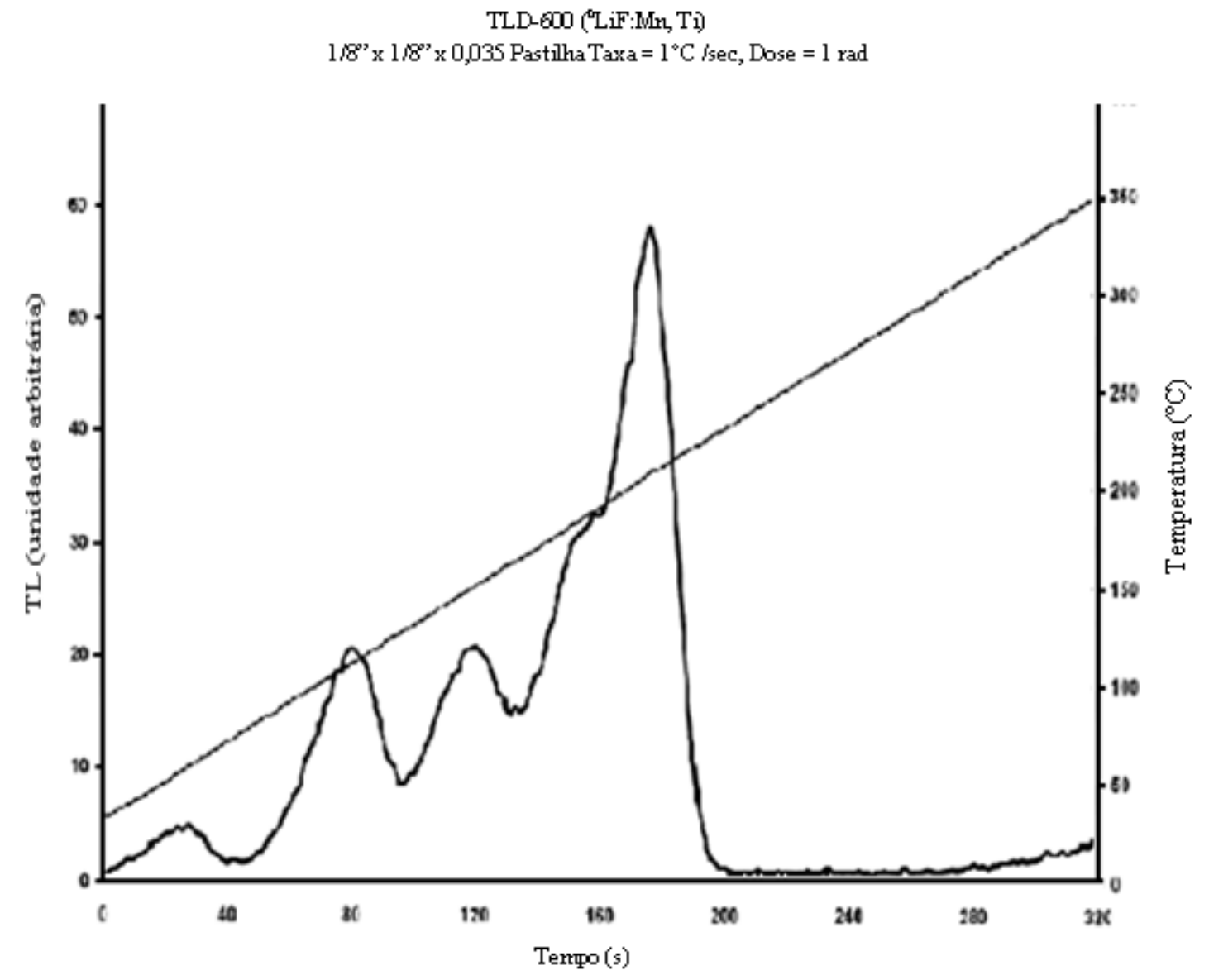

Figura 5 - Curva Termoluminescente do TLD-600 para uma taxa de aquecimento de $1^{\circ} \mathrm{C} / \mathrm{s}$. 


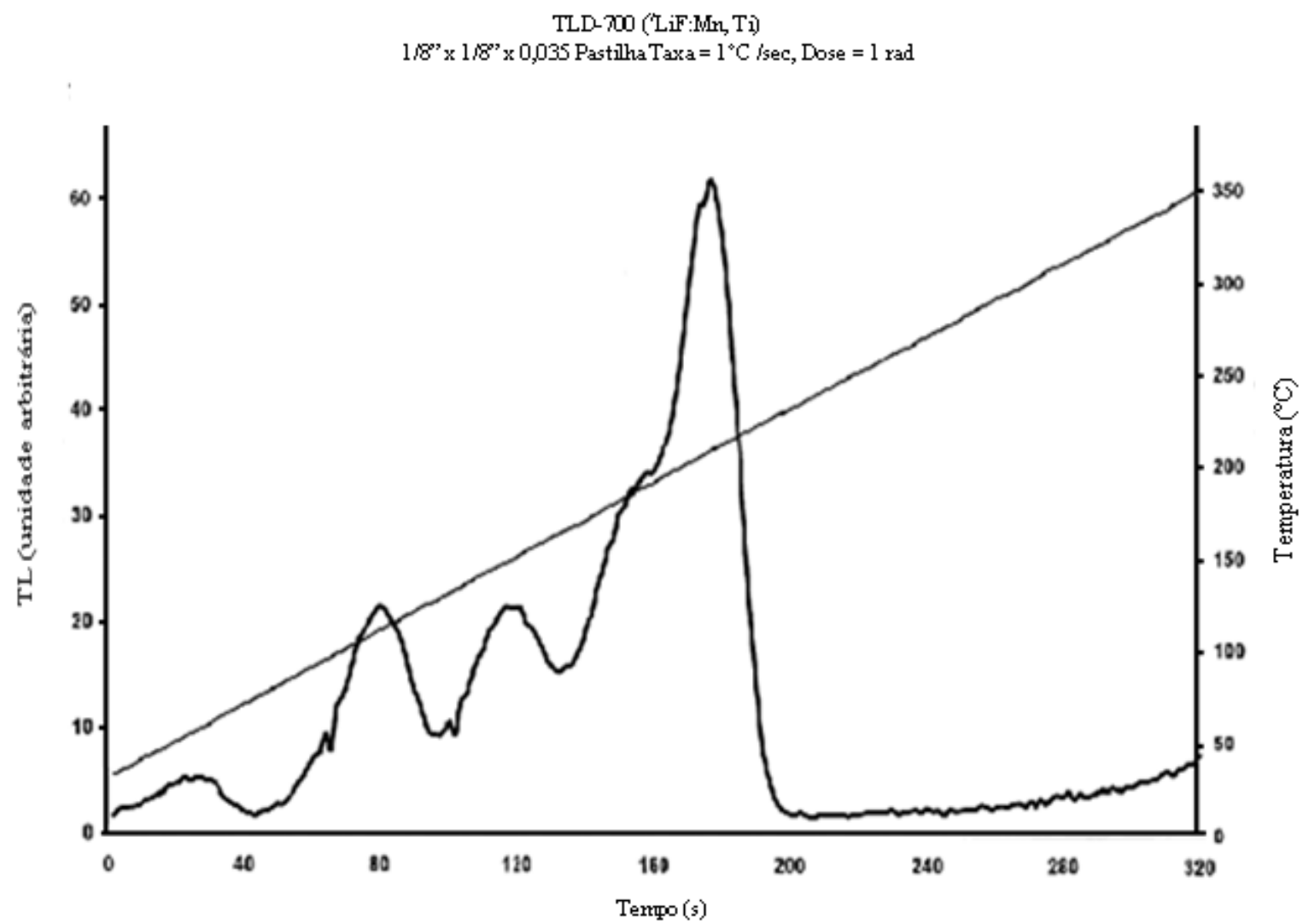

Figura 6 - Curva Termoluminescente do TLD-700 para uma taxa de aquecimento de $1^{\circ} \mathrm{C} / \mathrm{s}$.

Como já mencionado, a luminescência pode ser dividida em dois processos, fluorescência e fosforescência. No primeiro a emissão de luz se da espontaneamente, já no segundo é necessário o fornecimento de certa quantidade de energia para que os elétrons "presos" retornem a banda de valência, emitindo fótons de luz. No caso da termoluminescência é fornecida ao cristal energia térmica para liberar os elétrons. Ou seja, após irradiar os cristais, os elétrons ficam armadilhados nos estados metaestáveis e somente podem ser liberados mediante o fornecimento de energia, que no caso da termoluminescência é energia térmica.

Após medir as respostas termoluminescentes dos cristais por meio de uma fotomultiplicadora e eletrônica associada, processo conhecido como leitura do cristal, ainda restam alguns elétrons armadilhados ${ }^{[20]}$, por isso faz-se necessário aquecer os mesmos com uma temperatura maior que a temperatura utilizada no processo de leitura, durante um intervalo de tempo. Este procedimento é conhecido como tratamento térmico e possibilita a reutilização dos cristais. Neste trabalho foi utilizado para cada tipo de TLD o tratamento térmico recomendado pelo fabricante (Thermo Electron Coporation). 


\subsection{Teoria de Adirovitch para a Fosforescência}

Sendo a termoluminescência uma forma de fosforescência, o estudo da termoluminescência possibilita uma melhor a compreensão da fosforescência; bem como a compreensão de todas as formas de fosforescência, já que as mesmas se diferenciam apenas pela forma com a qual o material é excitado.

Para explicar os decaimentos da fosforescência observados nos sólidos no caso geral, Adirovitch (1956) ${ }^{[21]}$ usou um conjunto de três equações diferenciais que governam o tráfego de elétrons entre armadilhas, a banda de condução e centros de recombinação.

Ele considerou que na banda proibida a concentração dos centros de armadilhamento é $N$ e que, num determinado instante $t, n_{c}$ destes $N$ centros estão ocupados por elétrons. Neste mesmo instante $t, n_{c}$ elétrons por unidade de volume circulam pela banda de condução e $m$ centros de recombinação (regiões do cristal onde há ausência de elétrons) estão disponíveis para os elétrons na banda de valencia.

As armadilhas de elétrons estão a uma profundidade $\mathrm{E}$ da banda de condução de forma que a probabilidade por unidade de tempo de um elétron escapar da armadilha é dada por:

$$
p(t)=s \cdot e^{-\left(\frac{E}{K T}\right)}
$$

onde, $s$ é o fator de freqüência, $k$ é a constante de Boltzmann e $T$ é a temperatura.

Da equação 3.2.1 conclui-se que quanto menor a profundidade da armadilha, ou seja, quanto menor a diferença de energia entre a banda de valência e o estado metaestável, maior é a probabilidade de escape do elétron. Por sua vez, é possível aumentar a probabilidade de escape do elétron de sua respectiva armadilha aumentado a temperatura do cristal.

No processo de termoluminescência aumenta-se a probabilidade de escape do elétron, aumentando a temperatura do cristal.

Existem cristais termoluminecentes que apresentam diferentes estados metaestáveis, conseqüentemente, diferentes profundidades de armadilha. Isso é evidenciado nas curvas TL dos mesmos, como é o caso dos TLDs-600 e TLDs-700 (figuras 6 e 7) que apresentam 
diversos picos. Já o TLD-400 (figura 5) apresenta somente um pico de emissão termoluminescente. Conseqüentemente, este cristal tem somente uma profundidade de armadilha.

Ao fornecer energia térmica para o cristal, os elétrons podem seguir dois caminhos: ou são rearmadilhados ou se recombinam com as lacunas nos centros de recombinação. Este último caminho é o que provoca a liberação de energia sob forma de luz. A figura 8 mostra um esboço para o modelo de Adirovitch.

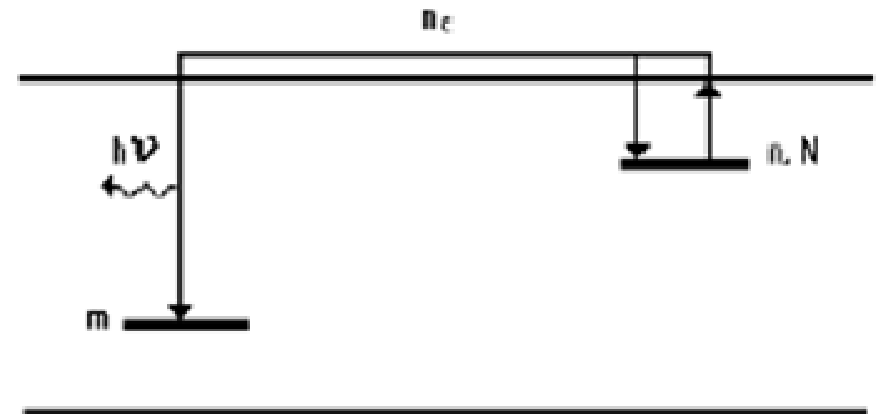

Figura 7 - Níveis de energia na banda proibida de um sólido.

Na figura acima $n, m_{\text {e }} n_{c}$ são as concentrações num dado instante de elétrons armadilhados nas lacunas nos centros de recombinação e elétrons livres na banda de condução, respectivamente. E a concentração total de armadilhas é $\mathrm{N}$ e hv a energia do fóton emitido.

O único processo pelo qual $m$ é reduzido é através da recombinação de um elétron livre com um buraco no centro de recombinação. A variação da concentração de centros de recombinação deve ser proporcional à concentração de elétrons livres na banda de condução, $n_{c}$, e a de lacunas nos centros $m$. Por outro lado, a intensidade de luz $I$ é proporcional à taxa de variação de $m$. Portanto a equação é dada por:

$$
I=-q \frac{d m}{d t}=A_{m} m n_{c}
$$

$A_{m}$ é uma constante de proporcionalidade, chamada de probabilidade de recombinação e $q$ é uma constante de proporcionalidade, que representa a eficiência com que a emissão de luz ocorre nesse processo. $\mathrm{O}$ sinal negativo indica que $m$ decresce durante $\mathrm{o}$ 
processo, ou seja, o decréscimo no numero de lacunas implica no aumento da intensidade luminosa.

Outra equação no conjunto de equações diferenciais trata do fluxo de elétrons entre as armadilhas e a banda de condução. Esta equação deve ter dois termos, o primeiro relacionado com o desarmadilhamento dos elétrons e o segundo com a recaptura dos portadores nas armadilhas. O termo que descreve o desarmadilhamento é proporcional à probabilidade de escape do elétron $p$ e à quantidade de elétrons $\operatorname{armadilhados} n$. A taxa de rearmadilhamento seria proporcional à concentração de elétrons livres $n_{c}$ e à concentração de armadilhas desocupadas, $N$ - $n$, onde $N$ é à concentração de armadilhas e $n$ é a concentração de elétrons armadilhados. A segunda equação é então dada por:

$$
\frac{d n}{d t}=s n e^{\left(-\frac{E}{k T}\right)}-n_{c}(N-n) A_{n}
$$

$A_{n}$ é um outro fator de proporcionalidade que representa a probabilidade de rearmadilhamento.

A terceira equação representa a neutralidade de carga e é dada por:

$$
m=n+n_{c}
$$

A condição de neutralidade de carga pode ser expressa como:

$$
\frac{d m}{d t}=\frac{d n}{d t}+\frac{d n_{c}}{d t}
$$

Substituindo (5.2.2) e (5.2.3) em (5.2.5), temos:

$$
\frac{d n_{c}}{d t}=s n e^{\left(-\frac{E}{k T}\right)}-n_{c}\left[m A_{m}+(N-n) A_{n}\right]
$$

A equação 3.2.6 representa a taxa de aumento dos elétrons na banda de condução. Esta, por sua vez, aumenta exponencialmente com o aumento da temperatura e decresce exponencialmente com a energia da armadilha. Quanto maior for profundidade da armadilha, menor será a taxa de aumento do numero de elétrons na banda de condução; e quanto maior for a temperatura, maior será esta taxa. 
Contudo, a energia necessária para retirar o elétron de sua respectiva armadilha é um parâmetro do cristal, ou seja, dependendo do tipo de impureza com a qual este cristal foi dopado ele apresentará diferentes profundidades de armadilhas. Sendo assim o parâmetro E da equação 3.2.6 depende de cada cristal, cada armadilha do mesmo cristal tem a sua profundidade

Experimentalmente varia-se a temperatura para maximizar o número de elétrons na banda de condução.

\subsection{Curva de Emissão Termoluminescente}

A curva de emissão representa a intensidade de luz emitida por um material TL em função da temperatura ou da taxa de aquecimento ao qual este é submetido. Esta curva pode apresentar um ou mais máximos, denominados de picos de emissão, de acordo com o número de diferentes armadilhas presentes no material e suas profundidades. As armadilhas podem capturar e segurar os portadores de carga em um poço de potencial por períodos longos de tempo.

A formação de um pico de emissão TL está relacionada com a probabilidade de escape do elétron ou do buraco da armadilha correspondente. Ou seja, quando a temperatura do material é menor que aquela característica do pico considerado, poucos portadores de carga (elétrons ou buracos) são liberados da armadilha e, assim, a luz emitida tem baixa intensidade (baixo valor de sinal TL).

A probabilidade dos elétrons ou buracos escaparem das armadilhas aumenta com o aumento da temperatura do material, causando assim um aumento de emissão, que é máxima na temperatura do pico. A intensidade do sinal TL decresce devido à redução de portadores armadilhados. A forma da curva de emissão depende dos tipos de armadilhas e dos centros de luminescência existentes no cristal. 


\subsection{Dose-Resposta}

A dose-resposta, $f(D)$, é definida como sendo a dependência funcional da intensidade do sinal TL medido em função da dose absorvida, ou seja, quanto maior o sinal do cristal, maior será a dose absorvida. O material dosimétrico ideal apresentaria uma resposta linear em um amplo intervalo de doses. No entanto, muitos dos materiais utilizados na prática em dosimetria apresentam uma faixa de efeitos não-lineares, conforme a figura 8.

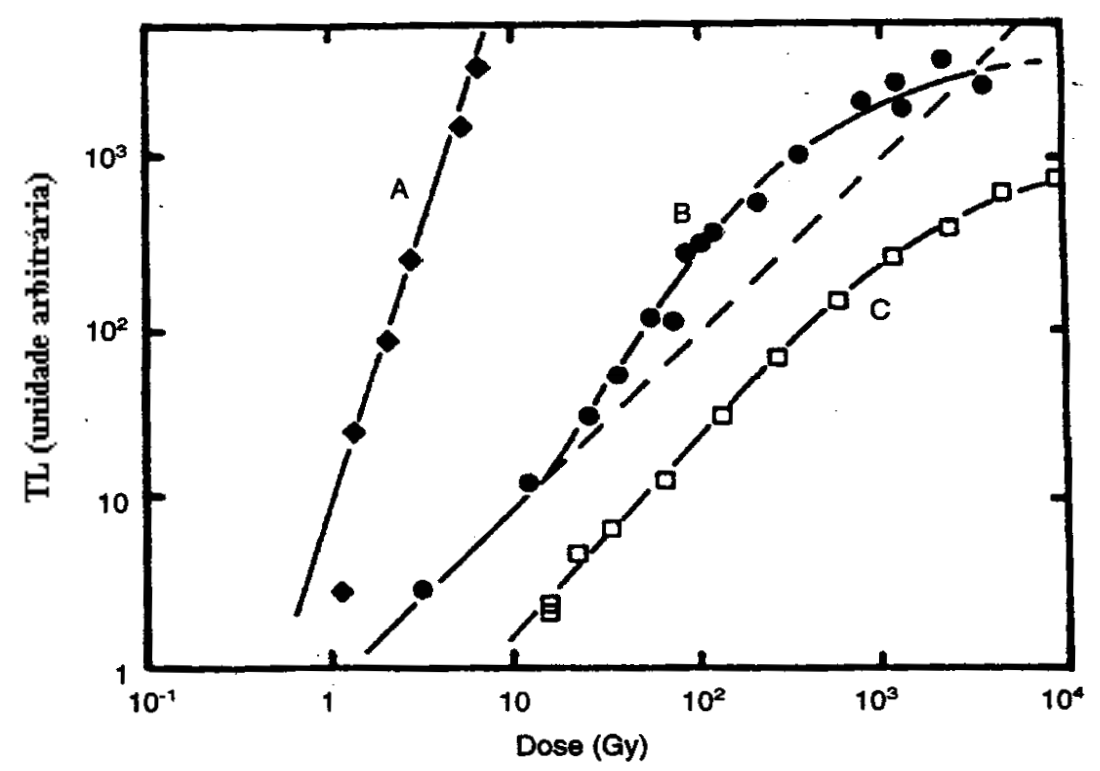

Figura 8 - Curva da resposta termoluminescente, em função da dose absorvida para o ${ }^{60} \mathrm{Co}$, para diferentes materiais termoluminescentes. $\mathrm{A}: \mathrm{SiO}_{2}$; B: $\mathrm{LiF}: \mathrm{Mg}, \mathrm{Ti} ; \mathrm{C}$ : TLD-400 $\left(\mathrm{CaF}_{2}: \mathrm{Mn}\right)^{[22]}$.

É particularmente comum que a resposta TL, $F(D)$, do material ocorra da seguinte forma: linear, supralinear e sublinear conforme a dose aumenta. Define-se a função de dose-resposta normalizada (ou o índice de supralinearidade) $f(D)$, na equação 3.4.1 como sendo:

$$
f(D)=\frac{(F(D) / D)}{\left(F\left(D_{1}\right) / D_{1}\right)}
$$

onde, $f(D)=$ índice de supralinearidade; $F(D)=$ dose-resposta para dose $D ; F\left(D_{1}\right)=$ doseresposta para a dose $D_{1}$, sendo $D_{1}$ a menor dose para a qual a resposta é linear. 


\subsection{Sensibilidade}

A sensibilidade de um dado material TL, é definida formalmente como sendo a razão da intensidade do sinal TL por unidade de dose absorvida. No entanto, definir tal parâmetro em termos absolutos é difícil, pois este parâmetro também depende do sistema de leitura TL usado na medição, incluindo os filtros óticos, da taxa de aquecimento e do método de medição do sinal TL (geralmente a área da curva de emissão entre duas temperaturas escolhidas ou a altura de um determinado pico TL). Para melhorar as incertezas associadas à medição absoluta da sensibilidade, normalmente é definida a sensibilidade relativa pela comparação entre o sinal TL do material de interesse com o sinal TL do LiF TLD-100. Dessa forma, o TLD de um dado material apresenta uma sensibilidade $S(D)$, que é definida pela equação 3.5. $1^{[23,24]}$ :

$$
S(D)=\frac{F(D)_{\text {material }}}{F(D)_{T L D-100}}
$$

Devido aos diferentes graus de supralinearidade dos diferentes materiais TL em diferentes doses, comparada a do TLD-100, a sensibilidade é, ela própria, uma função da dose. Mais que isso, dado que os diferentes picos de emissão dos diferentes materiais respondem de modos diferentes às mudanças na taxa de aquecimento e que eles emitem em diferentes comprimentos de onda, a sensibilidade também é uma função da taxa de aquecimento e da seleção de filtros óticos usadas na leitura do sinal TL.

\subsection{Desvanecimento Térmico}

Sendo o sinal TL de uma amostra instável em função do tempo, ou seja, se ele decai com o tempo decorrido da irradiação, diz-se que o sinal desvaneceu. O desvanecimento pode ter muitas causas, mas é prevalecente o desvanecimento térmico.

Reescrevendo a equação 3.2.1 constata-se que a constante de tempo para a liberação termicamente induzida das cargas aprisionadas $\left(\tau_{f}\right)$ em um defeito é dada por:

$$
\tau_{f}=p^{-1}=s^{-1} \exp (E / k T)
$$


em que todos os termos foram previamente definidos. Em concordância com a equação 3.6.1 define-se uma "meia vida" $\tau_{1 / 2}$ para o desvanecimento térmico dado assim por:

$$
\tau_{1 / 2}=\ln (2) \tau_{f}
$$

\subsection{Tratamento Térmico de Reutilização}

O tratamento térmico tem por finalidade devolver ao cristal as condições existentes antes da sua primeira exposição à radiação ionizante, ou seja, remover o sinal residual. $\mathrm{O}$ processo de aquecimento também evita um problema crítico que é a sensibilidade do cristal. Para tanto, grupos de dosímetros devem ser submetidos a ciclos de aquecimento idênticos. Isso é alcançado colocando-se todos os dosímetros juntos em um forno em uma bandeja feita de vidro, aço inoxidável ou alumínio deionizado para que durante o aquecimento não ocorra transferência de impureza da bandeja para o material TL. Muitos materiais TL apresentam curvas de emissão com vários picos, alguns deles localizados a baixas temperaturas, e, assim, sujeitos a um desvanecimento considerável à temperatura ambiente. Portanto, é conveniente aquecê-los a uma temperatura inferior aquela de sua avaliação, após estes serem irradiados, para se eliminar estes picos indesejáveis. Tal aquecimento é denominado tratamento térmico pós-irradiação ou pré-leitura. O ciclo de leitura deve incluir um aquecimento pré-leitura a cerca de $80^{\circ} \mathrm{C}$, no caso dos TLD-100, TLD-600 e TLD-700 para se eliminar o sinal dos picos de baixa temperatura, como recomendado pelo fabricante não havendo necessidade de tal procedimento para o TLD-400, devido à inexistência destes picos de baixa temperatura.

\subsection{Detectores de Ativação Tipo Folha}

O nêutron é uma partícula que não possui carga elétrica e por isso sua forma de detecção é indireta. Uma forma de detectar nêutrons é através da indução de radioatividade em materiais apropriados, e com a detecção da radiação emitida por estes, obtêm-se informações sobre o campo neutrônico em que os materiais foram expostos. Esta técnica é conhecida como análise por ativação ${ }^{[25]}$.

As medidas dos fluxos de nêutrons por ativação são feitas através da contagem da radioatividade induzida nos detectores de ativação (materiais como: $\mathrm{Au}, \mathrm{Ni}, \mathrm{Al}$ etc.), utilizando-se a espectrometria gama. Esta técnica é bem estabelecida na literatura ${ }^{[26]}$ e, a 
seguir, são apresentadas resumidamente às deduções necessárias para obter informações sobre a população de nêutrons.

Submetendo o detector de ativação a um campo neutrônico teremos a taxa de produção dos átomos radioativos:

$$
\frac{d n}{d t}=N \bar{\sigma}_{a c t} \phi-n \bar{\sigma}_{a} \phi-n \lambda
$$

onde,

n é o número de átomos radioativos formados;

$\mathrm{N}$ é o número de átomos não radioativos;

$\bar{\sigma}_{a c t}$ é a secção de choque de ativação média;

$\bar{\sigma}_{a}$ é a secção de choque de absorção média;

$\lambda$ é a constante de decaimento do átomo radioativo formado e;

$\phi$ é o fluxo integral dado por:

$$
\phi=\int_{0}^{\infty} \psi(E) d E
$$

$\Psi(E)$ é o fluxo neutronico com energia $E$.

$$
\bar{\sigma}=\frac{\int_{0}^{\infty} \sigma(E) \psi(E) d E}{\int_{0}^{\infty} \psi(E) d E}
$$

$\bar{\sigma}$ é a secção de choque média, dada por:

e, $\frac{d N}{d t}$ é a taxa de consumo dos átomos alvo, dada por:

$$
\frac{d N}{d t}=-N \bar{\sigma}_{T} \phi
$$

Onde $\bar{\sigma}_{T}$ é a secção de choque total.

A solução da equação (3.8.4) é :

$$
N=N_{0} e^{-\phi \sigma_{T}}
$$

onde $N_{0}$ é o número inicial de átomos não radioativos.

Substituindo (3.8.5) em (3.8.1), têm-se:

$$
\frac{d n}{d t}+n\left(\bar{\sigma}_{a} \phi+\lambda\right)=\phi \bar{\sigma}_{a c t} N_{0} e^{-\phi \overline{\sigma_{T}}}
$$


Resolvendo a equação (3.8.6) pela técnica do fator integrante $\left(e^{\left(\lambda+\phi \bar{\sigma}_{a}\right) t}\right)$, chega-se em:

$$
\frac{d}{d t}\left[n \cdot e^{\left(\phi \bar{\sigma}_{a}+\lambda\right) t}\right]=\bar{\sigma}_{a c t} N_{0} e^{-\left[-\sigma_{a} \phi+\bar{\sigma}_{T} \phi\right] t}
$$

Integrando a equação (3.8.7) considerando $\left(\bar{\sigma}_{a} \phi<<\lambda\right.$ e $\left.\bar{\sigma}_{T} \phi<<\lambda\right)$, tem-se:

$$
n=\frac{\sigma_{a c t} \phi N_{0}}{\lambda}\left(1-e^{-\lambda t}\right)=\sigma_{a c t} \phi N V\left(1-e^{-\lambda t}\right)
$$

onde $V$ é o volume irradiado.

Sendo $A_{0}=n \lambda$ a atividade ao final da irradiação e $\sum_{a c t}=N \bar{\sigma}_{a c t}$ a secção de choque macroscópica de ativação, obtém-se:

$$
A_{0}=\sum_{a c t} \phi V\left(1-e^{-\lambda t}\right)
$$

Com o cálculo da atividade ao fim da irradiação obtém-se a atividade de saturação ( $A_{\infty}$ na equação 3.8.10), que é a atividade máxima que o detector atingiria se fosse irradiado por um tempo infinito; a atividade de saturação é numericamente igual à taxa de reação a que o detector esteve exposto, mostrada a seguir:

$$
A_{0}=A_{\infty}\left(1-e^{-\lambda t}\right)
$$

Como, $A_{\infty}=\sum_{a c t} \phi V$, obtém-se o fluxo de nêutrons que é dado por:

$$
\phi=\frac{A_{\infty}}{\sum_{a c t} V}
$$

A figura 9, apresentada a seguir, mostra os pontos: atividade da folha ao final da irradiação $\mathrm{A}_{0}$, atividade de saturação $A_{\infty}$ e os instantes $t_{1}$ e $t_{2}$ (intervalo de contagem da folha). 


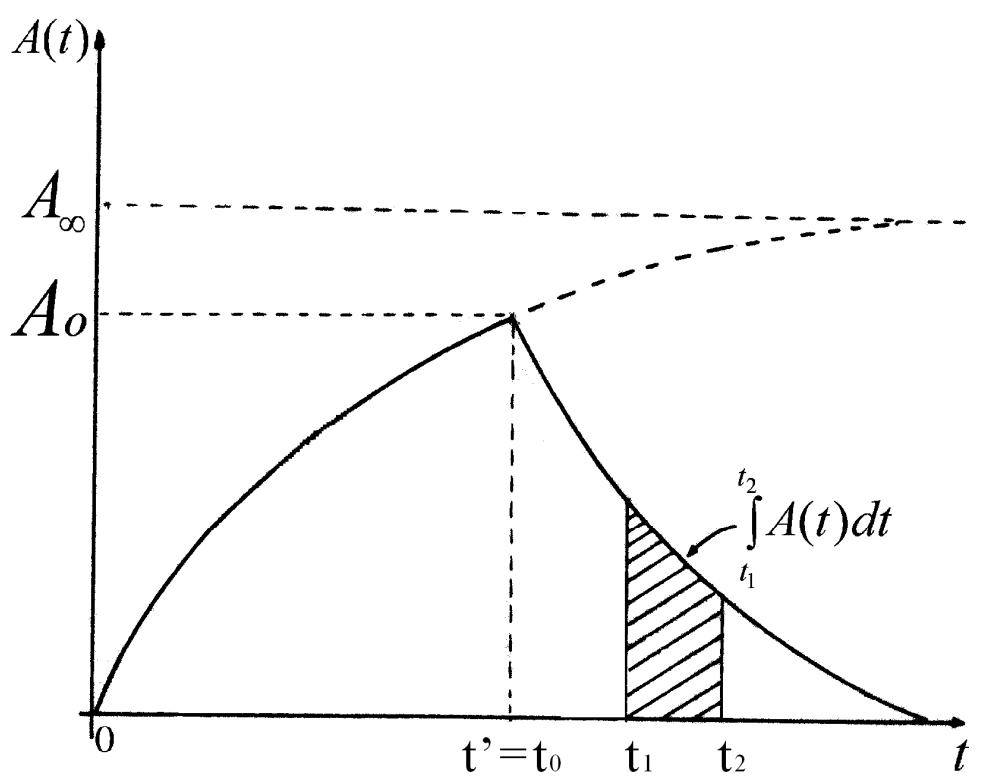

Figura 9 - Atividade da folha ao final da irradiação.

As contagens acumuladas entre os instantes $t_{1}$ e $t_{2}$ é dada por:

$$
C=\varepsilon \int_{t_{1}}^{t_{2}} A_{0} e^{-\lambda t} d t+B G
$$

Resolvendo a equação (3.8.12), obtém-se:

$$
A_{0}=\frac{\lambda C_{0} e^{\lambda t e}}{\varepsilon \mathrm{I}\left(1-e^{-\lambda t c}\right)}
$$

Onde $A_{0}$ é a atividade ao término da irradiação $\left(\mathrm{t}_{\mathrm{o}}\right)$;

$\lambda$ é a constante de decaimento do radioisótopo formado;

$C_{0}$ é a contagem líquida (descontado o BG) obtida na espectrometria gama;

$t_{e}$ é a igual a $\left(t_{1}-t_{o}\right)$ que é o tempo de espera;

$\varepsilon$ é a eficiência do sistema de detecção;

I é a probabilidade de emissão gama;

$t_{c}$ é igual a $\left(t_{2}-t_{1}\right)$ que é o tempo de contagem;

Rearranjando a equação (3.8.10)

$$
A_{\infty}=\frac{A_{0}}{\left(1-e^{-\lambda t i}\right)}
$$

$A_{\infty}$ é a atividade de saturação e $t_{i}$ é o tempo de irradiação. 
Atividade de saturação por núcleo alvo é dado por: $\frac{A_{\infty}}{N_{a l v}}$, dessa forma:

$$
N_{a l v}=\frac{6,022 \cdot 10^{23} m f}{A}
$$

onde $N_{a l v}$, é o número de núcleos alvo;

$M$ é a massa da folha de ativação;

$f$ é a fração isotópica;

$A$ é o peso atômico do núcleo alvo.

No item seguinte apresenta-se como a partir das atividades de saturação por núcleo alvo das folhas obtêm-se os fluxos térmico, epitérmico e rápido.

\subsection{Fluxos Térmico e Epitérmico}

A classificação de nêutrons em térmico, epitérmico e rápido baseia-se na energia cinética deles.

Neste trabalho, a classificação usada para cada região é: térmicos até $0,5 \mathrm{eV}$, epitérmicos entre $0,5 \mathrm{eV}$ e $0,5 \mathrm{MeV}$ e rápidos acima de $0,5 \mathrm{MeV}^{[26]}$. Para determinar o fluxo térmico e epitérmico neste trabalho utiliza-se a técnica de razão de cádmio, que consiste em irradiar em condições idênticas uma folha de ouro coberta com cádmio e outra sem cobertura de cádmio folha nua. $\mathrm{O}$ cádmio atua como um filtro absorvendo os nêutrons de até $0,5 \mathrm{eV}$ então a folha de ouro com cobertura de cádmio só sofrerá reações devido aos nêutrons epitérmicos, através da razão entre as atividades de saturação das folhas de ouro se obtêm os fluxos térmico e epitérmico. A seguir é feito a dedução matemática da técnica de razão de cádmio, em que:

A atividade de saturação da folha sem cobertura de cádmio e dado por:

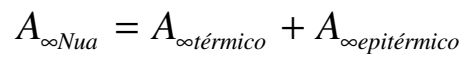

A razão de cádmio é dada por:

$$
R_{c d}=\frac{A_{\infty N u a}}{A_{\infty c d}}
$$


O fator de cádmio é dado por:

$$
F_{c d}=\frac{A_{\infty} \text { ipiérmico }}{A_{\infty c d}}
$$

Rearranjando as expressões (3.9.1), (3.9.2) e (3.9.3), temos:

$$
\begin{aligned}
& A_{\text {øtérmico }}=A_{\infty \text { юиа }}\left(1-\frac{F_{c d}}{R_{c d}}\right) \\
& A_{\infty \text { epitérmico }}=A_{\infty \text { пиа }} \frac{F_{c d}}{R_{c d}}
\end{aligned}
$$

Substituindo as equações (3.9.4) e (3.9.5) na equação (3.8.11): $\left(\phi=\frac{A_{\infty}}{\sum_{a c t} V}\right)$, obtémse:

$$
\phi_{\text {térmico }}=\frac{A_{\text {øиua }} / N_{a l v}\left(1-F_{c d} / R_{c d}\right)}{\bar{\sigma}_{a c t} K_{t}}
$$

onde $A_{\infty \text { пи }} / N_{a l v}$ é a atividade de saturação por núcleo alvo da folha de ouro nua; $F_{C d}=1,098$ é o fator de cádmio ${ }^{[27]}$, devido ao fato do cádmio não ser um filtro ideal, pois também apresenta uma secção de choque para nêutrons epitérmicos, faz com que o cádmio absorva aproximadamente $10 \%$ dos nêutrons epitérmicos;

$R_{c d}=\frac{A_{\infty} \text { пи }}{A_{\infty C d}}$ é a razão entre a atividade de saturação da folha sem cádmio e a da folha coberta com cádmio; $\overline{\sigma_{a c t}}=98,5$ barns ${ }^{[26]}$ é a secção de choque do ouro para nêutrons com a energia mais provável $(\mathrm{E}=0,0253 \mathrm{eV})$ no grupo dos nêutrons térmicos; e $K_{t}=0,977^{[27]}$, este fator é devido a perturbação que a folha causa no fluxo térmico, em que:

$$
\phi_{\text {epitérmico }}=\frac{A_{\infty \text { пиа }} / N_{a l v} F_{c d}}{I_{r} R_{c d} \text { Kepit }}
$$

onde $I_{R}=1575$ barns é a secção de choque de ressonância do ouro para nêutrons epitérmicos e, $K_{\text {epit }}=0,426^{[27]}$ é o fator devido a perturbação que o ouro causa no fluxo epitérmico. 


\subsection{Fluxo Rápido}

Para o fluxo de nêutrons rápidos utilizam-se detectores de energia limiar $\left(\mathrm{E}_{\mathrm{L}}\right)$ tais como: $\mathrm{In}, \mathrm{Fe}, \mathrm{Mg}$, Ni e $\mathrm{Al}$ ), ou seja, materiais em que a reação nuclear só ocorre a partir de uma determinada energia do nêutron (reação endotérmica) ${ }^{[26]}$. Neste trabalho utiliza-se o método do fluxo integral, ou seja, o fluxo acima da energia limiar efetiva ( $\left.\mathrm{E}_{\mathrm{eff}}\right)$. A energia limiar efetiva é definida como a energia acima da qual a secção de choque é constante e abaixo dela a secção de choque é zero. A figura 10 representa este método. Para esta técnica é necessário obter uma secção de choque ponderada com a distribuição de nêutrons do local onde é realizada a medida do fluxo rápido. O valor do fluxo é obtido através da dedução a seguir.

Fluxo Integral.

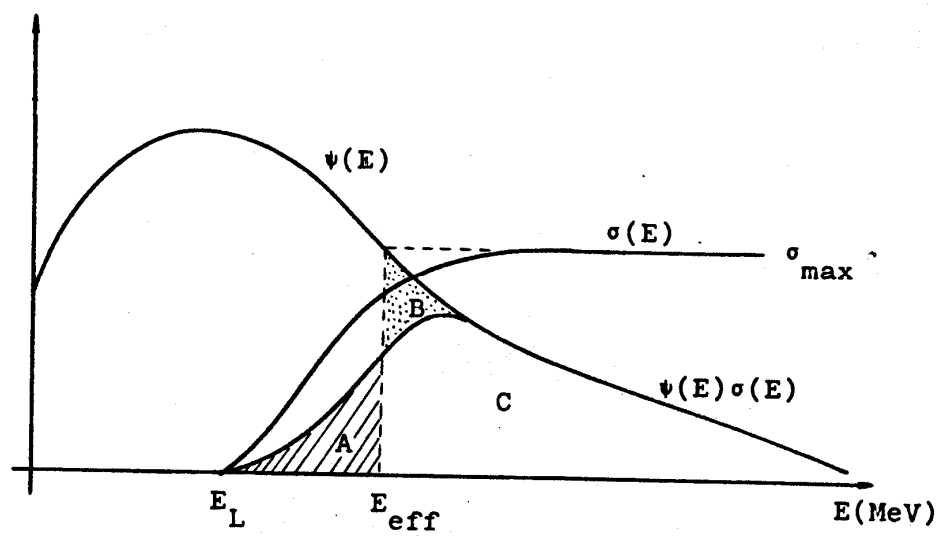

Figura 10 - Definição de Energia Limiar Efetiva.

$$
A_{\infty}=N_{a l v} \int_{\text {Eeff }}^{\infty} \sigma_{\max } \psi(E) d E
$$

Resolvendo a integral:

$$
\phi_{\text {rápido }}\left(E \geq E_{\text {eff }}\right)=\frac{A_{\infty} / N_{a l v}}{\sigma_{\text {pond }}}
$$

onde $\phi_{\text {rapido }}(E \geq E$ eff $)$ é o fluxo rápido acima da energia limiar efetiva; $A_{\infty} / N_{a l v}$ é a atividade de saturação por núcleo alvo do detector de ativação; e $\sigma_{\text {pond }}$. é a secção de choque ponderada com a distribuição de nêutrons.

Devido às secções de choque dos detectores de energia limiar serem pequenas (da ordem de $10^{-3} \mathrm{~b}$ ), a perturbação do fluxo rápido causada pelos detectores é desprezível. 


\subsection{Determinação do Espectro de Nêutrons por Detectores de Ativação}

A distribuição energética dos nêutrons (espectro de nêutrons) é obtida utilizando-se o código computacional SAND-BP (Spectrum Analysis by Neutron Detectors, Budapest version $)^{[28]}$. O código gera o espectro de energia de nêutrons utilizando um método iterativo a partir dos dados de entrada, ou seja, a atividade de saturação por núcleo alvo dos detectores de ativação e um espectro inicial. O espectro inicial foi gerado pelo grupo de BNCT do IPEN/CNEN, através da simulação utilizando o código DOT 3.5.

O processo iterativo consiste $\mathrm{em}^{[27,28]}$ :

a) Calcular a atividade de saturação por núcleo alvo, baseado no espectro inicial de nêutrons;

b) As atividades de saturação por núcleo alvo calculadas são comparadas com as medidas, obtendo-se fatores de correção em várias faixas de energias;

c) Uma função normalizante de energia é obtida para cada folha, baseada na integral de resposta de cada detector;

d) É obtido um fator de correção médio a partir da comparação da atividade de saturação por núcleo alvo medida e calculada em cada região de energia a onde cada detector é sensível;

e) Os fatores de correção médios obtidos na interação $\mathrm{k}$ são aplicados na iteração k+1 a cada faixa de energia, obtendo-se novo espectro de energia de nêutrons;

O processo interativo é encerrado quando uma das condições é atingida ${ }^{[28]}$ :

a) O número máximo de iterações especificada na entrada é atingido;

b) $\mathrm{O}$ valor de alguns dos parâmetros definidos torna-se menor do que o especificado pela entrada;

c) Nenhuma convergência é detectada como, por exemplo: se a melhoria no desvio padrão médio dos valores medidos para os calculados for menor do que 1 por cento em duas etapas sucessivas da iteração. 


\section{METODOLOGIA}

Neste trabalho utilizou-se detectores de ativação (detectores de ativação tipo folha) com alto grau de pureza. Esta técnica foi utilizada para caracterizar o campo de radiação devido a nêutrons. Na instalação para pesquisa em BNCT , os detectores ficam ativados após a irradiação e posteriormente são analisados por espectrometria gama, obtendo-se assim informações que permitem determinar os fluxos térmico, epitérmico, rápido (faixas de energia) e o espectro de energia de nêutrons.

A determinação do fluxo de nêutorns térmico e epitérmico é obtida utilizando-se folhas de ouro com e sem cobertura de cádmio. Para o espectro de energia de nêutrons, além das folhas de ouro, são utilizadas folhas de ressonância e de energia limiar. As atividades de saturação por núcleo alvo dessas folhas serão utilizadas como dado de entrada do programa computacional SAND-BP, para a obtenção do espectro de energia de nêutrons.

As doses devido a raios gama e nêutrons são determinadas utilizando dosímetros termoluminescentes que são instrumentos capazes de fornecer uma leitura correspondente à dose absorvida. Para isso foram utilizados TLDs (dosímetros termoluminescentes) - $\left(\mathrm{CaF}_{2}\right.$, ${ }^{6} \mathrm{LiF}$ e $\left.{ }^{7} \mathrm{LiF}\right)$.

Os dosímetros utilizados neste trabalho são formados de cristais de fluoreto de lítio (LIFs) dopados com magnésio (Mg) e titânio (Ti), LiF:Mg,Ti. Além disso, também foram utilizados cristais de fluoreto de cálcio $\left(\mathrm{CaF}_{2}\right)$ dopado com manganês $(\mathrm{Mn}), \mathrm{CaF}_{2}: \mathrm{Mn}$. Os cristais fluoreto de lítio usado em dosimetria pode ter diferentes composições isotópicas, e dependendo desta composição, ele é classificado como: TLD-100, fluoreto de lítio no qual o lítio é encontrado na sua abundância isotópica natural (92,5\% de ${ }^{7} \mathrm{Li}$ e 7,5\% de ${ }^{6} \mathrm{Li}$ ); TLD-700 $\left(99,99 \%\right.$ de ${ }^{7} \mathrm{Li}$ e $0,01 \%$ de $\left.{ }^{6} \mathrm{Li}\right)$; TLD-600 (4,38\% de ${ }^{7} \mathrm{Li}$ e $95,62 \%$ de $\left.{ }^{6} \mathrm{Li}\right)$. O cristal de $\mathrm{CaF}_{2}: \mathrm{Mn}$ é classificado como: TLD- $400^{[12]}$.

A fim de se obter as doses, devidas à radiação gama, serão utilizados dosímetros termoluminescentes calibrados do tipo TLD-700. Neste material o lítio é enriquecido em ${ }^{7} \mathrm{Li}$ porque esse isótopo tem um grande coeficiente de atenuação para fótons entre $1 \mathrm{keV}$ e $10 \mathrm{MeV}$ (os raios gama procedentes do reator estão compreendidos predominantemente nesta faixa de energia) respectivamente $3,31 \times 10^{3}$ a $2,02 \times 10^{-2} \mathrm{~cm}^{2} / \mathrm{g}^{[13]}$, admitindo uma densidade de 
$3,18 \mathrm{~g} / \mathrm{cm}^{3}$ que é a densidade fornecida pelo fabricante para este TLD. Estes cristais interagem pouco com nêutrons térmicos e com nêutrons rápidos, devido a secção de choque total deste material ser pequena, com um pico de aproximadamente $10 \mathrm{~b}$ para nêutrons com energia da ordem de $150 \mathrm{keV}$, como evidenciado na figura 11.

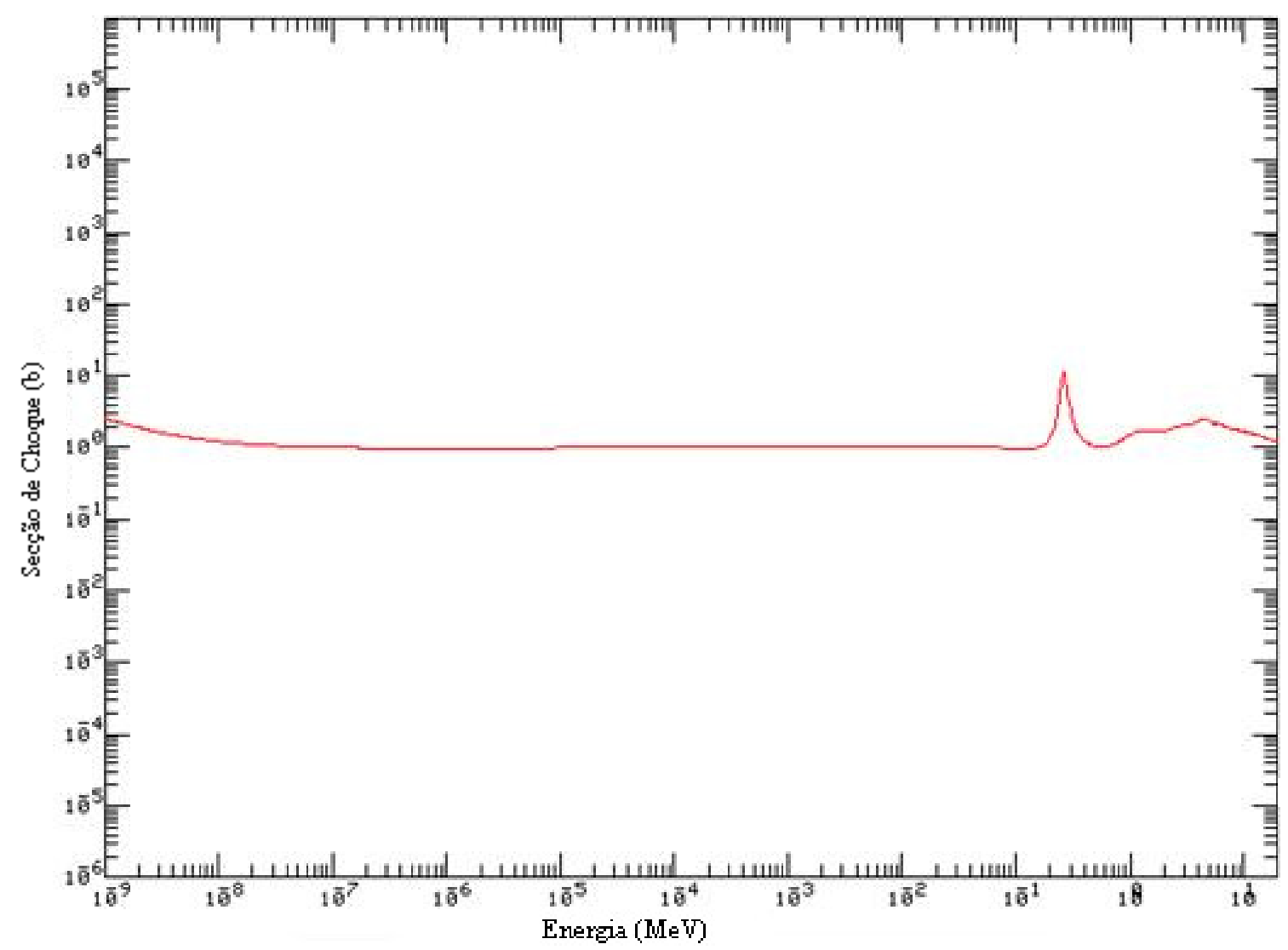

Figura 11 - Curva de secção de choque total para o ${ }^{7} \mathrm{Li}$.

Também foram utilizados TLDs-400 $\left(\mathrm{CaF}_{2}: \mathrm{Mn}\right)$, pois o intervalo no qual esses dosímetros apresentam resposta linear com a dose devido aos raios gama é maior do que para os TLDs-700: segundo o fabricante (Thermo Electron Corporation), o TLD-700 apresenta resposta linear até 10 Gy e o TLD-400 tem um intervalo de linearidade que chega a 100 Gy. Comparações, quanto à precisão na medida das doses, foram feitas entre os dois dosímetros, para saber qual deles apresenta a melhor reprodutibilidade.

Para se medir a dose devido aos nêutrons foram utilizados TLDs-600. Este material também é um fluoreto de lítio, porém, contém uma alta porcentagem de ${ }^{6} \mathrm{Li}$, cuja secção de 
choque total do ${ }^{6} \mathrm{Li}$ para nêutrons térmicos é muito grande, (aproximadamente $1000 \mathrm{~b}$ para nêutrons térmicos de energia igual a $2,5 \times 10^{-8} \mathrm{MeV}$ ) como mostrado na figura 12.

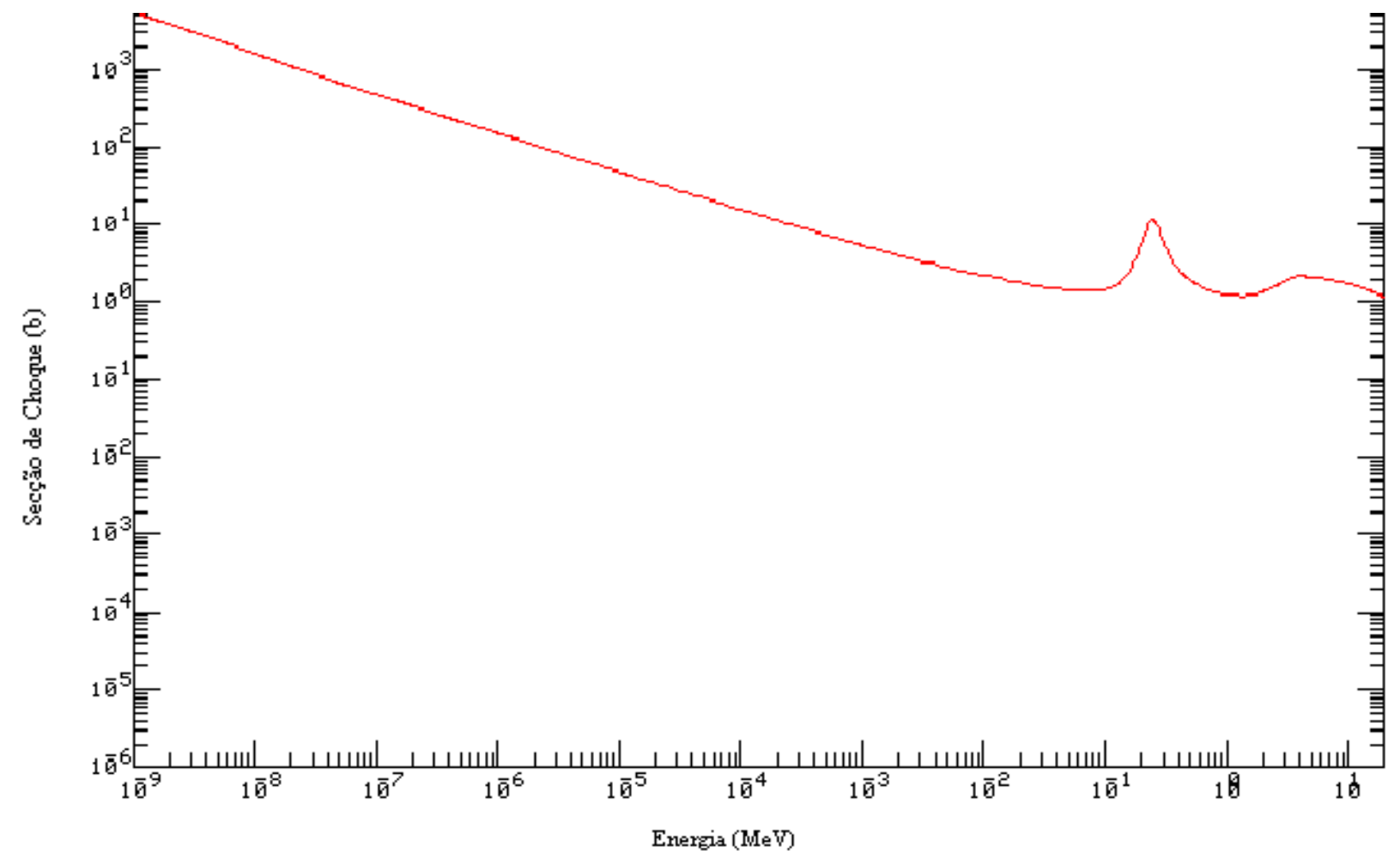

Figura 12 - Curva de secção de choque total para o ${ }^{6} \mathrm{Li}$. 


\section{MATERIAIS E MÉTODOS}

\subsection{DESCRIÇÃO DA INSTALAÇÃO PARA PESQUISA EM BNCT}

Nos últimos anos vem sendo utilizada a instalação no reator IEA-R1 para a pesquisa na área de BNCT, utilizando-se o canal de irradiação número 3 ("beam hole" número 3, BH-3), com comprimento de $261,51 \mathrm{~cm}$ e diâmetro interno de $20,32 \mathrm{~cm}^{[12]}$.

A instalação foi projetada para que seja possível colocar e retirar amostras do canal de irradiação com o reator ligado e por isto foi necessário uma blindagem externa ao $\mathrm{BH}-3$ (figura1).

Durante a operação do reator os níveis de dose são altos na área delimitada pela blindagem biológica (interior da instalação), não sendo possível à entrada de pessoas nesta área quando o reator estiver em operação.

No interior da instalação existem câmeras de vídeo para acompanhar a colocação e retirada de amostras. As imagens são visualizadas através de um monitor localizado fora da instalação, conforme pode ser visto nas figuras 13 e 14.

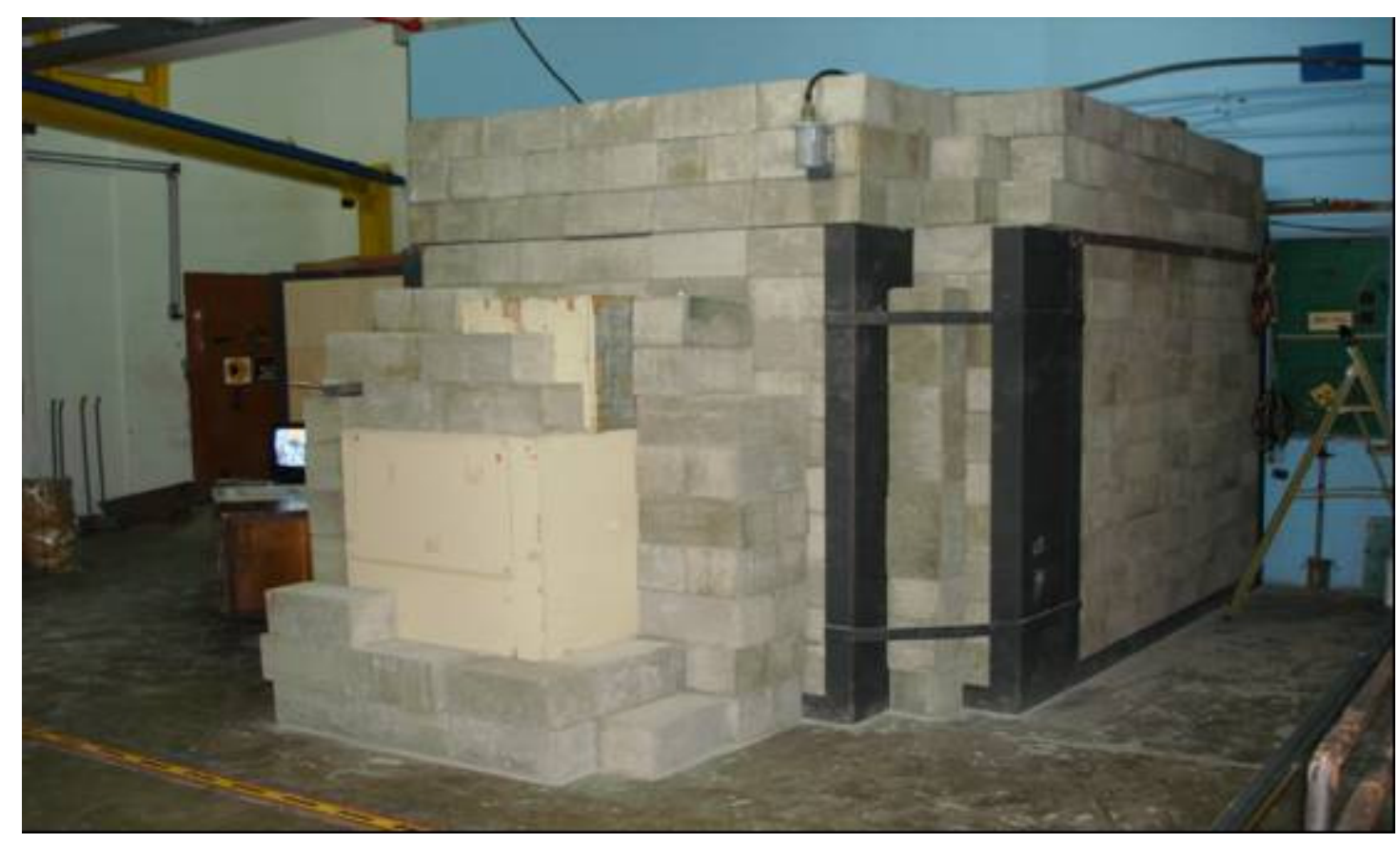

Figura 13 - Vista externa da instalação para pesquisa em BNCT, lado direito. 


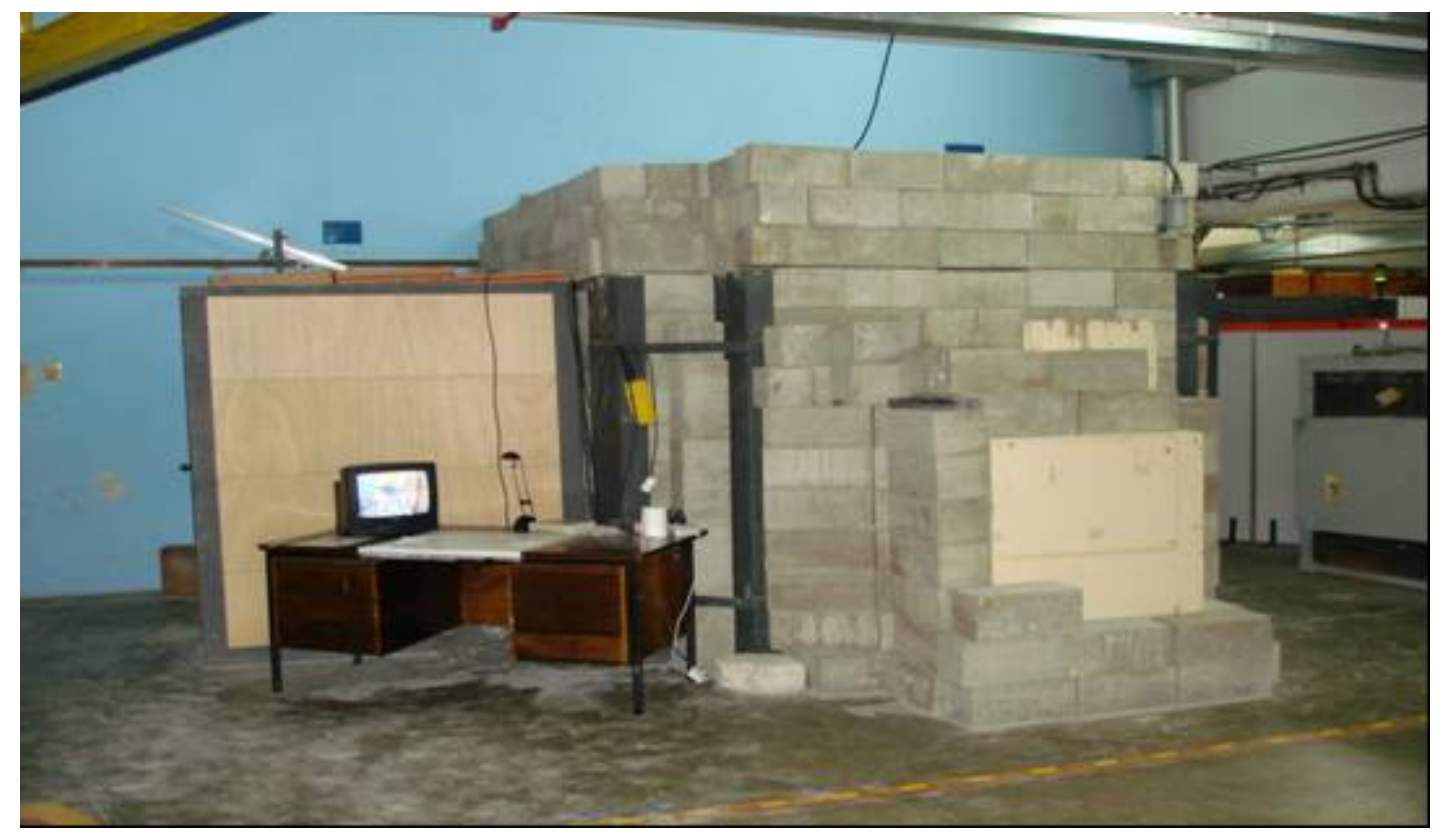

Figura 14 - Vista externa da instalação para pesquisa em BNCT, lado esquerdo.

$\mathrm{Na}$ figura 15(a) pode-se observar uma das câmeras dentro da instalação para a visualização da inserção e retirada de amostras. Na figura 15(b) observa-se a mesa com o monitor que projeta as imagens das câmeras dentro da instalação.

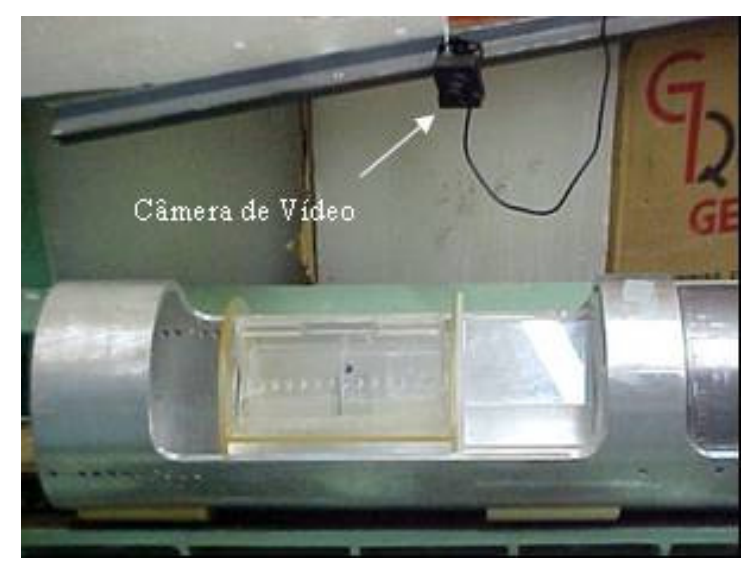

(a)

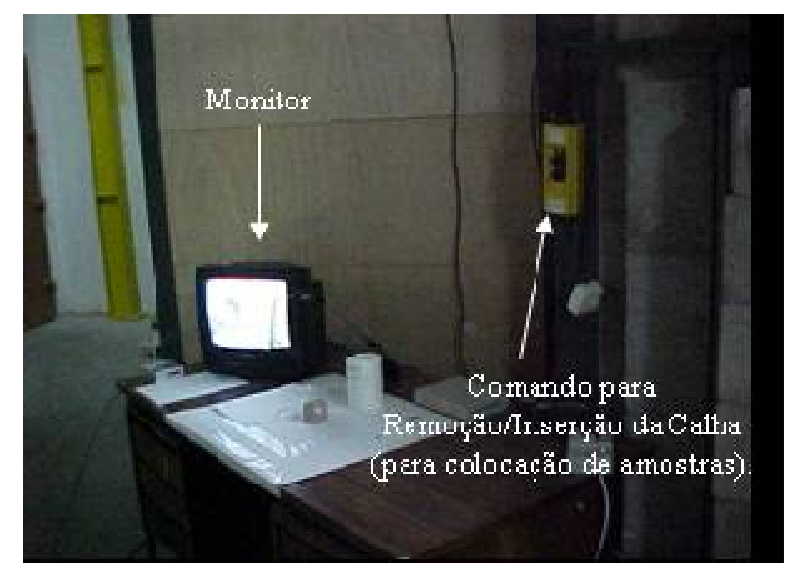

(b)

Figura 15 - (a) câmeras dentro da instalação para a visualização da inserção e retirada de amostras; (b) monitor que projeta as imagens das câmeras dentro da instalação.

Para colocar e retirar amostras, com o reator em operação, da posição de irradiação, utiliza-se o sistema da seguinte forma: 
Primeiro Passo: prende-se a amostra na garra quando esta se encontra fora da instalação, conforme figura 16(a).

Segundo Passo: aciona-se o comando para remoção da calha do BH-3, então a garra desce pelo trilho empurrada pelo cabo de aço até a calha, onde se coloca a amostra, mostrado na figura $16(b)$.

Terceiro Passo: ao chegar à posição o suporte com as amostras é liberado da garra, conforme visto na figura 16(c), então a garra é puxada para fora da instalação e a calha é inserida no BH-3 por um sistema motorizado com comando remoto, visualizado na figura 16(d). Destaca-se que, para a retirada das amostras é realizada a operação inversa.

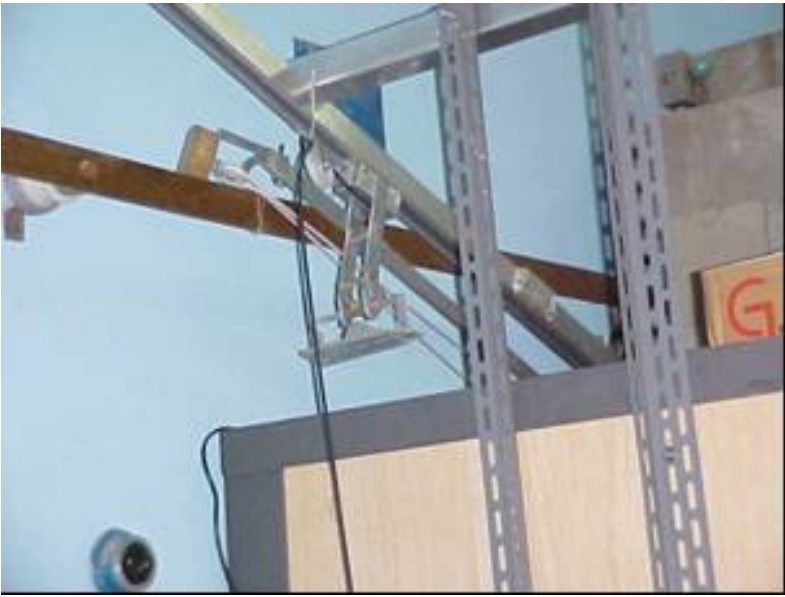

(a)

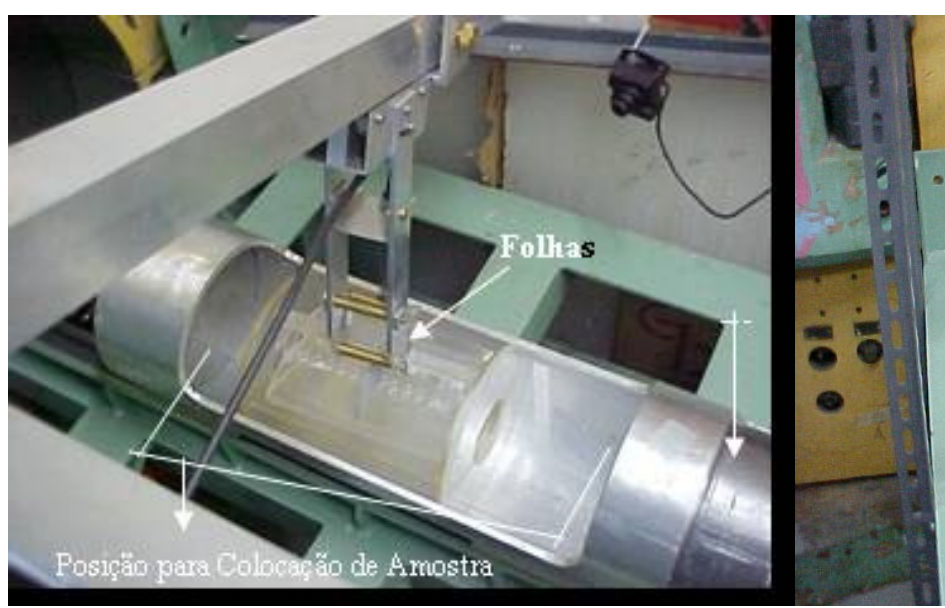

(c)

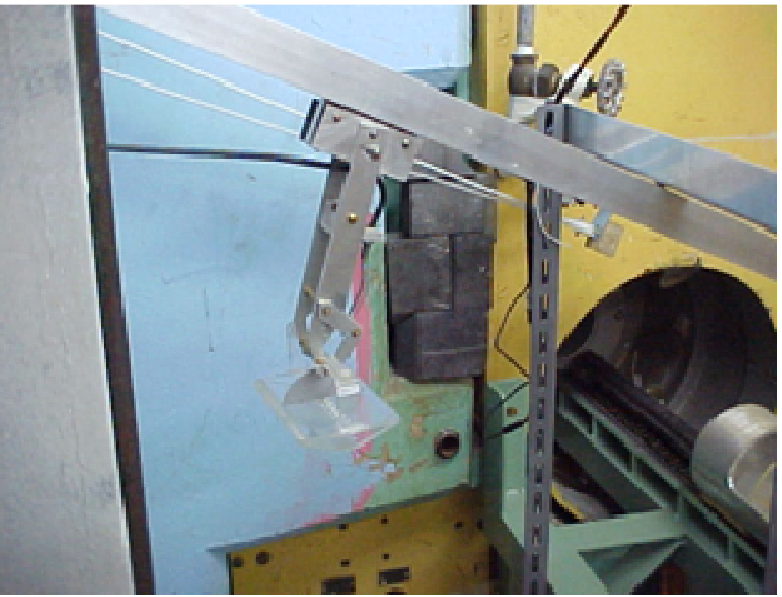

(b)

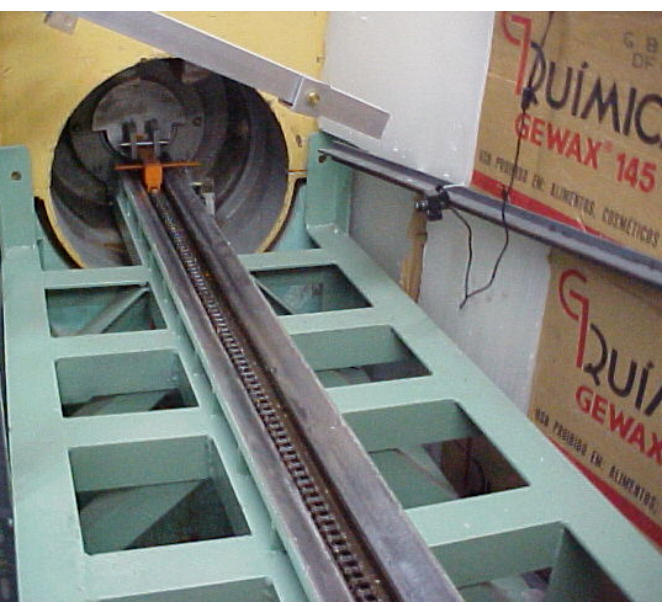

(d)

Figura 16 - (a) Amostra presa à garra fora da instalação; (b) Garra com a amostra descendo pelo trilho; (c) Amostra na calha para inserção no BH-3; (d) calha inserida no BH-3 para irradiação de amostra. 


\subsection{Procedimento Experimental Para os TLDs}

\subsubsection{Selecionamento dos TLDs-700, TLDS- 600 e TLDs-400}

Para medir a dose na instalação de Pesquisas em BNCT utilizando cristais termoluminescentes (pastilhas) foi necessário realizar dois procedimentos: selecionar os cristais, ou seja, separar as pastilhas mais reprodutíveis e construir curvas de calibração.

A descrição de como foi realizado o selecionamento do TLD-700, TLD-600 e TLD-400, é apresentada a seguir.

\subsubsection{Pré-Seleção}

As pastilhas são selecionadas em função de sua geometria, aquelas que tiverem defeitos físicos, tais como: rachadura ou alguma parte quebrada, são descartadas, restando então somente as pastilhas mais regulares.

A realização deste procedimento tornou-se necessária já que, o lote de pastilhas compradas não era regular, ou seja, existiam algumas pastilhas danificadas neste lote, quando foram fornecidas pelo fabricante - Thermal Electron-Eberline.

Foram selecionadas visualmente e com o auxílio de um paquímetro, 90 pastilhas de TLDs-700, 90 pastilhas de TLDs-400 e 45 pastilhas de TLDs-600 com volumes parecidos, tendo um volume próximo de $(3 \times 3 \times 1 \mathrm{~mm})$ cada.

Após o processo de pré-seleção as pastilhas foram acomodadas em uma placa perfurada (figura 17), construída na oficina do IPEN. Esta placa tem a função de manter as pastilhas protegidas. 


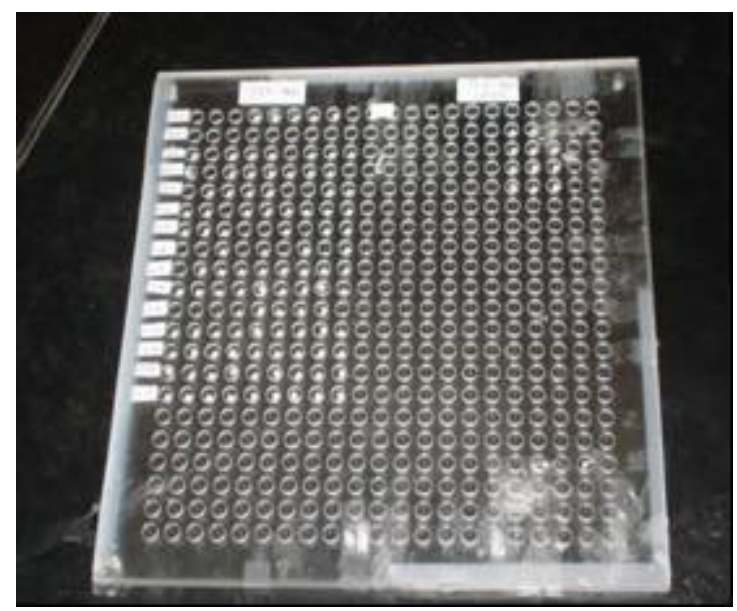

Figura 17 - Placa para acomodação dos dosímetros.

Noventa pastilhas do TLD 400 e do TLD 700 foram dispostas em uma placa acrílica, como mostradas na figura 17. As pastilhas foram dispostas em grupos de nove pastilhas. Essa disposição foi mais uma forma de classificá-las, ou seja, as linhas da matriz são chamadas de grupos.

Estes grupos foram criados tendo em vista o suporte onde os dosímetros são irradiados (figura 18). Este suporte comporta nove dosímetros, ou seja, em cada suporte pode ser acomodado um grupo. Desta forma os dosímetros foram mantidos em ordem ao serem retirados da placa.

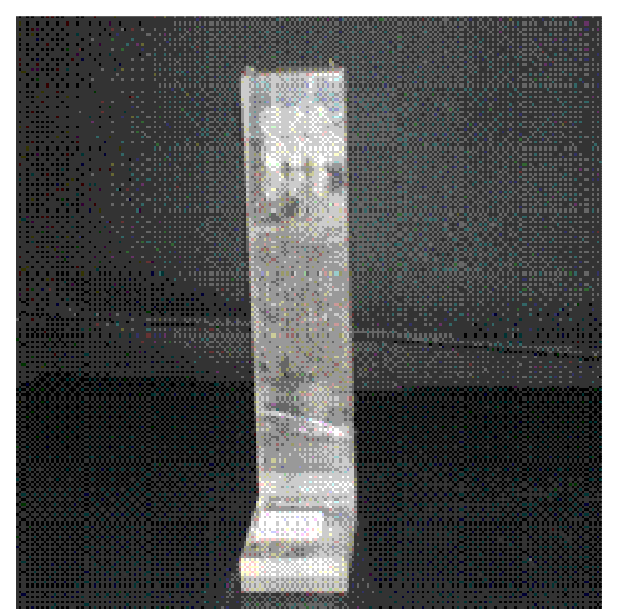

Figura 18 - Suporte para irradiação e transporte dos dosímetros.

Esses suportes são feitos de acrílico e suas dimensões estão evidenciadas na figura 19. A tampa de cada suporte tem uma espessura de $3 \mathrm{~mm}$ de acrílico, ou seja, as pastilhas não são irradiadas no ar tendo uma placa para o equilíbrio eletrônico. O equilíbrio eletrônico consiste em impedir que os elétrons liberados com a interação dos fótons com os átomos do ar e os 
raios gama de baixa intensidade atinjam o material irradiado, fazendo com que a dose seja mais uniforme nas pastilhas. A placa também serve como suporte mecânico e impede que as pastilhas se movam.

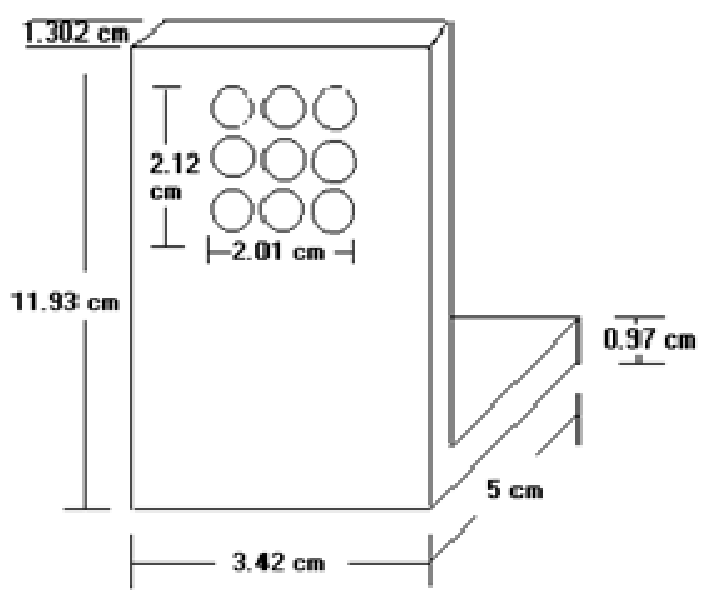

Suporte para irradiação com nove cavidades em forma de circulo com $2 \mathrm{~mm}$ de profundidade, $5 \mathrm{~mm}$ de diâmetro e é coberto por uma placa (também de acrílico) de 119,3 mm de comprimento por 34,2 mm de largura e $3 \mathrm{~mm}$ de espessura que está fixada na parte frontal do suporte.

Figura 19 - Esquema do suporte para irradiação e transporte dos dosímetros.

\subsubsection{Tratamento térmico nos TLDs-700, TLDS- 600 e TLDs-400}

Os TLDs-700 e os TLDs-600 foram submetidos ao tratamento térmico recomendado pelo fabricante (Thermal Electron-Eberline), que consiste em expor as pastilhas a uma temperatura de $400{ }^{\circ} \mathrm{C}$ durante um intervalo de uma hora e logo em seguida, submetê-las a uma temperatura de $100{ }^{\circ} \mathrm{C}$ durante um intervalo de duas horas. Estes tratamentos térmicos foram realizados em uma mufla - Heatech furnece modelo 4814-1 (figura 20).

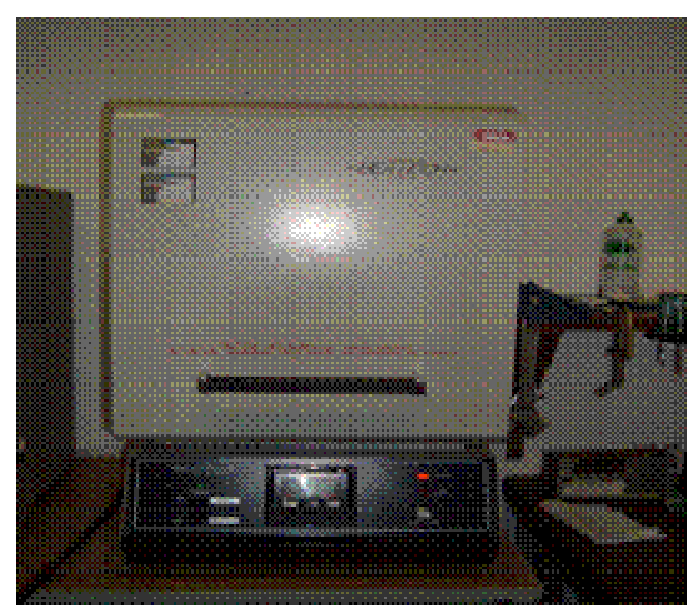

Figura 20 - Forno utilizado para o tratamento térmico. 
Destaca-se que os TLDs-400 diferem dos demais (TLDs-700 e TLDs-600), já que, de acordo com o fabricante, para o seu tratamento, ele só necessita ser submetido a uma temperatura de $400{ }^{\circ} \mathrm{C}$ durante um intervalo de uma hora.

O tratamento térmico é de vital importância já que, esse processo faz com que a pastilha retorne a condição pré-irradiação, ou seja, esse procedimento esvazia as armadilhas desses cristais.

\subsubsection{Irradiação dos dosímetros TLD-400 e TLD-700}

Os TLDs foram irradiados no LDT/IPEN, em uma fonte panorâmica de ${ }^{60} \mathrm{Co}$. Esta é uma fonte de baixa intensidade que se localiza em um bunker, administrado pelo LDT/IPEN. O procedimento de irradiação segue todas as normas de proteção radiológica ${ }^{[16]}$.

A figura 21 mostra a fonte exposta, que é uma fonte selada de ${ }^{60} \mathrm{Co}$ com atividade de 5,46mCi no mês de junho de 2007, que se localiza aproximadamente onde está a seta vermelha.

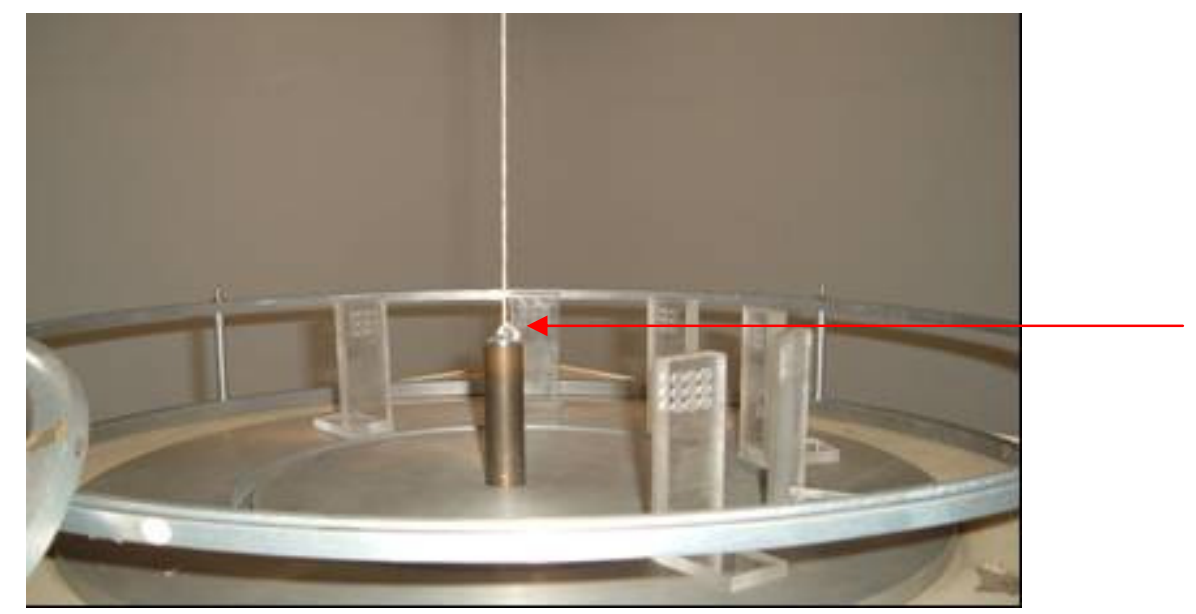

Figura 21 - Fonte pertencente ao LDT, suportes contendo nove TLDs colocados a uma distância de $15 \mathrm{~cm}$ da fonte.

Para irradiar os dosímetros o aro utilizado é retirado, pois o mesmo encontra-se na mesma altura que os dosímetros dentro do suporte.

O processo de irradiação consiste de alguns passos: 
O cálculo foi realizado levando-se em conta o decaimento da fonte de ${ }^{60} \mathrm{Co}$. A dose utilizada foi de $5 \mathrm{mGy}$.

\section{$2^{\circ}$ Passo: Disposição das Pastilhas nos Suportes}

Os suportes com as pastilhas são dispostos como mostrado na figura 22. São anotados, na folha de dados, quais grupos de pastilhas estão em cada suporte assim como, a data da irradiação e a dose a qual os mesmos são submetidos.

$3^{\circ}$ Passo: Posicionamento dos Suportes

Os suportes são dispostos a uma distância de $15 \mathrm{~cm}$ em relação à fonte e tangentes à base do aro (figura 22) para manter a distância de todos os suportes igual em relação a fonte e com isso manter a dose igual para todos os TLDs.

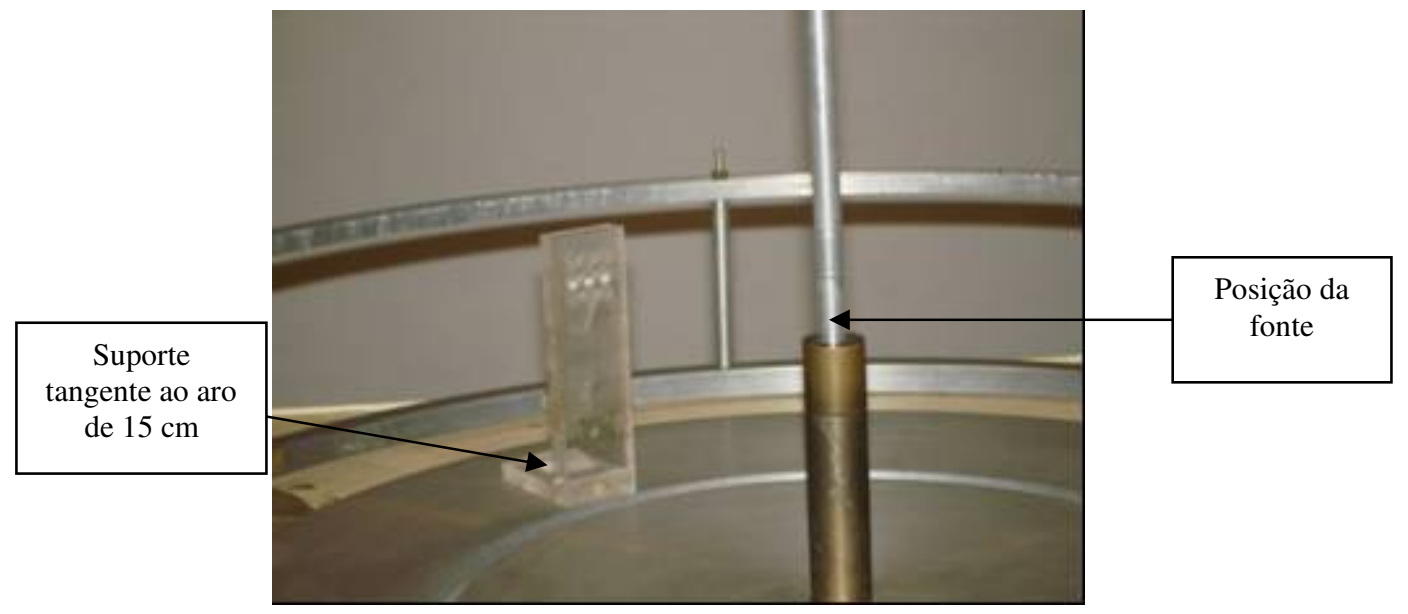

Figura 22 - Posicionamento do suporte para ser irradiado. A posição da seta no bastão de alumínio indica o local onde está a fonte.

Neste arranjo experimental, as pastilhas posicionadas na linha central do suporte ficam a uma distância de $15,65 \pm 0,05 \mathrm{~cm}$ da fonte. A primeira linha do suporte fica a $15,95 \pm 0,05 \mathrm{~cm}$ e a ultima a $16,25 \pm 0,05 \mathrm{~cm}$.

Considerando que a resposta destes TLDs está dentro do intervalo de linearidade, foi feita a correção das doses para a diferença de distância para cada linha do suporte. Contudo, 
foi notado que a incerteza da resposta dos dosímetros, que é da ordem de 0,05 cobre essa diferença de distância entre as linhas do suporte.

Após a irradiação os dosímetros são levados para a o LDT/IPEN a fim de que as suas respostas TL sejam determinadas.

Já os TLDs-600 foram irradiados no Instituto de Radioproteção e Dosimetria(IRD/CNEN), onde foram submetidos a doses que vão de 0,5 mGy a $100 \mathrm{mGy}$. A irradiação não foi realizada no IPEN, já que não existe uma fonte intensa de nêutrons.

\subsubsection{Leitura}

As respostas termoluminescentes foram obtidas na leitora Harshaw modelo 2000, (figura 23).

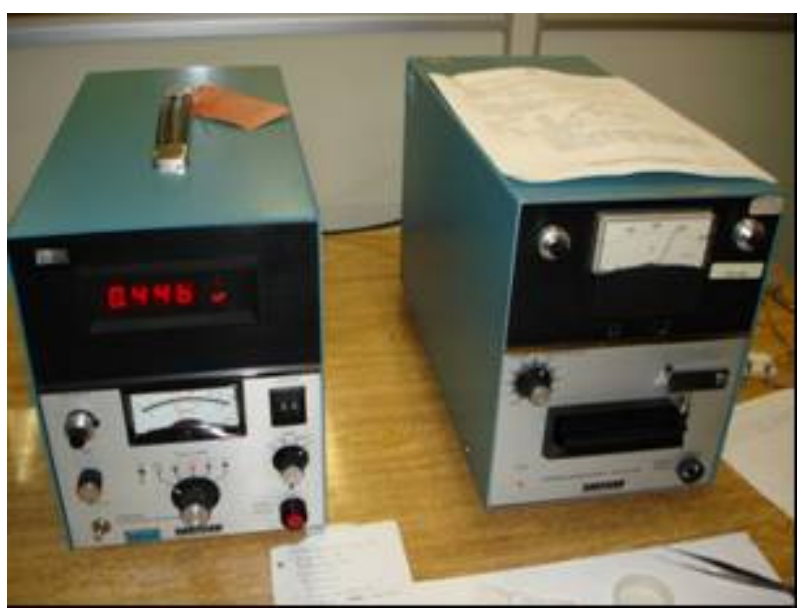

Figura 23 - Leitora Harshaw modelo 2000 pertencente ao LDT/IPEN, os dois módulos constituem o sistema de leitura dos dosímetros.

A leitora termoluminescente é composta basicamente de uma chapa metálica para o aquecimento do TLD, de uma fotomultiplicadora para colher a luz emitida pelo TLD e de um circuito eletrônico que processa o sinal elétrico da saída da fotomultiplicadora e o converte em uma quantidade de carga, indicando então a leitura do TLD em termos da carga elétrica.

Leitora Harshaw modelo 2000 pertencente ao LDT/IPEN, em que os dois módulos constituem o sistema de leitura dos TLDs. Os principais componentes destes dois módulos mostrados na figura 23 são: mostrador digital da resposta do TLD (existem duas escalas em $\mathrm{nC}$ e $\mu \mathrm{C}$ ) módulo esquerdo. O módulo da direita é onde ocorre o aquecimento do TLD e 
regula-se a faixa de temperatura na qual ocorrera a contagem da carga gerada pela luz emitida.

O intervalo de temperatura utilizado para os TLDs-700 e TLDs-600 foi o recomendado pelo fabricante, ou seja, de $80^{\circ} \mathrm{C}$ até $270^{\circ} \mathrm{C}$. Destaca-se que a taxa de aquecimento foi de $10^{\circ} \mathrm{C} / \mathrm{s}$.

Ressalta-se que no caso dos TLDs-400, a temperatura foi de $50^{\circ} \mathrm{C}$ a $300^{\circ} \mathrm{C}$, de acordo com o que foi recomendado pelo fabricante. Neste caso, a taxa de aquecimento também foi de $10^{\circ} \mathrm{C} / \mathrm{s}$

Antes de começar a leitura dos dosímetros a leitora já deve estar ligada por pelo menos uma hora, para que o ganho da fotomultiplicadora se estabilize. O gás nitrogênio que refrigera a prancheta da leitora, também dever ser ligado para que a temperatura da fotomultiplicadora se estabilize.

Os dois procedimentos descritos acima têm a finalidade de manter as condições da fotomultiplicadora as mais estáveis possíveis, pois, variações em uma destas condições podem causar mudanças no ganho da mesma e alterar significativamente o valor da leitura dos dosímetros.

Os parâmetros de leitura, tais como taxa de aquecimento e intervalo de temperatura devem ser selecionados para a leitura do dosímetro em questão. A taxa de aquecimento influencia diretamente no formato do pico de emissão termoluminescente (aumenta ou diminui), portanto, este parâmetro deve ser bem ajustado para que os picos de interesse fiquem bem definidos e possibilite uma boa definição do intervalo de integração da leitora (intervalo de temperatura), ou seja, para que a resposta em carga - integral sob a curva - do pico seja totalmente mensurável. O intervalo de temperatura é selecionado em dois potenciômetros localizados na parte da frente da leitora (figura 24) e a taxa de aquecimento é ajustada na parte de trás.

\subsubsection{Parâmetros}

Umidade 
O medidor de umidade registra a umidade ambiente. Esta não deve estar acima de $60 \%$, caso contrário, as medidas não podem ser realizadas. A umidade afeta a eletrônica do sistema de leitura. Para manter a umidade em níveis aceitáveis de medida é utilizado um desumidificador.

Temperatura Ambiente

Se a temperara exceder $30{ }^{\circ} \mathrm{C}$, a medida também não pode ser realizada devido a sensibilidade da fotomultiplicadora com o aumento da temperatura ambiente. A temperatura no interior da sala é mantida em condições aceitáveis para efetuar a leitura dos TLDs, utilizando-se um aparelho de ar condicionado.

Janela Aberta

É realizada uma medida da sensibilidade da fotomultiplicadora a luz de referência. Para tanto, a gaveta onde são colocados os dosímetros é aberta (figura 24) e o aquecimento da chapa não é acionado. A resposta mostrada no display é anotada. $\mathrm{O}$ valor médio da resposta da leitora para a medida feita com a gaveta aberta é de aproximadamente $256 \pm 2,32 \eta \mathrm{C}$.Esta medida é importante para avaliar a estabilidade da leitora.

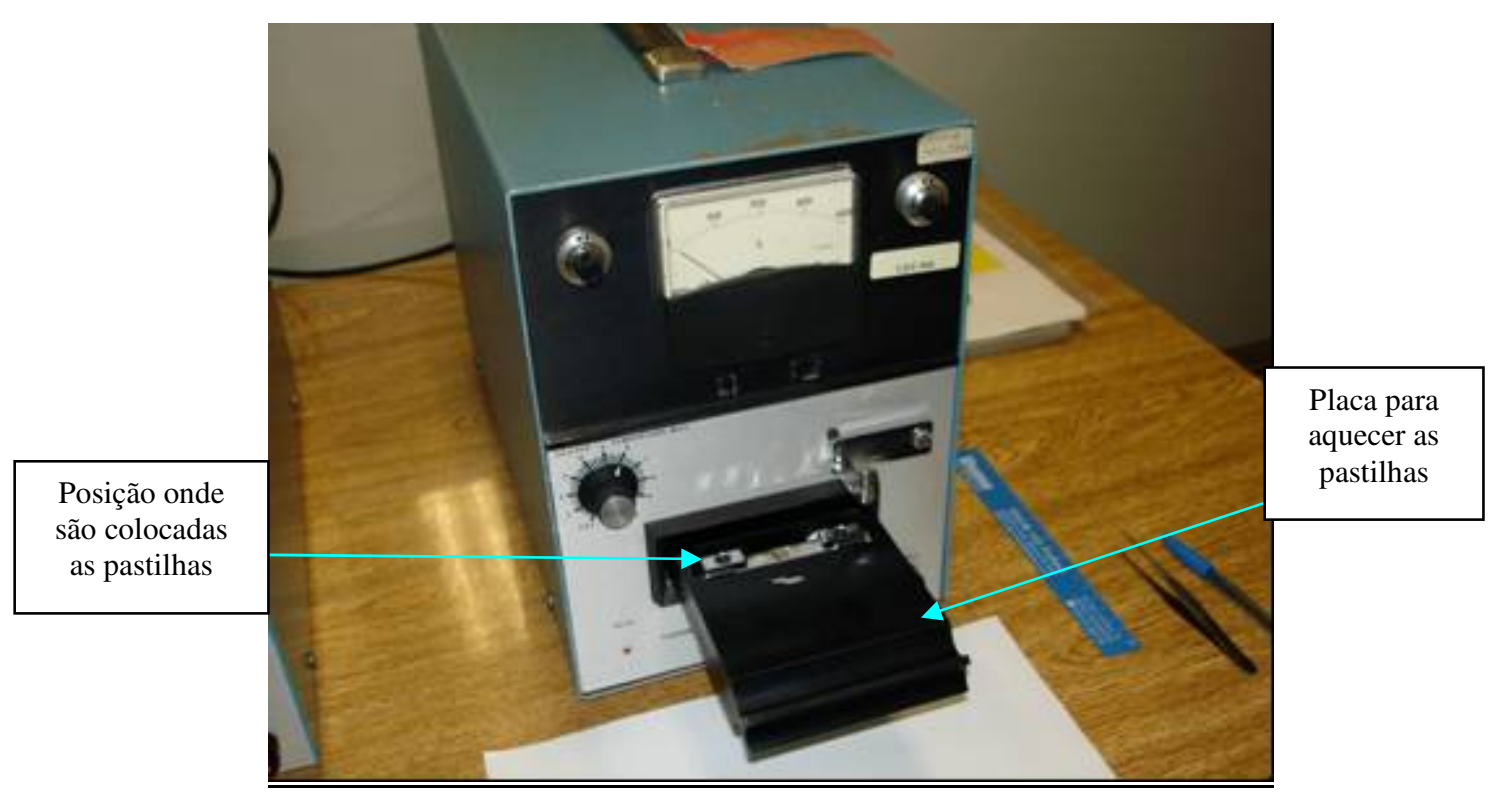

Figura 24 - Leitora de TLDs com a gaveta aberta. 
Janela fechada

Com a gaveta fechada, o botão de aquecimento da chapa é acionado e a resposta é anotada.

Esta medida tem a finalidade de quantificar o ruído da leitora, se este exceder $8 \mu \mathrm{C}$, a leitora não está em condições ideais de medição. Este valor baseia-se na reprodutibilidade dos TLDs-400, ou seja, que não deve ser maior do que $5 \%$.

Teste de Zero

Abaixo do display onde a resposta da pastilha é mostrada, existe uma escala na qual é possível medir a corrente que passa pela resistência que esquenta a chapa onde são colocados os dosímetros. Abaixo desta escala, existe um botão onde é possível selecionar o tipo de medida, corrente ou tensão. Há ainda a opção para "zero": ao selecionar esta opção o ponteiro deve ficar alinhado com o traço do zero da escala que mede a corrente.

O processo de leitura da pastilha consiste basicamente em colocar a mesma na gaveta, fechá-la, acionar o botão de aquecimento e anotar a leitura na folha de dados. Para medir a próxima pastilha espera-se até que a temperatura da chapa esteja abaixo de $30^{\circ} \mathrm{C}$ por meio do sistema de refrigeração

\subsection{Selecionamento dos TLDs-400}

Os dosímetros foram submetidos ao tratamento térmico recomendado pelo fabricante (Thermal Electron-Eberline), citado no item 7.1.3.

Para que o tratamento selecionamento seja bem sucedido, é necessário que todos os dosímetros sejam submetidos à mesma temperatura. Para tanto, os mesmos são colocados em uma placa de aço, como recomendado pelo fabricante (figura 25) que é posicionada na prateleira central da mufla. Para esfriar a placa com os dosímetros é utilizada uma chapa de alumínio, esses cuidados se tornam necessário para manter condições idênticas para todo o grupo. 


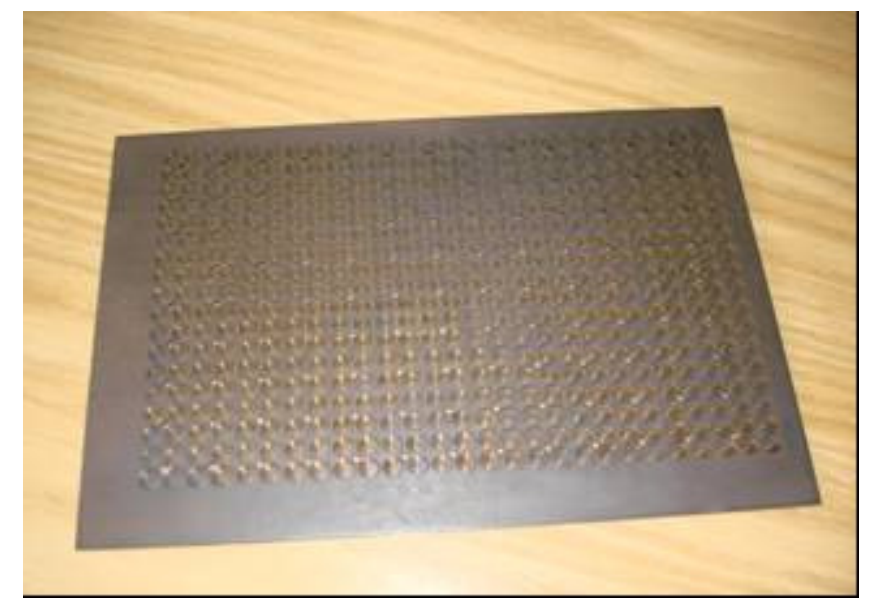

Figura 25 - Chapa de aço utilizada para o tratamento térmico dos dosímetros. Ela é perfurada para que a ordem dos dosímetros seja mantida.

\subsubsection{Repetição do Processo}

Os procedimentos de irradiação, leitura e tratamento térmico foram realizados três vezes e as respostas dos dosímetros são apresentadas no histograma (figura 26) e no gráfico a seguir (figura 27), em que o histograma mostra a distribuição dos TLDs por respostas e o gráfico mostra a variação da resposta de cada TLD. Os valores obtidos em cada rodada de radiação encontra-se na tabela do anexo 1. Esta é a parte mais importante do selecionamento, já que, por meio desta tabela foram separadas as pastilhas mais reprodutíveis e criados grupos de pastilhas com sensibilidade semelhante.

Histograma TLDs 400

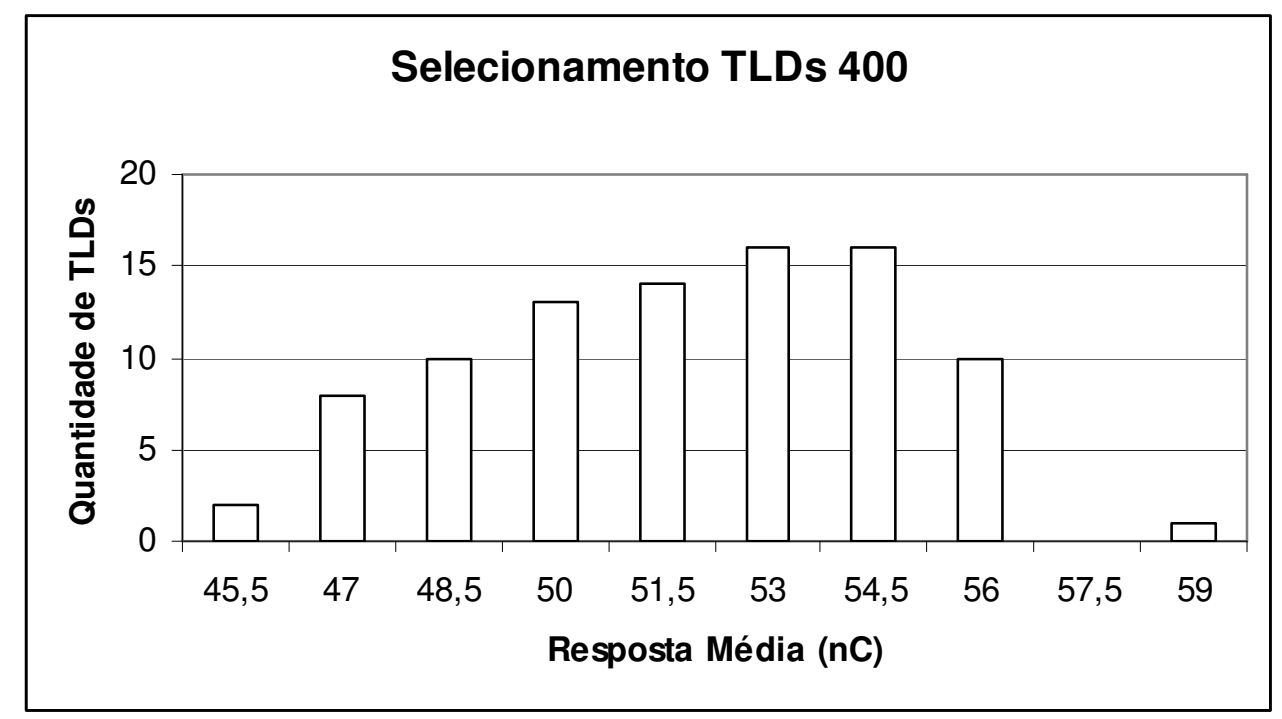

Figura 26 - Respostas dos TLDs 400. 
Gráfico TLDs 400

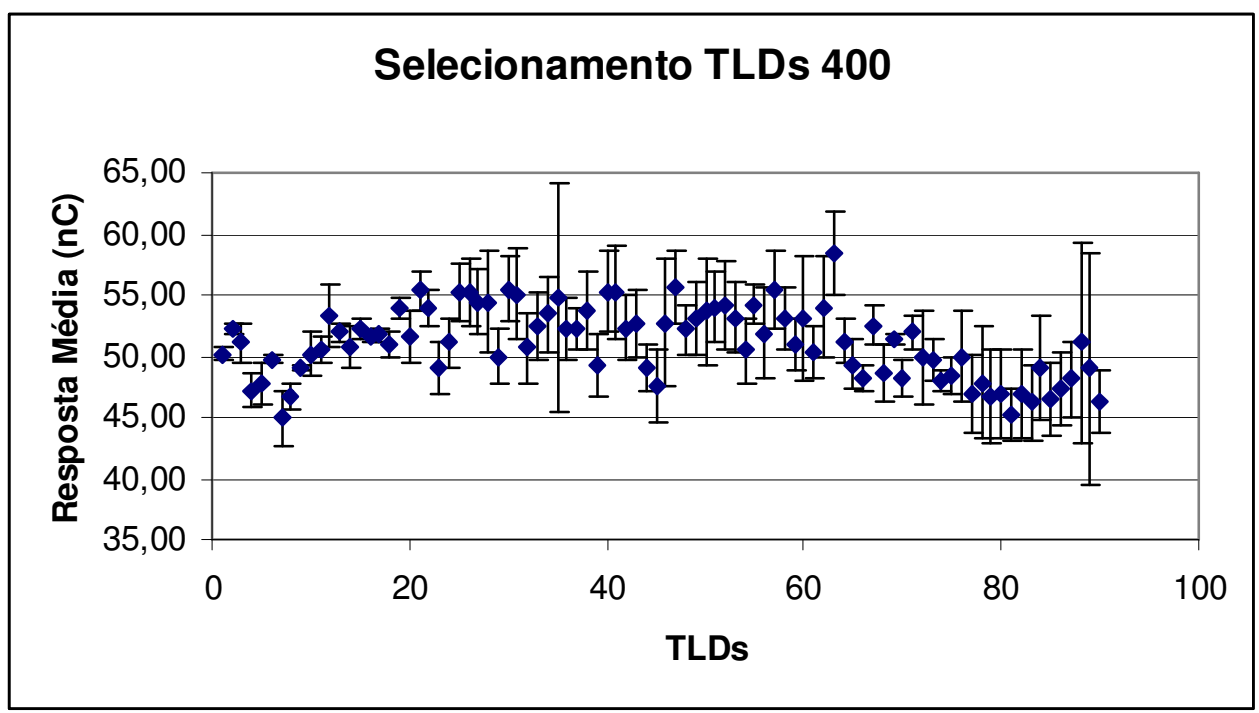

Figura 27 - Respostas dos TLDs 400.

\subsubsection{Planilha de Selecionamento}

Foi calculada a média das respostas das três irradiações para cada pastilha, assim como, seus respectivos desvios padrão e incerteza . Com essa média foi calculada a média das respostas de todas as pastilhas, bem como o desvio padrão da média.

Com a incerteza percentual de cada pastilha, foi criada uma condição (utilizando uma função de lógica do Excel) que tinha como finalidade reprovar as pastilhas com incerteza percentual maior do que $5 \%$. Além da condição de $5 \%$, as pastilhas deveriam ter resposta média o mais próximo possível da média global das três rodadas. Para isso foi estipulado um valor limite de afastamento desta média. Esse valor corresponde à metade do desvio padrão calculado para as três rodadas, na literatura recomenda-se utilizar TLDs com um desvio menor ou igual a $3 \%$.

Foram selecionadas 30 pastilhas das noventa iniciais. Contudo, 5 pastilhas destas trinta satisfazem a condição de $5 \%$, porém, não satisfazem a condição de estarem contidas dentro de metade do desvio padrão das três rodadas, mas, estão muito próximo desta condição. Isso foi feito porque foram utilizados 10 suportes e as pastilhas foram colocadas sempre na linha central do suporte como mostrado na figura 21, totalizando 30 posições. Como só havia 25 pastilhas, ainda eram necessárias mais 5 pastilhas. 


\subsection{Selecionamento dos TLDs -700}

O processo de selecionamento destas pastilhas seguiu basicamente a mesma metodologia adotada para o selecionamento dos TLDs-400, sendo diferente apenas em alguns tópicos. Dessa forma, será descrito somente os pontos nos quais o selecionamento dos TLDs-700 diferente do selecionamento dos TLDs-400.

O processo de pré-seleção não foi necessário, pois essas pastilhas eram bem regulares. O número de TLDs-700 antes do selecionamento era de 90 pastilhas, estas foram colocadas em uma placa de acrílico idêntica a utilizada para os TLDs-400. A irradiação das pastilhas também foi idêntica a dos TLDs-400.

\subsubsection{Leitura}

Esse processo foi basicamente o mesmo, contudo, a faixa de temperatura utilizada para ler estas pastilhas foi diferente $\left(80\right.$ a $\left.270^{\circ} \mathrm{C}\right)$ já que, o pico dosimétrico dos mesmos termina um pouco antes do pico dosimétrico dos TLDs-400 para a mesma taxa de aquecimento. Como mostrado nas figura 5 e 6 , a taxa de aquecimento utilizada é de $10^{\circ} \mathrm{C} / \mathrm{s}$.

\subsubsection{Tratamento térmico}

O tratamento térmico destas pastilhas difere do tratamento térmico dos TLDs-400. Os TLDs-700 além de serem submetidos a $400{ }^{\circ} \mathrm{C}$ por uma hora também são submetidos a uma temperatura de $100^{\circ} \mathrm{C}$ por duas horas em outro forno. Para esfriar a placa de tratamento térmico com os dosímetros é utilizada a chapa de alumínio.

Este forno tem uma escala analógica para temperatura, onde as posições entre 3, 5 e 4 do cursor equivalem aproximadamente a $100{ }^{\circ} \mathrm{C}$. Isso é conhecido por meio de um termômetro localizado na parte superior do forno.

\subsubsection{Repetição do Processo}

Assim como para os TLDs-400, o processo foi repetido três vezes e foram selecionadas as pastilhas mais reprodutíveis utilizando a mesma planilha utilizada para 
selecionar os TLDs-400. Os resultados do selecionamento destas pastilhas estão no histograma (figura 28) e gráfico (figura 29) a seguir e os resultados para cada pastilha encontra-se no anexo 2. Após o selecionamento foram separadas 20 pastilhas para realizar a calibração.

Histograma TLDs 700

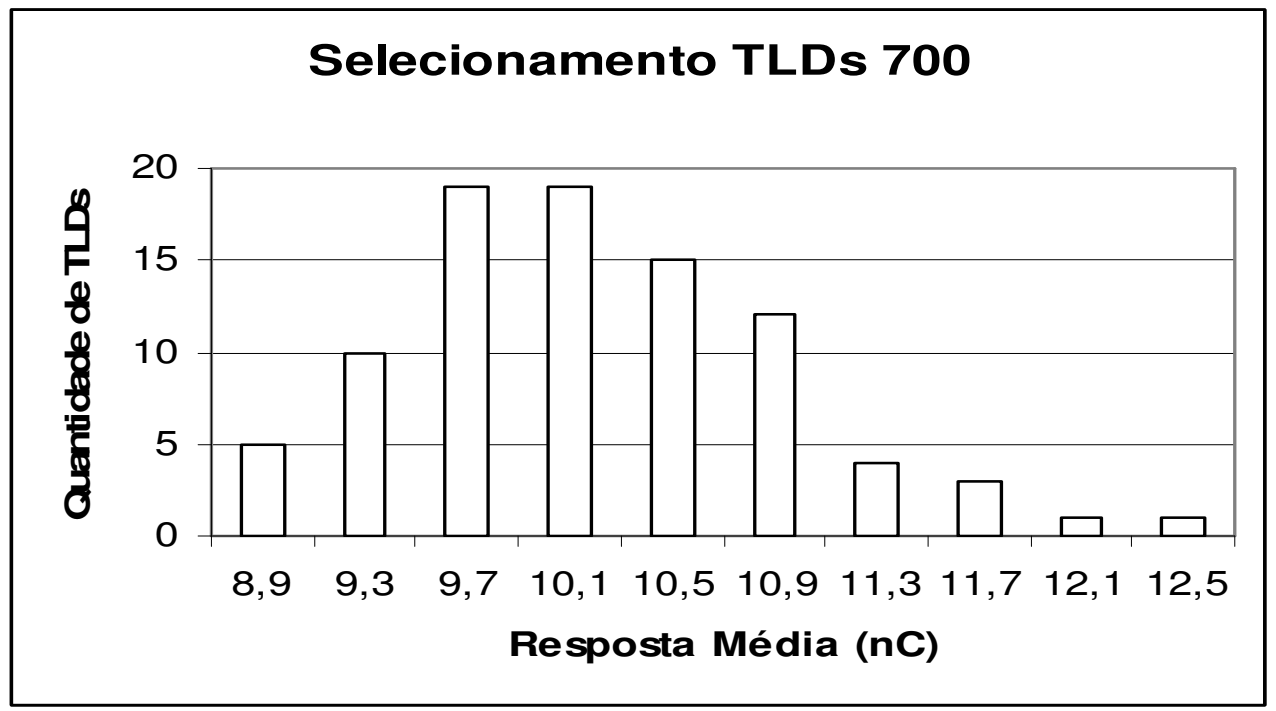

Figura 28 - Respostas dos TLDs 700.

Gráfico TLDs 700

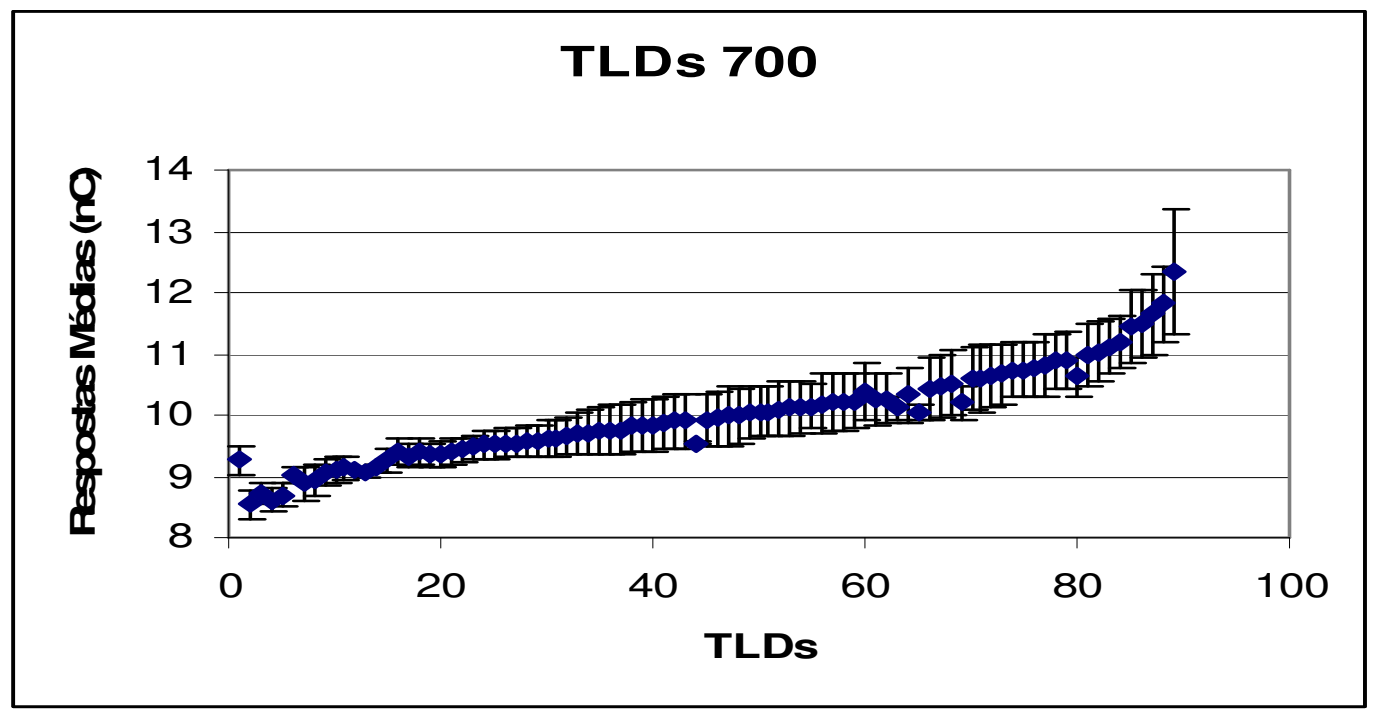

Figura 29 - Respostas dos TLDs 700.

Os TLDs-600 não foram selecionados, devido a falta de uma fonte intensa de nêutrons, contudo, os resultados da calibração foram considerados bons. 


\subsection{Calibração dos TLD-400}

Após o selecionamento, as pastilhas foram calibradas, ou seja, foram construídas curvas de resposta termoluminescente em função da dose para o lote de pastilhas obtido através do selecionamento. Dos noventa TLDs-400, foram selecionadas 30 pastilhas conforme critérios preestabelecidos de reprodutibilidade e de proximidade da média global das respostas de todas as pastilhas. Portanto, a curva de calibração foi obtida utilizando pastilhas de mesma sensibilidade.

\subsubsection{Irradiação}

Após realizar a última rodada do selecionamento, as pastilhas são tratadas termicamente e colocadas novamente nos suportes para realizar o processo de calibração. Diferentemente do selecionamento onde eram colocadas nove pastilhas em cada suporte, na calibração são colocados apenas três TLDs na linha central do suporte para que não seja necessário nenhum tipo de correção da resposta do dosímetro. Isso ocorre, já que, diferentemente do selecionamento, uma pequena variação na distância dos dosímetros em relação a fonte causa uma variação perceptível na resposta das pastilhas, pois as doses utilizadas para realizar a calibração são muito maiores do que as doses utilizadas para realizar o selecionamento. O intervalo de dose utilizado foi de 0,5 até $1000 \mathrm{~Gy}$.

As irradiações para calibração das pastilhas, foram realizadas em uma fonte panorâmica de ${ }^{60} \mathrm{Co}$, com atividade de $2072,99.10^{10} \mathrm{~Bq}$ no mês de abril de 2008 , administrada pelo CTR/IPEN (Figura 30).

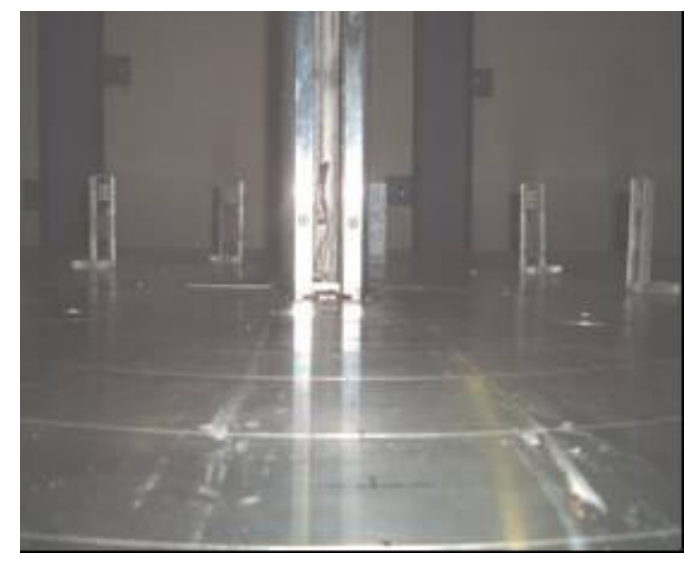

Figura 30 - Fonte pertencente ao (CTR/IPEN), suportes contendo três TLDs-400 na linha central. 


\subsubsection{Leitura}

As pastilhas foram levadas para o LDT/IPEN onde foram lidas e anotadas (folha de dados anexo 2) suas respostas termoluminescentes na leitora Harshaw modelo 2000. As condições de leitura destes dosímetros, tais como: taxa de aquecimento e intervalo de temperatura foram as mesmas do selecionamento. Também foram respeitadas as condições ambientais de leitura, assim como: temperatura ambiente inferior a $30{ }^{\circ} \mathrm{C}$; umidade do ar inferior a 60\%; janela aberta em aproximadamente $256 \pm 2$ $\mathrm{CC}$ e janela fechada em aproximadamente $8 \mu \mathrm{C}$.

\subsubsection{Tratamento Térmico}

Após a leitura de cada dose, os dosímetros foram submetidos ao mesmo tratamento térmico utilizado para o selecionamento, ou seja, uma hora a $400^{\circ} \mathrm{C}$.

\subsection{Calibração do TLD-700}

O processo de calibração destas pastilhas foi análogo ao procedimento de calibração dos TLDs-400.

\subsubsection{Irradiação}

Antes de realizar a leitura, as pastilhas foram submetidas a uma temperatura de $80^{\circ} \mathrm{C}$ durante 10 minutos, segundo recomendado pelo fabricante.

Essas pastilhas foram irradiadas na mesma fonte do CTR/IPEN utilizadas para as irradiações dos TLDs 400, desde 0,5 até 1000 Gy. Também foram colocadas três pastilhas na linha central do suporte.

\subsubsection{Leitura}

Para a leitura destes dosímetros foram respeitadas as mesmas condições utilizadas em seu selecionamento, assim como as condições ambientais de leitura. 


\subsubsection{Tratamento Térmico}

O tratamento térmico foi o mesmo que do selecionamento, uma hora a $400^{\circ} \mathrm{C}$ e duas horas a $100^{\circ} \mathrm{C}$.

\subsection{Calibração do TLD-600}

Mesmo sem estas pastilhas terem sido selecionadas, foi realizado o procedimento de calibração.

\subsubsection{Irradiação}

Como estas pastilhas medem dose devido aos nêutrons, elas foram levadas para o Instituto de Radioproteção e Dosimetria (IRD/CNEN) para serem irradiadas numa fonte isotópica de ${ }^{252} \mathrm{Cf}+\mathrm{D}_{2} \mathrm{O}$ com uma taxa de emissão de 2,5.10 ${ }^{8} \mathrm{n} / \mathrm{s}-19 / 09 / 1996$. O intervalo de calibração dos dosímetros foi de 0,5 até $100 \mathrm{mGy}$.

\subsubsection{Leitura}

A leitura destes dosímetros foi realizada utilizando os mesmos parâmetros dos TLDs700. Dessa forma, para estes dosímetros foi realizado um pré-aquecimento de $80^{\circ} \mathrm{C}$ por 10 minutos. Também foram respeitadas as condições ambientes para a realização da leitura.

\subsubsection{Tratamento Térmico}

O tratamento térmico destes dosímetros foi o mesmo realizado para o tratamento térmico dos TLDs-700.

\subsection{Medidas na Instalação para Pesquisas em BNCT}

Foram realizadas medições de dose devido a nêutrons e radiação gama na posição onde as amostras são irradiadas, como mostrado na Figura 1. 
Para colocar os TLDs na posição de irradiação de amostras, foi utilizado um suporte onde pode ser encaixado um disco de plástico no qual os TLDs são dispostos (figura 31).

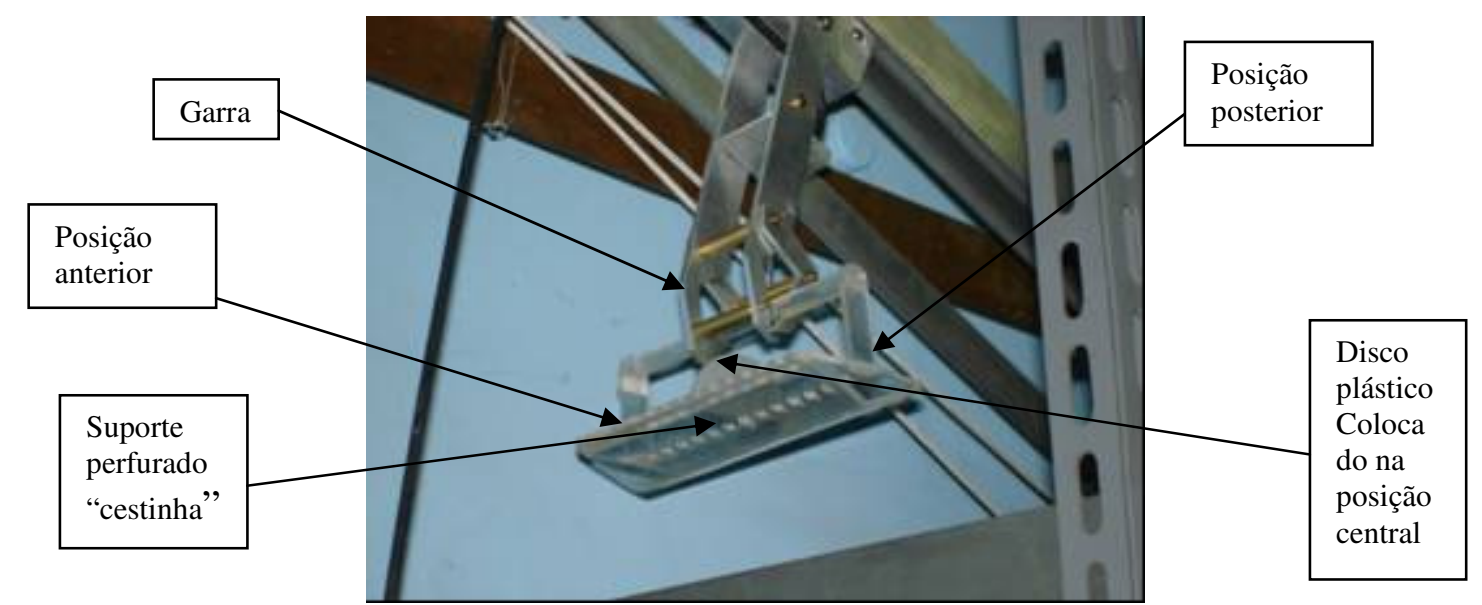

Suporte perfurado para medidas axiais de dose. Disco de plástico (cor cinza) onde são posicionados os TLDs e garra para fixar a cestinha. Posição anterior. Posição central e posição posterior.

Figura 31 - Suporte de acrílico utilizado para colocar os dosímetros na posição onde as amostras são irradiadas.

Neste trabalho, foram realizadas medições em três posições ao longo do suporte: posição anterior (mais próximo do núcleo do reator, como mostra a figura 1), nesta posição, os dosímetros foram colocados no suporte (como mostrado na Figura 32); posição central, nesta, os dosímetros são colocados no disco de plástico e este é fixado no furo central do suporte; posição posterior, os dosímetros são dispostos da mesma forma que na posição anterior, contudo, eles ficam antes da placa de acrílico que serve de sustentação para a alça do suporte.

A maior parte das medições de dose realizadas neste trabalho, foram realizadas na posição central do suporte, devido a necessidade de caracterizar esta posição para as irradiações futuras.

Na posição onde as amostras são irradiadas existe uma estrutura sobre a qual o suporte contendo os dosímetros (“cestinha”) é apoiado. Isso é possível uma vez que o formato das duas peças têm sua base em forma de "v", permitindo que a cestinha se encaixe no suporte fixo a posição onde as amostras são irradiadas, como mostrado a seguir (Figura 32). 


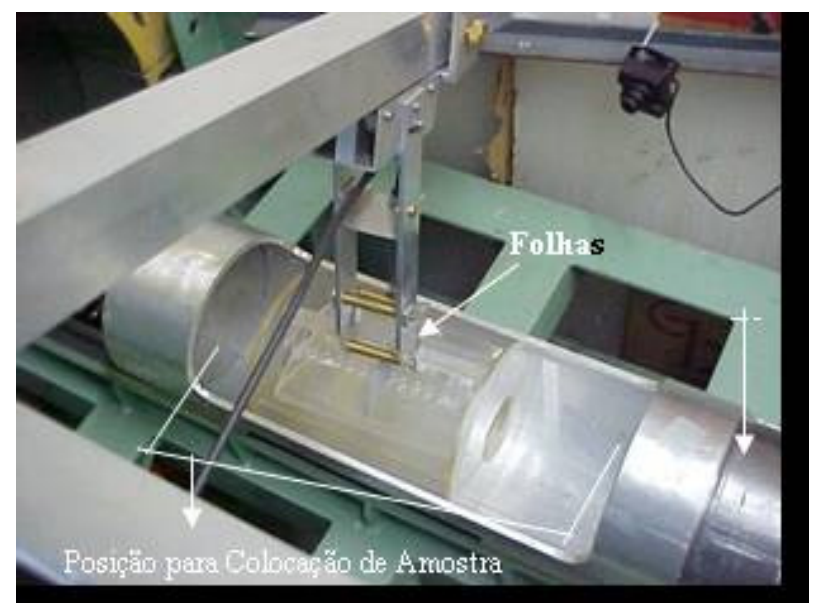

Figura 32 - Apoio dos suportes para os TLDs.

Os dosímetros podem ser colocados para irradiar mesmo com o reator operando. Isso é possível pela existência de um sistema automático que insere e retira a calha de alumínio que contém os discos de chumbo (blindagem) e o local onde está fixado o suporte sobre o qual é posicionada a cestinha (Figura 33).

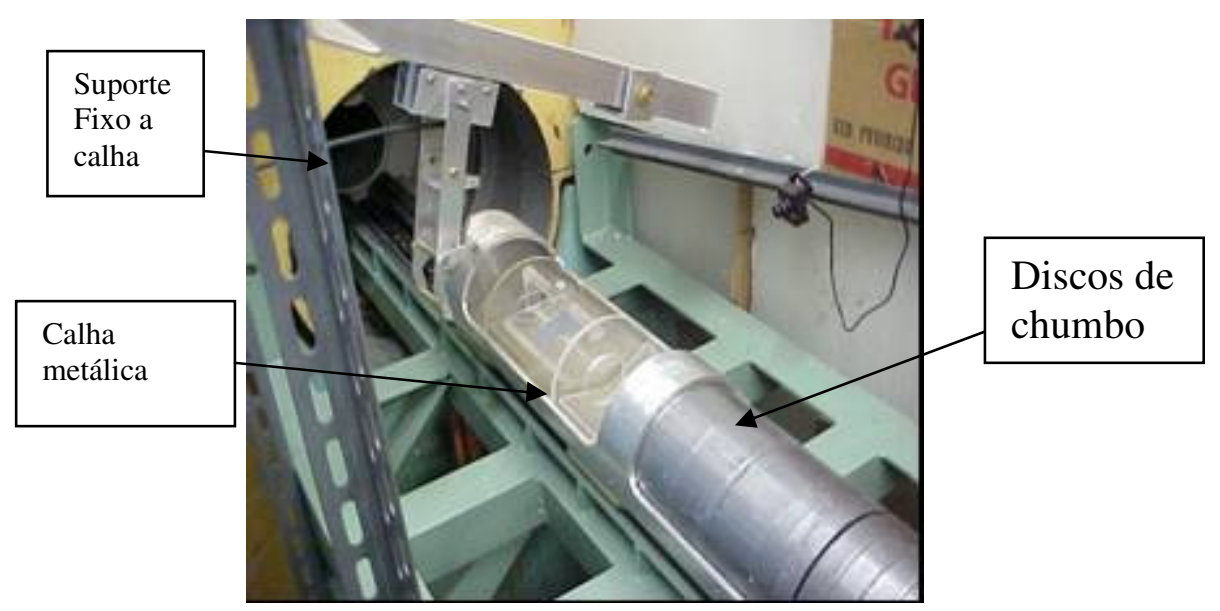

Figura 33 - Calha onde estão os discos de chumbo (blindagem) e o local onde as amostras são posicionadas para serem irradiadas. Suporte fixo a calha metálica e cestinha posicionada em cima do mesmo.

Esse sistema consiste basicamente de um trilho, no qual existe uma corrente que está fixada por meio de um engate a calha de alumínio. O conjunto calha mais corrente está em cima de uma mesa (figura 34). O tempo necessário para inserir é igual ao tempo para retirá-la, aproximadamente 45 segundos. 


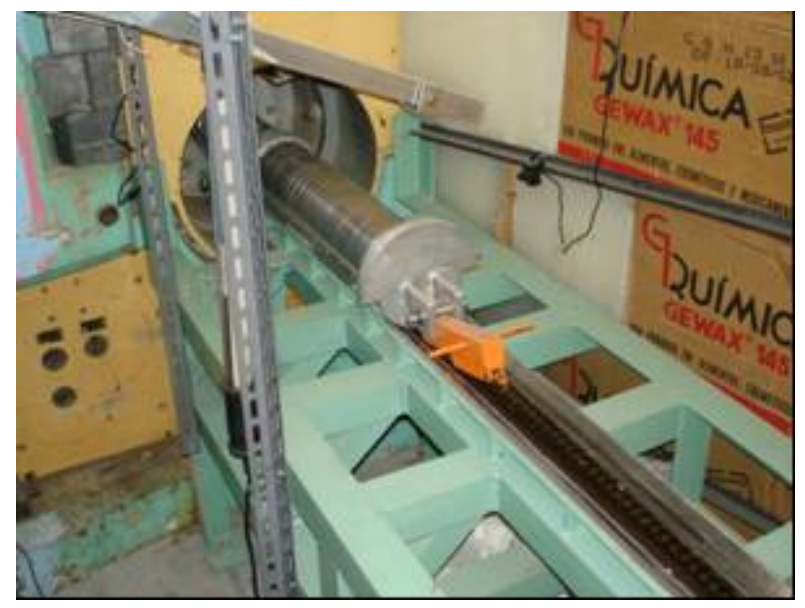

Figura 34 - Mesa com o conjunto calha mais esteira está em cima de uma mesa.

Ao retirar a calha de dentro do "beam hole" o feixe vindo do núcleo do reator fica totalmente sem blindagem, por isso, existe uma blindagem biológica para proteger os trabalhadores que estão realizando as medições, assim como, todas as outras pessoas presentes no $1^{\circ}$ andar do reator. Esta blindagem é composta de placas de chumbo, blocos de concreto (para radiação gama) e de blocos de parafina (para os nêutrons) num total de aproximadamente 35 toneladas de material.

Para posicionar a "cestinha" contendo as amostras em cima do suporte fixo a calha de alumínio, utiliza-se um sistema composto por um trilho metálico, uma garra metálica, um cabo e um gatilho (figura 32). Quando o gatilho é puxado e liberado pela primeira vez a alça da cestinha, é presa na garra. Por meio de um cabo conectado a garra, é possível empurrá-la, isso faz com que ela deslize sobre o trilho até que a cestinha esteja devidamente posicionada sobre o suporte fixo a calha de alumínio. O gatilho é puxado e liberado pela segunda vez, fazendo com que a garra se abra e a cestinha apóie em cima do suporte fixo na calha de alumínio (figura 35). 


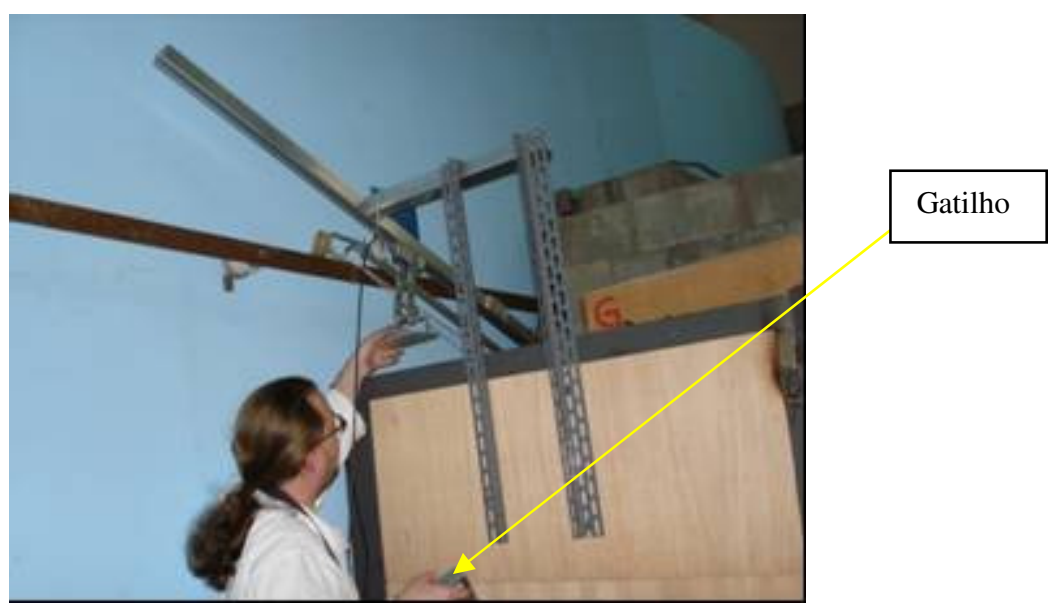

Figura 35 - Trilho metálico, gatilho e cabo.

Posicionada a cestinha no suporte, a calha de alumínio é inserida para dentro do "beam hole". Após a entrada completa da calha, é cronometrado o tempo de irradiação. O erro no tempo de irradiação é de aproximadamente noventa segundos, tempo de entrada ou de saída da calha.

A realização dos procedimentos, mencionados anteriormente, fazem da irradiação de amostras, mesmo com o reator operando, um processo seguro.

\subsection{Procedimento Experimental das Folhas}

Antes da irradiação das folhas os detectores tipo folha tiveram sua massa medida (balança Mettler H20). As tabelas 3, 4 e 5, a seguir, apresentam os valores medidos.

Tabela 3 - Massa das Folhas Irradiadas nos dias: 19/12/05 e as de Ouro (20/12/05).

\begin{tabular}{|c|c|c|}
\hline Folhas & $\operatorname{Massa}(\mathrm{g})$ & * $\sigma \operatorname{Massa}(\mathrm{g})$ \\
\hline In & 0,086640 & 0,000005 \\
\hline $\mathrm{Fe}$ & 0,205250 & 0,000005 \\
\hline $\mathrm{Mg}$ & 0,050150 & 0,000005 \\
\hline $\mathrm{Ni}$ & 0,420540 & 0,000005 \\
\hline $\mathrm{Al}$ & 0,031220 & 0,000005 \\
\hline $\mathrm{Au}$ com $\mathrm{Cd}$ & 0,009540 & 0,000005 \\
\hline Au Nua & 0,012500 & 0,000005 \\
\hline
\end{tabular}


Tabela 4 - Folhas de Ouro Irradiadas (07/03/06).

\begin{tabular}{c|c|c}
\hline \hline Folhas & Massa $(\mathrm{g})$ & $\sigma$ Massa $(\mathrm{g})$ \\
\hline \hline $\mathrm{Au}$ com $\mathrm{Cd}$ & 0,01430 & 0,000005 \\
\hline Au nua & 0,01200 & 0,000005 \\
\hline \hline
\end{tabular}

Tabela 5 - Folhas Irradiadas (20/03/06).

\begin{tabular}{c|c|c}
\hline \hline Folhas & Massa $(\mathrm{g})$ & $\sigma$ Massa $(\mathrm{g})$ \\
\hline \hline $\mathrm{Al}$ & 0,030770 & 0,000005 \\
\hline $\mathrm{Ni}$ & 0,434770 & 0,000005 \\
\hline $\mathrm{Ti}$ & 0,144900 & 0,000005 \\
\hline \hline
\end{tabular}

Depois de terem sido realizadas as medidas das massas das folhas, estas foram colocadas no suporte, através do sistema da garra descrito anteriormente (Descrição da Instalação para Pesquisa em BNCT). Os detectores foram todos irradiados na posição de amostra do BH-3 (figura 1), com o reator a uma potência de 3,5 MW.

Após a irradiação das folhas, estas foram levadas para o laboratório do reator IPEN/MB01 (Figura 36) onde foi feito a espectrometria gama em um sistema composto de um detector tipo Germânio hiper - puro (HPGe), eletrônica associada (figura 37) ${ }^{[10]}$ e o software Maestro 3.2 - ORTEC $^{[11]}$, desenvolvido pelo fabricante dos equipamentos.

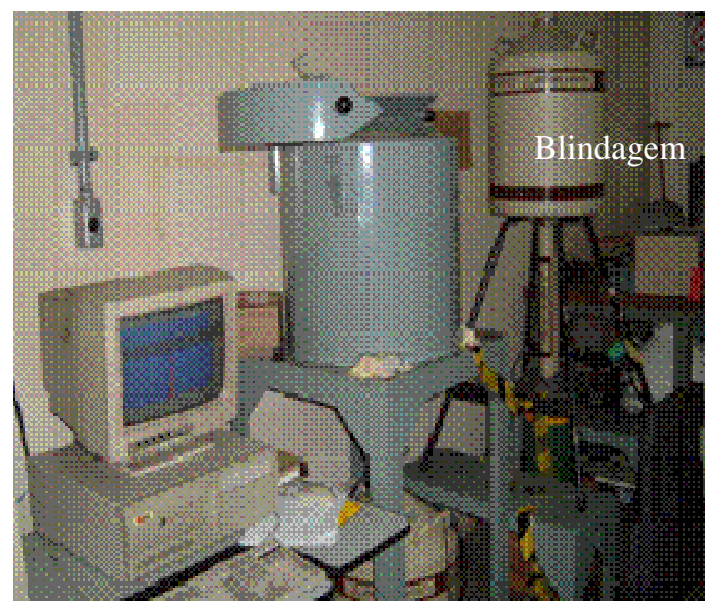

(a)

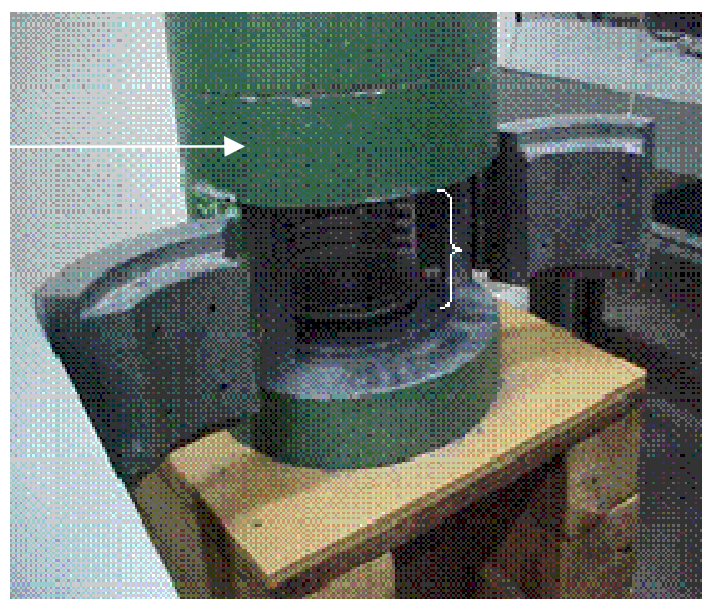

(b)

Figura 36 - (a) Laboratório do reator IPEN/MB01 e (b) Detalhe das gavetas a onde são colocadas as folhas para a espectrometria gama. 


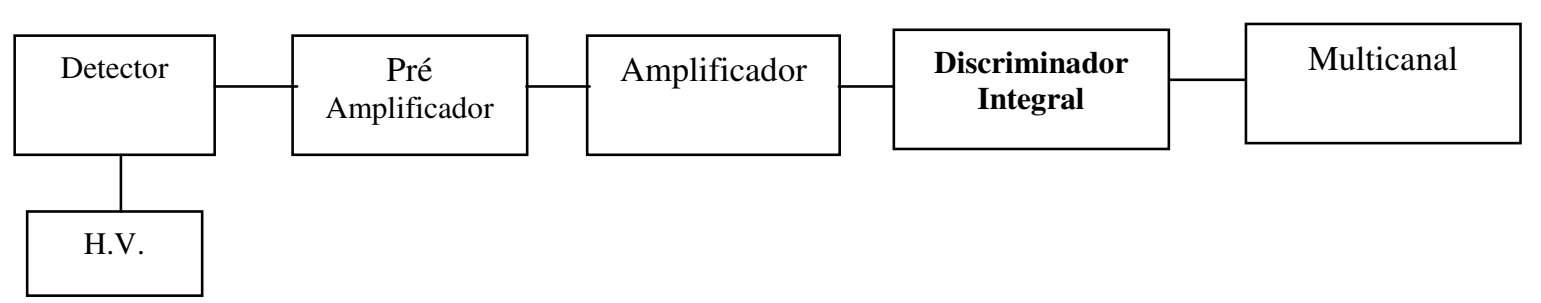

Figura 37 - Conjunto de toda eletrônica.

No diagrama acima (figura 37) a função de cada dispositivo é:

a) Alta tensão (H.V.) polariza o detector reversamente aumentando a região de depleção do detector; b) Detector semicondutor de Germânio Hiper Puro (HPGe); c) PréAmplificador amplia o sinal para que este possa ser transmitido pelo cabeamento sem deteriorar a relação sinal/ruído; d) Amplificador amplia o sinal que vem do pré-amplificador; e) Discriminador integral elimina o ruído eletrônico; f) Multicanal registra a contagem da radiação gama para cada energia, ou seja, para cada fóton detectado é registrado a informação em seu respectivo canal de energia.

A determinação da eficiência absoluta do sistema de detecção foi realizada pela equipe do laboratório do reator IPEN/MB01 utilizando-se uma fonte de Európio $\left({ }^{152} \mathrm{Eu}\right)$ com atividade de 13,3 kBq $\pm 0,6 \mathrm{~Bq}$ as energias utilizadas da fonte de Európio estão na tabela 6 .

Tabela 6 - Energias emitida pela fonte de ${ }^{152} \mathrm{Eu}$.

\begin{tabular}{ccc}
\hline \hline Energia $(\mathbf{k e V})$ & Intensidade & $\boldsymbol{\sigma}_{\text {Intensidade }}$ \\
\hline 244,6989 & 0,0751 & 0,0005 \\
344,2811 & 0,26580 & 0,0018 \\
411,115 & 0,02234 & 0,00013 \\
443,976 & 0,03120 & 0,00018 \\
778,903 & 0,1296 & 0,007 \\
964,131 & 0,1462 & 0,0006 \\
1112,116 & 0,1356 & 0,0006 \\
1408,01 & 0,2085 & 0,0008 \\
\hline
\end{tabular}

Após um tempo de contagem que permita uma boa estatística de contagem, ou seja que defina bem a curva de contagem, tem-se a contagem para as energias que a fonte de Európio emite, como a atividade da fonte é conhecida, sabe-se quantos fótons a fonte emitiu 
com cada energia durante o tempo de contagem. Com a razão da contagem do detector e o número de emissões da fonte obtêm-se a eficiência absoluta do sistema de detecção para as energias do Európio; então, faz-se um gráfico de eficiência absoluta por energia e ajusta-se uma função exponencial (ajuste realizado com o programa Origin 5.0), este procedimento foi realizado para cada gaveta.

A seguir são apresentadas as curvas e equações da eficiência das gavetas 3,5 e 7 (figura 38).

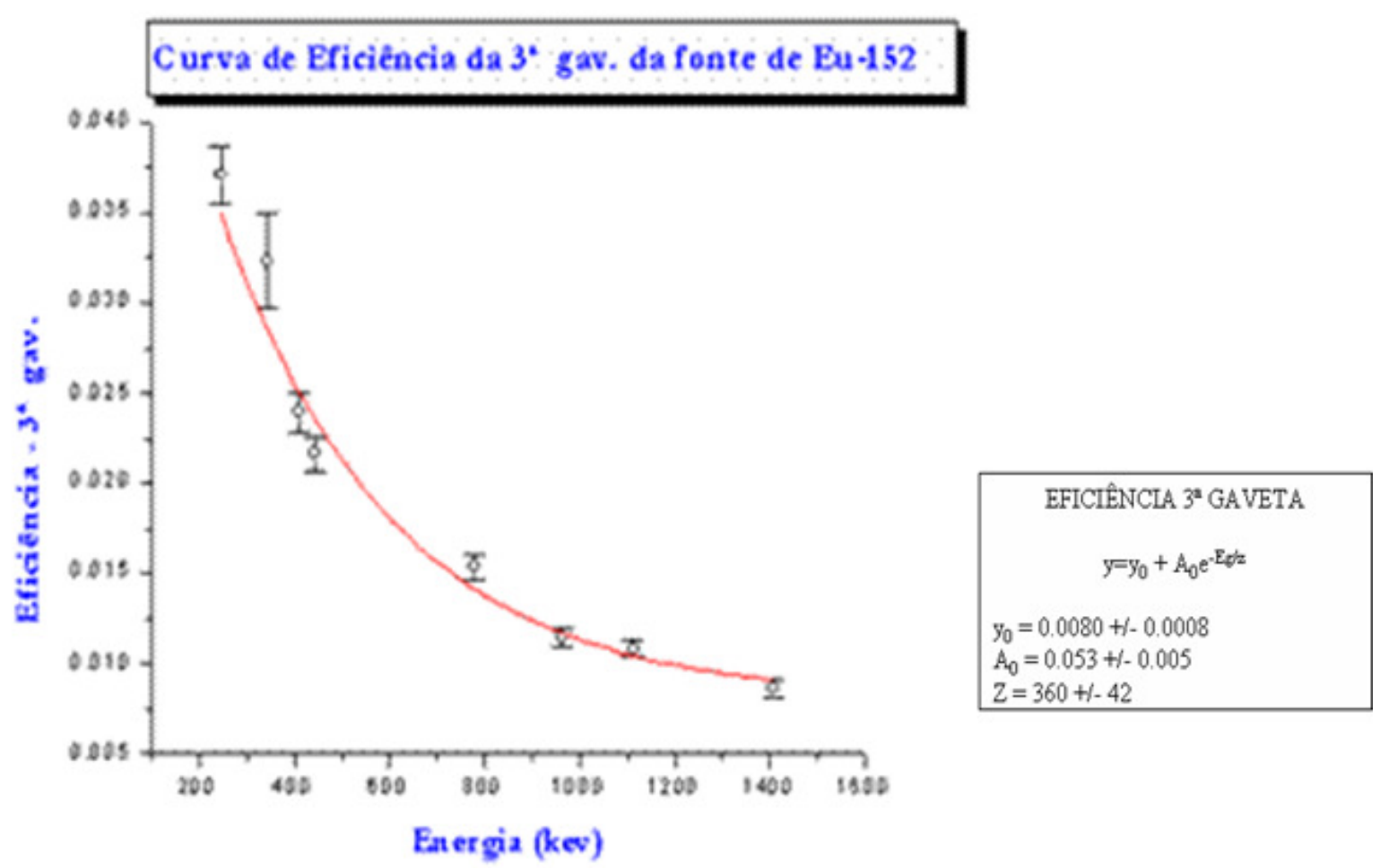

(a) 


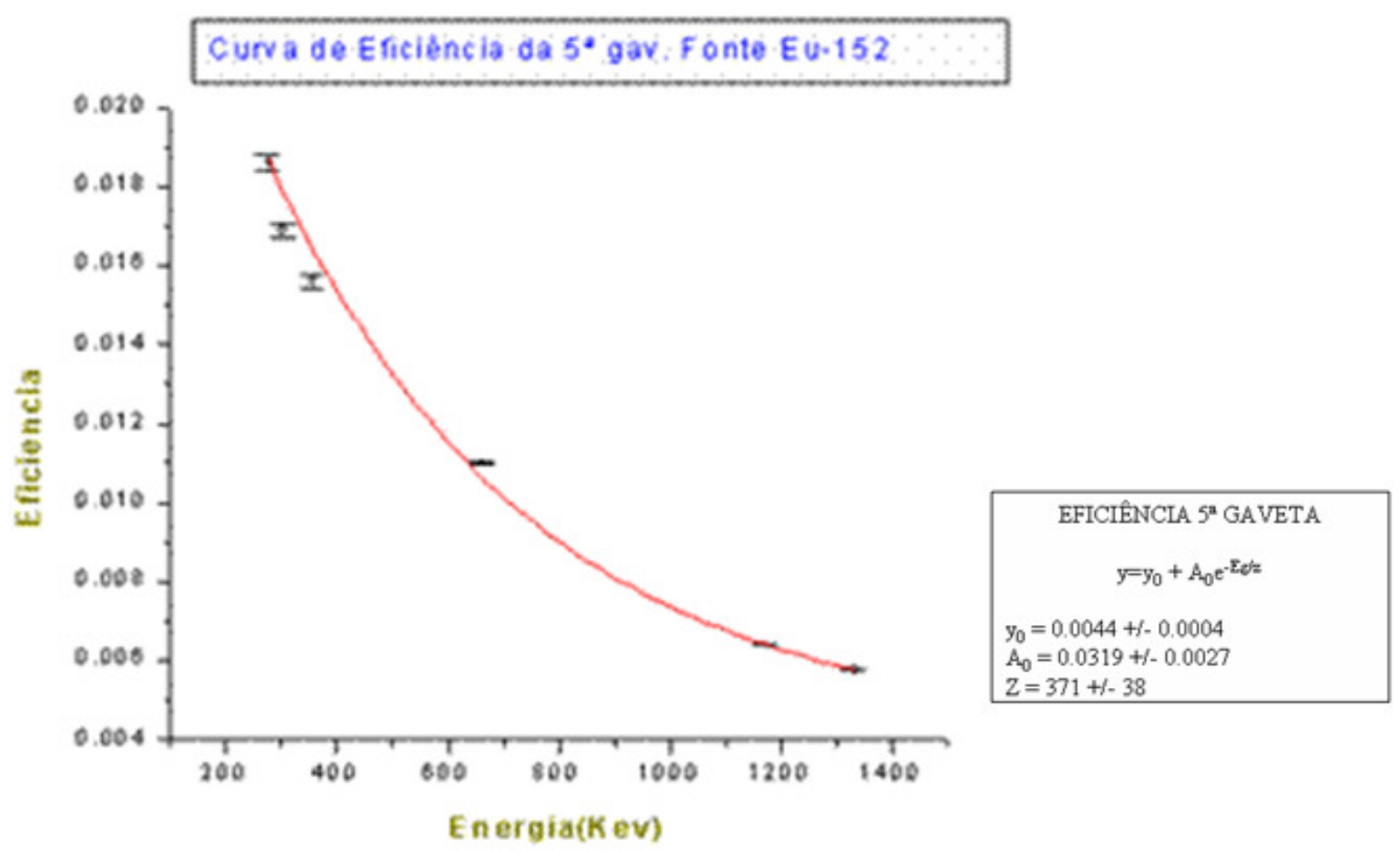

(b)

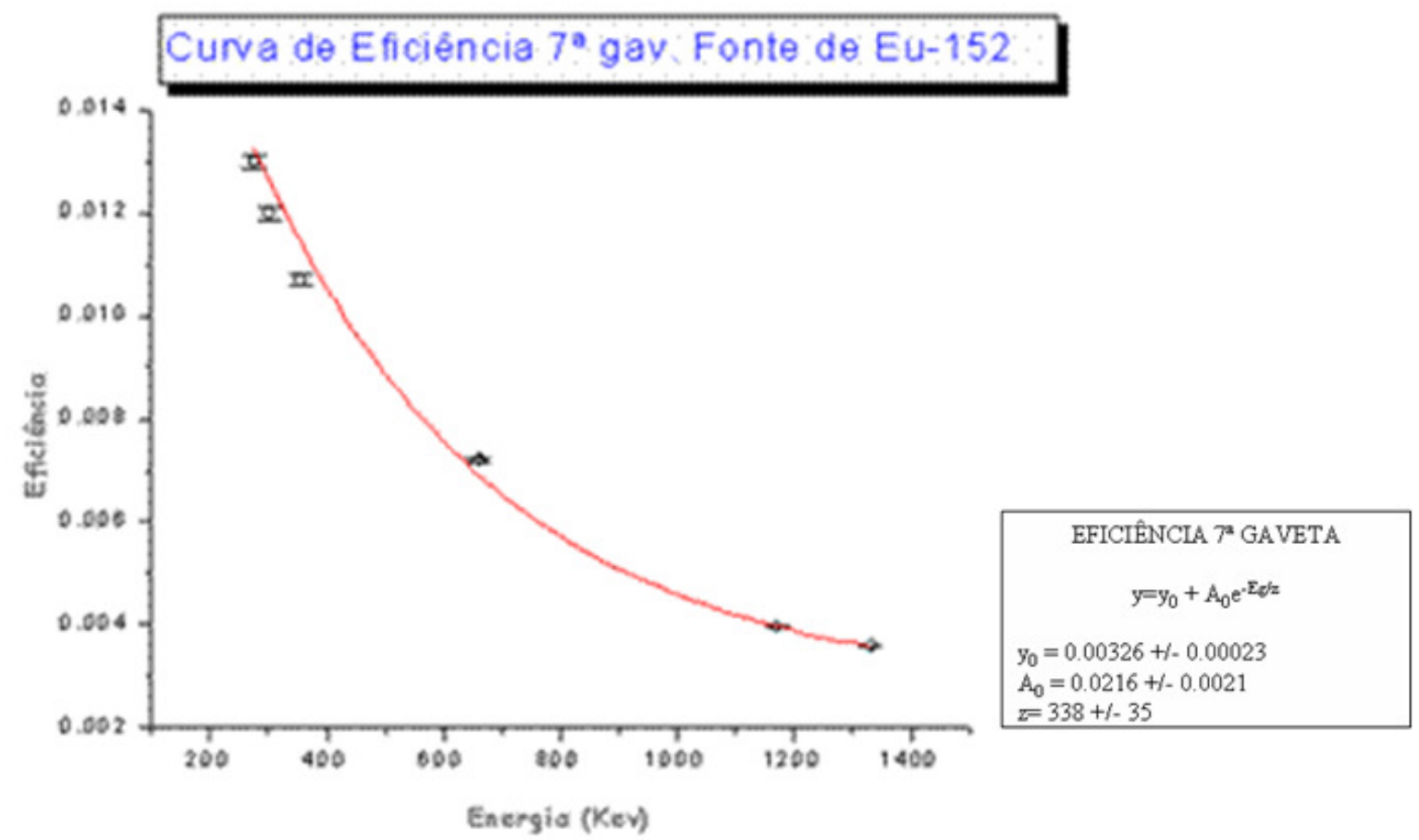

(c)

onde: $y$, eficiência em cada gaveta; $\mathrm{y}_{0}, \mathrm{~A}_{0}$ e $\mathrm{z}$, são parâmetros ajustados pelo programa Origim 5.0; Eg, energia do fotopico medida.

Figura 38 - Curvas de eficiência das gavetas: 3 (a), 5 (b) e 7 (c). 
A análise da contagem líquida (descontada a radiação de fundo) de cada folha foi obtida, através do software Maestro. Como exemplo tem-se abaixo (figura 39), a tela do programa com a informação da contagem líquida.

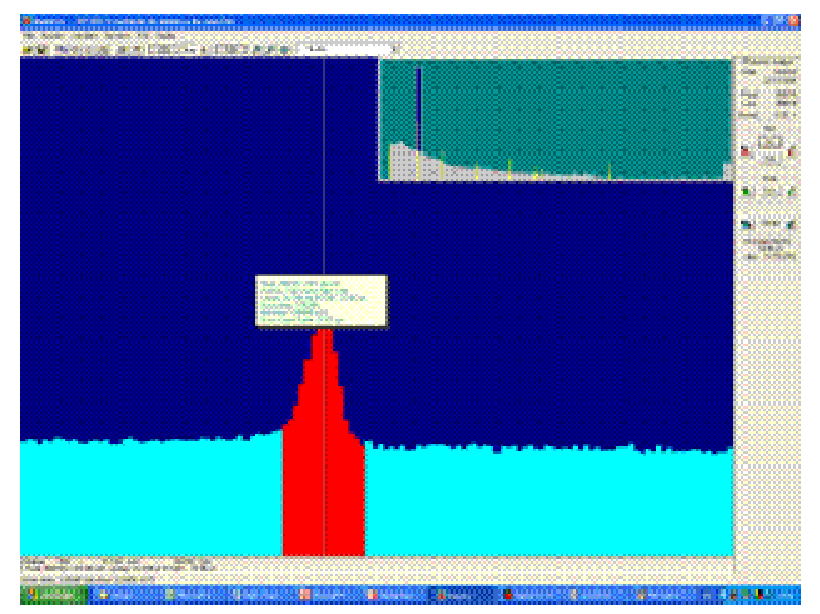

Peak: $888.69=411.86 \mathrm{KeV}$

FWHM: 1.56 FW(1/5)M: 2.44

Library: Au-198 at $411.80 ; 37.86$ cA

Gross Area: 135285

Net Area: $129890 \pm 371$

Gross Count Rate: 37.67 cps

Figura 39 - Tela do software Maestro para a folha de ouro nua irradiada no dia 20/12/05.

Com as contagens liquidas mensurada e utilizando-se as equações 3.8.12, 3.8.13 e 3.8.14 obteve-se as atividades de saturação por núcleo alvo dos detectores; os referidos valores encontram-se nas Tabela 7, 8 e 9 , a seguir.

Tabela 7 - Atividades de Saturação por Núcleo Alvo dos Detectores Irradiados em 19/12/05 em 20/12/05 (ouro).

\begin{tabular}{|c|c|c|c|}
\hline FOLHAS & Reação & $\begin{array}{c}\mathbf{A}_{\infty} / \mathbf{N}_{\text {alv. }} \\
(\mathbf{B q})\end{array}$ & $* \sigma \mathrm{A} / \mathrm{N}_{\mathrm{alv}}(\mathrm{Bq})$ \\
\hline In & ${ }^{115} \operatorname{In}\left(n, n^{\prime}\right)^{115 m} \operatorname{In}$ & $4.1 \mathrm{E}-18$ & 4.E-19 \\
\hline Fé & ${ }^{56} \mathrm{Fe}(\mathrm{n}, \mathrm{p}){ }^{56} \mathrm{Mn}$ & $1.20 \mathrm{E}-19$ & $1.3 \mathrm{E}-20$ \\
\hline $\mathrm{Mg}$ & ${ }^{24} \mathrm{Mg}(\mathrm{n}, \mathrm{p}){ }^{24} \mathrm{Na}$ & $1.62 \mathrm{E}-19$ & $1.6 \mathrm{E}-20$ \\
\hline $\mathrm{Ni}$ & ${ }^{58} \mathrm{Ni}(\mathrm{n}, \mathrm{p}){ }^{58} \mathrm{Co}$ & $4.7 \mathrm{E}-18$ & 6.E-19 \\
\hline $\mathrm{Ni}$ & ${ }^{58} \mathrm{Ni}(\mathrm{n}, 2 \mathrm{n}){ }^{57} \mathrm{Ni}$ & $2.2 \mathrm{E}-21$ & 4.E-22 \\
\hline $\mathrm{Al}$ & ${ }^{27} \mathrm{Al}(\mathrm{n}, \mathrm{a}){ }^{24} \mathrm{Na}$ & $9.1 \mathrm{E}-20$ & 9.E-21 \\
\hline $\mathrm{Au}(\mathrm{cd})$ & ${ }^{197} \mathrm{Au}(\mathrm{n}, \mathrm{g}){ }^{198} \mathrm{Au}$ & $2.5 \mathrm{E}-15$ & 3.E-16 \\
\hline $\mathrm{Au}$ (nua) & ${ }^{197} \mathrm{Au}(\mathrm{n}, \mathrm{g}){ }^{198} \mathrm{Au}$ & $1.58 \mathrm{E}-14$ & $1.7 \mathrm{E}-15$ \\
\hline
\end{tabular}

Tabela 8 - Atividades de Saturação por Núcleo Alvo das Folhas de Ouro Irradiadas em 07/03/06.

\begin{tabular}{|c|c|c|c|}
\hline FOLHAS & Reação & $\begin{array}{c}\mathbf{A}_{\curvearrowright} / \mathbf{N}_{\text {alv. }} \\
(\mathbf{B q})\end{array}$ & $\sigma \mathrm{A} / \mathbf{N}_{\mathrm{alv}}(\mathbf{B q})$ \\
\hline $\mathrm{Au}(\mathrm{cd})$ & ${ }^{197} \mathrm{Au}(\mathrm{n}, \mathrm{g}){ }_{108}^{198} \mathrm{Au}$ & $2.28 \mathrm{E}-15$ & $2.6 \mathrm{E}-16$ \\
\hline $\mathrm{Au}$ (nua) & ${ }^{197} \mathrm{Au}(\mathrm{n}, \mathrm{g}){ }^{198} \mathrm{Au}$ & $1.67 \mathrm{E}-14$ & $1.9 \mathrm{E}-15$ \\
\hline
\end{tabular}


Tabela 9 - Atividades de Saturação por Núcleo Alvo dos Detectores Irradiados em 20/03/06.

\begin{tabular}{cccc}
\hline \hline \multirow{2}{*}{ FOLHAS } & Reação & $\begin{array}{c}\mathbf{A}_{\infty} / \mathbf{N}_{\text {alv. }} \\
(\mathbf{B q})\end{array}$ & $\boldsymbol{\sigma} \mathbf{A} / \mathbf{N}_{\text {alv }}(\mathbf{B q})$ \\
\hline \hline $\mathrm{Al}$ & ${ }^{27} \mathrm{Al}(\mathrm{n}, \mathrm{a})^{24} \mathrm{Na}$ & $7.6 \mathrm{E}-20$ & $8 . \mathrm{E}-21$ \\
$\mathrm{Ni}$ & ${ }^{58} \mathrm{Ni}(\mathrm{n}, \mathrm{p})^{58} \mathrm{Co}$ & $4.1 \mathrm{E}-18$ & $5 . \mathrm{E}-19$ \\
$\mathrm{Ni}$ & ${ }^{58} \mathrm{Ni}(\mathrm{n}, 2 \mathrm{n})^{57} \mathrm{Ni}$ & $1.5 \mathrm{E}-21$ & $3 . \mathrm{E}-22$ \\
\hline \hline
\end{tabular}

A incerteza da atividade de saturação por núcleo alvo de cada detector foi obtida pela combinação das incertezas equação 20: Atividade ao final da irradiação e eficiência absoluta de detecção, visto que as outras incertezas (massa da folha, tempo de irradiação, tempo de espera, tempo de contagem) são desprezíveis em relação às incertezas da contagem líquida e da eficiência absoluta.

$$
\sigma_{A \infty / N a l v}^{2}=A^{2} \sigma_{A}^{2}+E .^{2} \sigma_{E}^{2}
$$

Para o fluxo rápido é necessária a secção de choque ponderada, conforme discutido anteriormente. As secções de choque ponderadas para a posição de irradiação de amostra foram obtidas pelo grupo de BNCT, utilizando-se simulações de transporte de radiação com o código DOT 3.5. Os valores das secções de choque para os detectores encontram-se na TABELA 10.

Tabela 10 - Secções de Choque Ponderadas para a Posição de Irradiação de amostra

\begin{tabular}{cccc}
\hline \hline \multirow{2}{*}{ Folhas } & Reação & $* \mathbf{E}_{\text {eff }}(\mathbf{M e V})$ & $\boldsymbol{\sigma}_{\text {ponderada }}(\mathbf{b})$ \\
\hline $\mathrm{Ni}$ & ${ }^{58} \mathrm{Ni}(\mathrm{n}, \mathrm{p})^{58} \mathrm{Co}$ & 2,8 & $3,61 \mathrm{E}-02$ \\
$\mathrm{Fe}$ & ${ }^{56} \mathrm{Fe}(\mathrm{n}, \mathrm{p})^{56} \mathrm{Mn}$ & 6,0 & $1,46 \mathrm{E}-02$ \\
$\mathrm{Al}$ & ${ }^{27} \mathrm{Al}(\mathrm{n}, \mathrm{a})^{24} \mathrm{Na}$ & 7,2 & $1,15 \mathrm{E}-02$ \\
$\mathrm{Ni}$ & ${ }^{58} \mathrm{Ni}(\mathrm{n}, 2 \mathrm{n})^{57} \mathrm{Ni}$ & 13,5 & $2,24 \mathrm{E}-02$ \\
\hline \hline
\end{tabular}

Os fluxos térmico e epitérmico são obtidos da atividade de saturação por núcleo alvo das folhas de ouro, com e sem cobertura de cádmio conforme as equações 3.9.6 e 3.9.7. No caso do fluxo rápido é utilizada a atividade de saturação por núcleo alvo do detector de energia limiar efetiva e sua respectiva secção de choque ponderada segundo a equação 3.10.2 As atividades de saturação por núcleo alvo são utilizadas como dado de entrada para o programa SAND-BP, para obtenção do espectro de nêutrons. 


\section{RESULTADOS E DISCUSSÕES - TLD}

\subsection{Correção de Resposta TLDs-400}

Para corrigir as respostas foi utilizada uma planilha de calculo de dose construída pelo LDT/IPEN. Variando a distância da fonte ao TLD foi calculada a dose a qual as pastilhas localizadas na primeira linha do suporte foram submetidas. A planilha fornece o valor de dose para os aros de 15 e $20 \mathrm{~cm}$. Porém, a fonte esta posicionada acima do suporte, com isso a

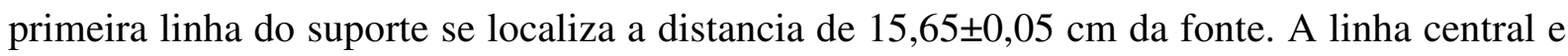
a ultima linha do suporte se encontram respectivamente a $15,95 \pm 0,05 \mathrm{~cm}$ e $16,25 \pm 0,05 \mathrm{~cm}$.

Portanto, é necessário corrigir a dose para as diversas linhas do suporte, pois o tempo de irradiação para que a dose seja de 5,00 mGy é sempre calculado para o aro de $15 \mathrm{~cm}$. Sendo assim, foram realizadas correções de dose para as diversas linhas do suporte levando em consideração a distância de irradiação. Para as pastilhas localizadas na primeira linha do

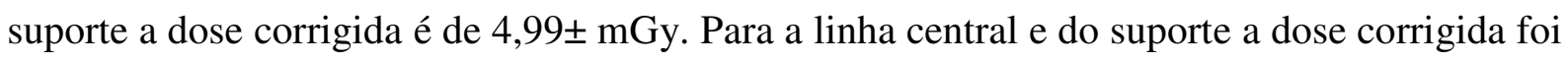

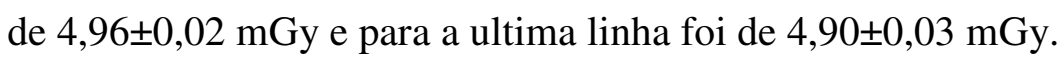

Como os TLDs tem resposta linear para estas doses foi feita uma interpolação para conhecer quais seriam suas respostas para a dose de 5,00 mGy.

\subsection{Tabela de Estudo da Janela Aberta e Fechada}

Antes de realizar as medidas é feito o teste de janela aberta e fechada, para verificar a se houve mudança na eficiência da leitora. Foram feitas dez medidas de janela aberta e fechada, e calculado o valor médio e desvio padrão para as mesmas. Para o processo de leitura são realizadas apenas duas medidas, uma antes de começar a bateria de medidas e outra no final. Na Tabela11 e Tabela12 pode ser visto os resultados. 
Tabela 11 - Teste de janela aberta.

\begin{tabular}{cccc}
\hline \hline Medidas & J.A. $(\mathbf{n C})$ & Média $(\boldsymbol{\eta} \mathbf{C})$ & Desv. pad. $(\boldsymbol{\eta} \mathbf{C})$ \\
\hline \hline 1 & 251,23 & & \\
2 & 254,74 & & \\
3 & 256,30 & & \\
4 & 257,21 & & \\
5 & 255,50 & 252 \\
6 & 256,30 & & \\
7 & 259,65 & & \\
8 & 257,84 & & \\
9 & 258,61 & \\
10 & 256,30 & \\
\hline \hline
\end{tabular}

$\mathrm{Na}$ Tabela 12 pode ser visto os resultados da janela fechada.

Tabela 12 - Tabela de Estudo da Janela Fechada.

\begin{tabular}{cccc}
\hline \hline Medidas & J.F. $(\mathbf{n C})$ & Média $(\boldsymbol{\eta} \mathbf{C})$ & Desv. Pad. $(\boldsymbol{\eta} \mathbf{C})$ \\
\hline \hline 1 & 7,56 & & \\
2 & 7,84 & & \\
3 & 8,00 & & \\
4 & 8,52 & & 0,34 \\
5 & 8,23 & \multirow{2}{*}{8,06} & \\
6 & 8,12 & & \\
7 & 7,87 & & \\
8 & 7,92 & & \\
9 & 7,83 & & \\
10 & 8,67 & & \\
\hline \hline
\end{tabular}

\subsection{Resultado do Selecionamento dos TLDs-400}

O processo de selecionamento se repetiu três vezes. As respostas não estão corrigidas, pois foi evidenciado através da planilha de correção que é muito pequena a diferença entre as repostas das pastilhas sem correção e as pastilhas com correção, e as incertezas das respostas dos TLDs cobrem essa diferenças.

O resultado do selecionamento obtido por meio da planilha de selecionamento se encontra no anexo 1. O resultado do selecionamento se baseia em duas condições:

a) os desvios percentuais não devem exceder 5\%; 
b) as respostas não devem se distanciar da média global $51,09 \pm 2,92 \eta \mathrm{C}$ por mais do que metade do desvio padrão, ou seja, $\pm 1,46 \eta$ C.

No gráfico do TLD-400 e no anexo 1, a segunda condição foi dividida em duas; condição 2 e condição 3 . A de numero dois reprova as pastilhas que tem respostas menores do

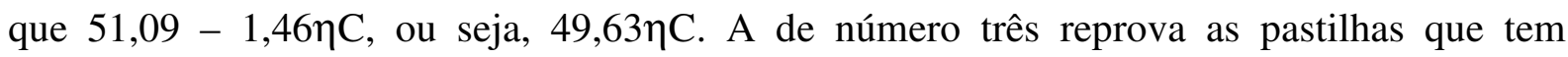
respostas maiores do que $51,09+1,46 \eta \mathrm{C}$, ou seja, $52,55 \eta \mathrm{C}$.

O número de pastilhas, que satisfizeram as três condições, foi de 25 pastilhas para completar 30 pastilhas e facilitar seu transporte dentro dos suportes foram escolhidas mais 5 pastilhas que ficaram mais próximo da média apesar de não satisfazerem as três condições.

\subsection{Resultado do Selecionamento dos TLDs-700}

O processo de selecionamento destes TLDs levou em consideração as mesmas condições utilizadas para os TLDs-400.

A resposta média para as noventa pastilhas foi de $9,977 \pm 0,749 \eta \mathrm{C}$ e o número de pastilhas selecionadas foi de 35 pastilhas. O resultado do selecionamento destes dosímetros se encontra no anexo 1.

\subsection{Calibração dos TLDs-400}

Após o selecionamento foi feita a calibração utilizando três pastilhas por ponto, ou seja, cada ponto dos gráficos (figuras 40, 41 e 42) representa a média da resposta de três dosímetros à dose a qual os mesmos foram submetidos.

A figura 40 mostra a curva de calibração dos TLDs-400 para o intervalo de dose de 0,5Gy até $90 \mathrm{~Gy}$, sabe-se ${ }^{[23]}$ que os mesmos são lineares até 100,0Gy, porém, o ajuste linear só foi possível até 90,0Gy. Foi obtido um ajuste linear utilizando o programa ORIGIN, os parâmetros do ajuste bem como as respectivas incertezas. 
Para ler as pastilhas submetidas a dose superiores a 90Gy foi utilizada uma placa perfurada para barrar parte da luz emitida pelo TLD, isso foi feito para que a leitora não saturasse. Sendo assim, a quantidade de luz emitida pelo TLD é proporcional a uma constante chamada de fator de máscara. Para medir esta constante foram irradiadas novamente as mesmas pastilhas utilizadas para as doses de 5,0;10,0 e 80,0Gy. Portanto o fator de máscara foi calculado fazendo a divisão da resposta sem máscara pela resposta com máscara, os resultados das medidas se encontram na tabela 13.

Tabela 13 - Cálculo do fator de máscara.

\begin{tabular}{c|c|c|c|c|c|c}
\hline \hline Dose $(\mathrm{Gy})$ & $\begin{array}{c}\text { Resposta } \\
(\boldsymbol{\mu C}) \mathbf{c} /\end{array}$ & Resposta $(\mu \mathrm{C}) \mathbf{s} /$ & Fator & Fator médio & $\boldsymbol{\sigma}_{\text {fator médio }}$ & $\boldsymbol{\sigma} \%$ \\
\hline \hline 5,00 & 0,16 & 34,81 & 217 & \multirow{2}{*}{235} & \multirow{2}{*}{16} & \multirow{2}{*}{7} \\
\hline 10,00 & 0,31 & 73,55 & 237 & & & \\
\hline 80,00 & 3,42 & 855,00 & 250 & & & \\
\hline \hline
\end{tabular}

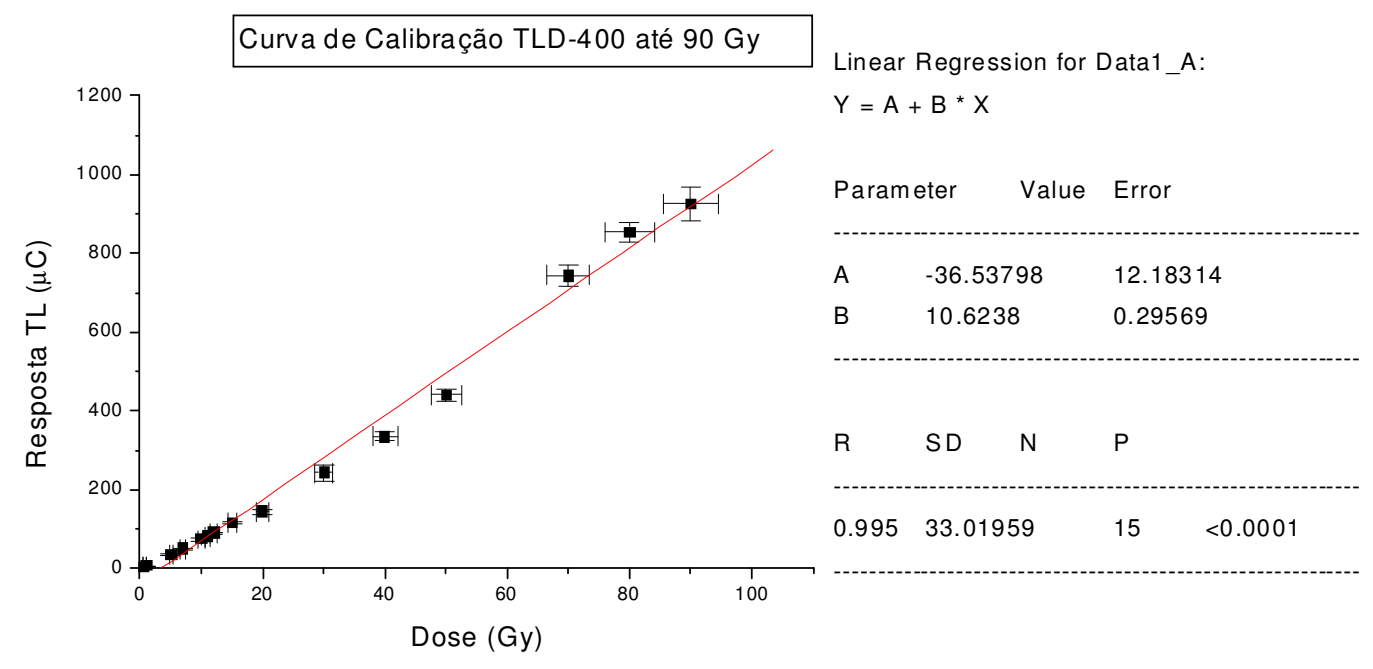

Figura 40 - Curva de calibração para os TLDs-400 para o intervalo de dose de 0,5 até 90Gy.

A figura 41 mostra a curva de calibração dos TLDs-400 de 100 Gy até 500 Gy. Como é possível notar o ajuste feito neste intervalo de calibração é um ajuste polinomial (polinômio de segunda ordem), fica evidenciado o comportamento supralinear destes dosímetros neste intervalo de dose. Sabe-se que estas pastilhas apresentam este tipo de comportamento acima de $100 \mathrm{~Gy}{ }^{[23]}$.

Não foi encontrado na literatura um ajuste melhor para esta região da curva de calibração destes dosímetros, por isso foram feitos vários testes no programa ORIGIN para 
comprovar qual o melhor ajuste. Levando em consideração os parâmetros de $\mathrm{R}^{2}$ e as respectivas incertezas nos coeficientes da equação, este foi o melhor ajuste.

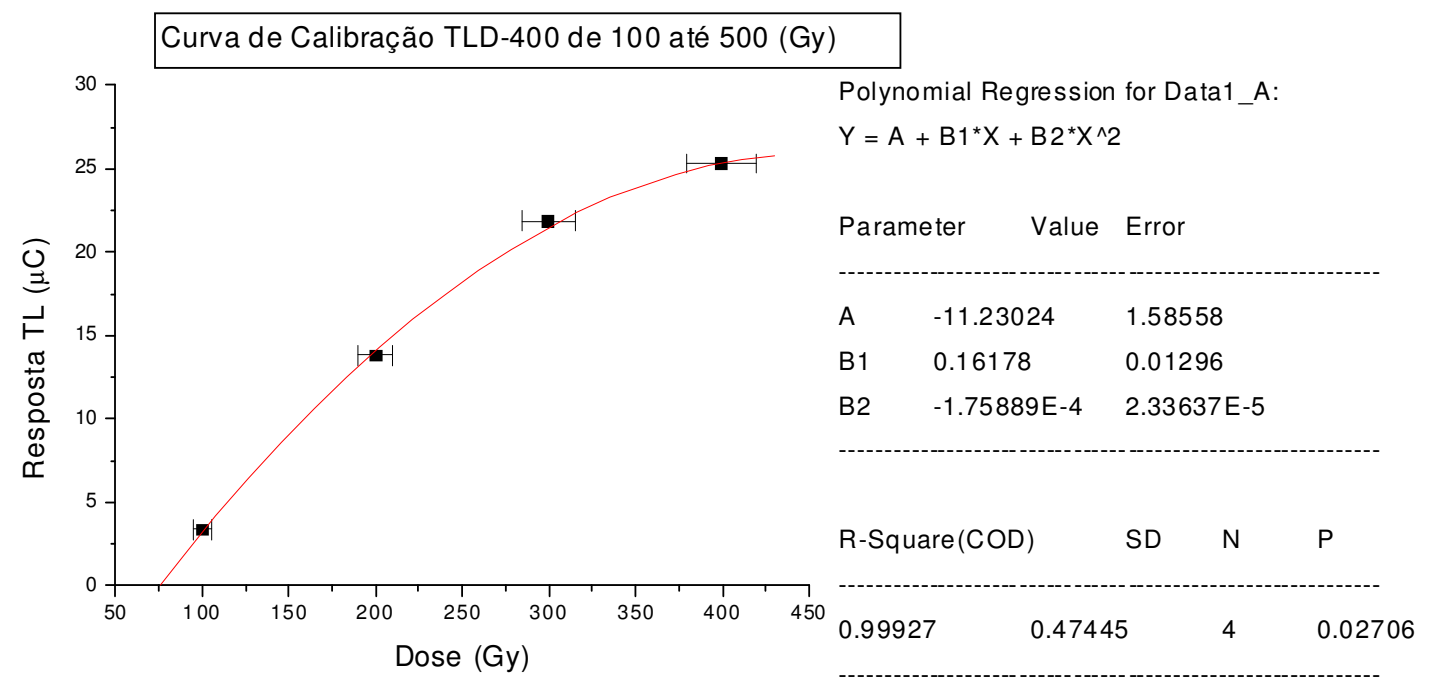

Figura 41 - Curva de calibração para os TLDs-400 para o intervalo de dose de 100 até $500 \mathrm{~Gy}$.

A figura 42 mostra a curva de calibração dos TLDs-400 desde 0,5 até 1000Gy. Neste gráfico ficam evidentes os três tipos de comportamento que esta pastilha apresenta segundo a literatura, ou seja, comportamento linear, supralinear e saturação; esta última fica evidente a partir de 500Gy.

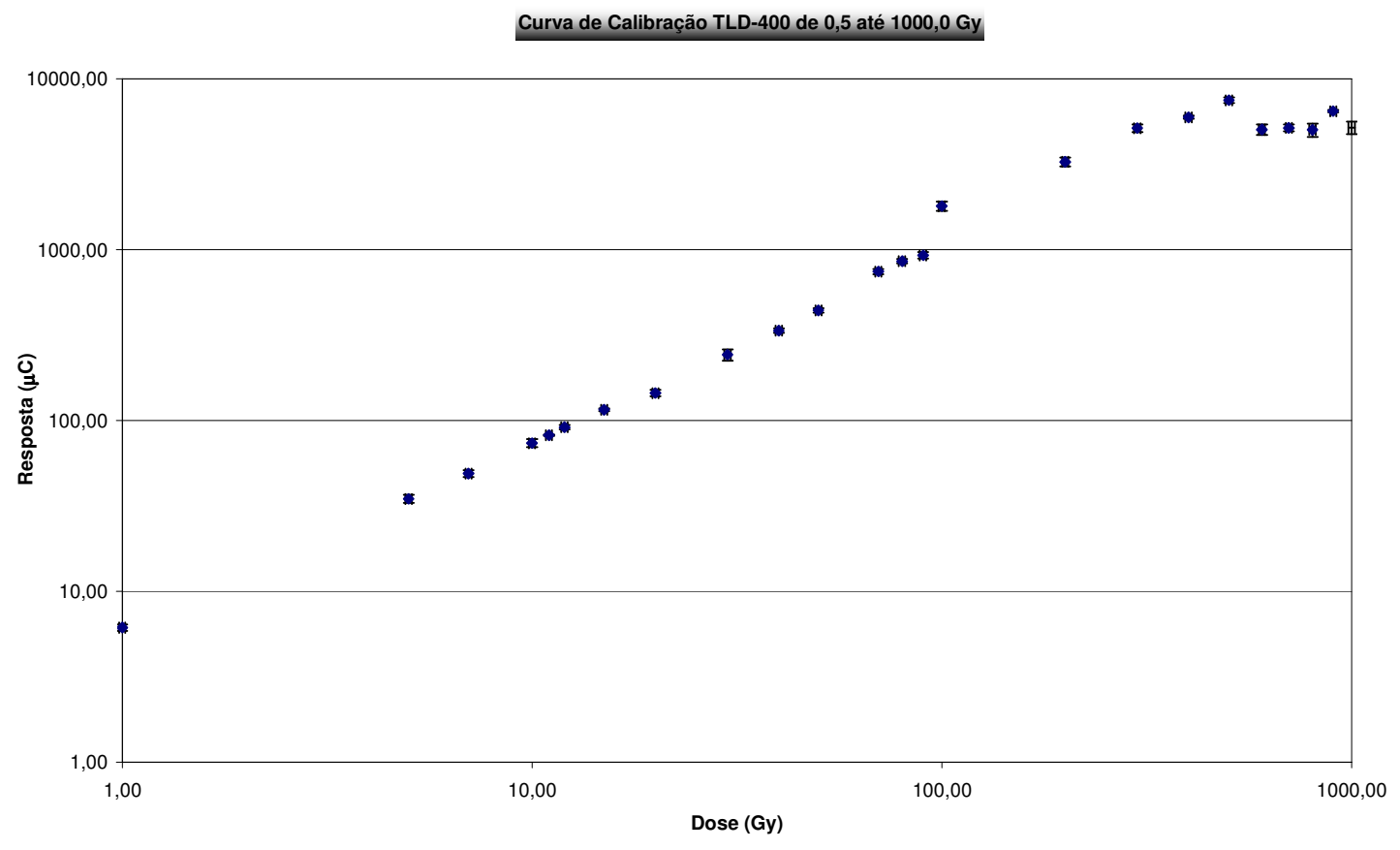

Figura 42 - Pontos experimentais obtidos para os TLDs-400 para o intervalo de dose de 0,5 até $1000 \mathrm{~Gy}$. 


\subsection{Calibração dos TLDs-700}

Para a calibração destes dosímetros foi utilizado o mesmo fator de máscara. Parece que o fator não é adequado para doses acima de $400 \mathrm{~Gy}$, isso porque estes apresentam menor sensibilidade do que os TLDs-400.

Estes dosímetros apresentam também três regiões na sua curva de calibração, assim como os TLDs- $400^{[24]}$. A primeira região corresponde ao comportamento linear, a segunda ao comportamento supralinear e a terceira a saturação. Essas três regiões são evidenciadas nas figuras 43,44 e 45 .

O TLD-700, segundo o fabricante apresenta linearidade até $10 \mathrm{~Gy}$, porém conseguimos realizar uma extrapolação linear até 20 Gy, conforme figura 43.

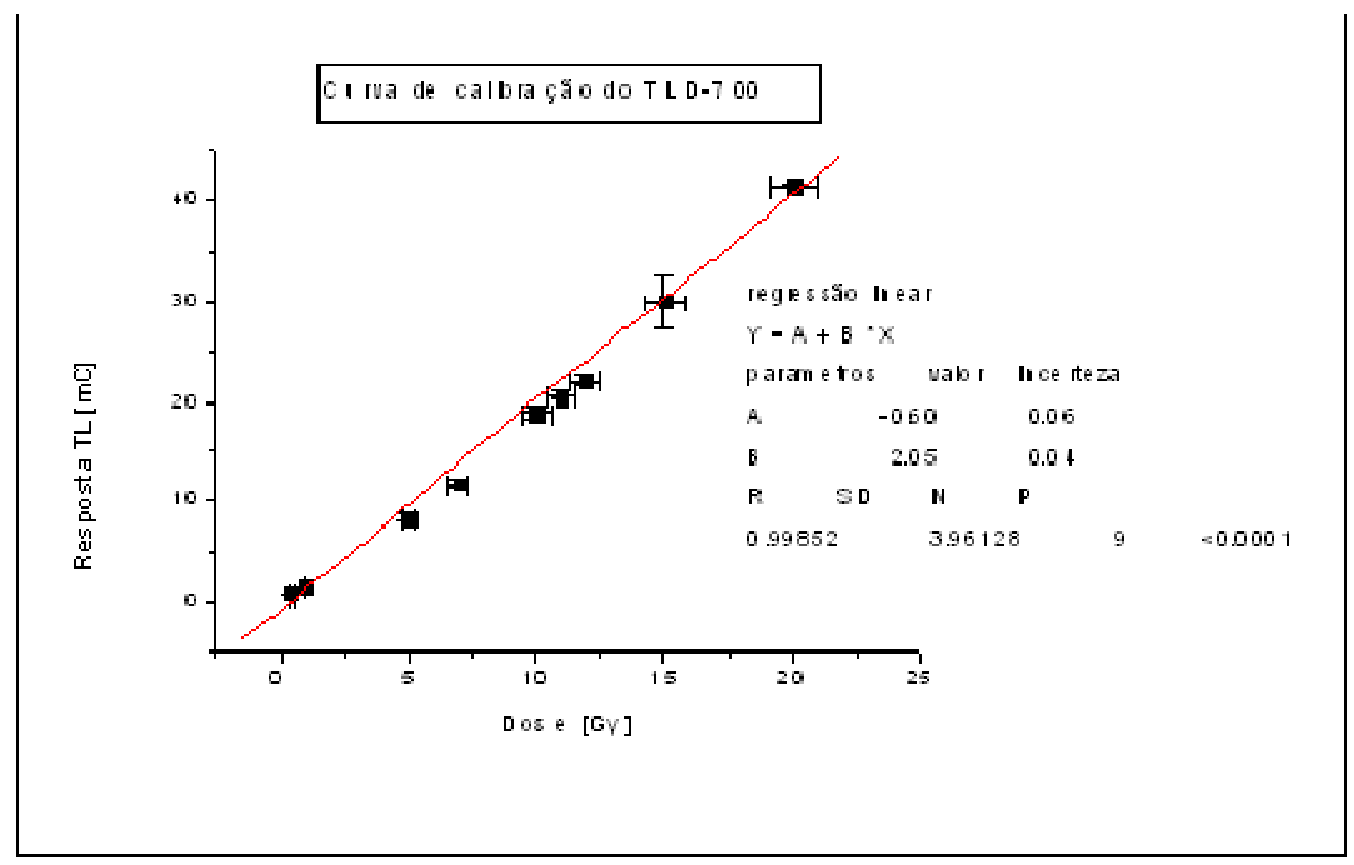

Figura 43 - Curva de calibração para os TLDs-700 para o intervalo de dose de 0,5 até 20 Gy.

A região da curva de calibração, que apresenta comportamento supralinear, é apresentada na figura 44 . 


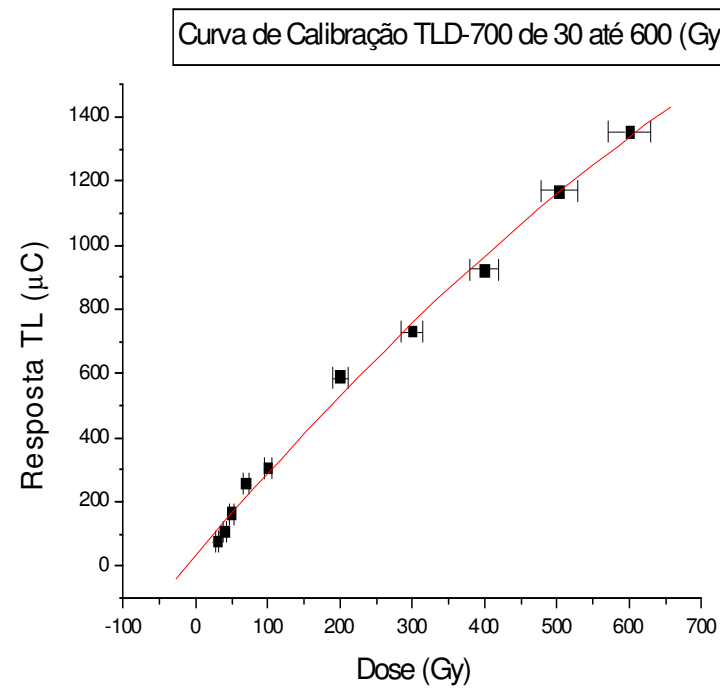

Polynomial Regression for Data1_A:

$\mathrm{Y}=\mathrm{A}+\mathrm{B} 1^{*} \mathrm{X}+\mathrm{B} 2^{*} \mathrm{X}^{\wedge} 2$

Parameter Value Error

A $\quad 30.39344 \quad 25.46182$

$\begin{array}{lll}\text { B1 } & 2.65958 & 0.2544\end{array}$

B2 -8.02233E-4 4.2267E-4

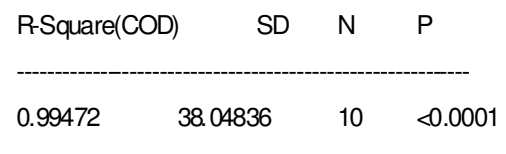

Figura 44 - Curva de calibração para os TLDs-700 para o intervalo de dose de 30 até 600Gy.

Os pontos experimentais obtidos para os TLDs-700 para o intervalo de dose de 0,5 até 1000,0Gy são apresentados na figura 45 .

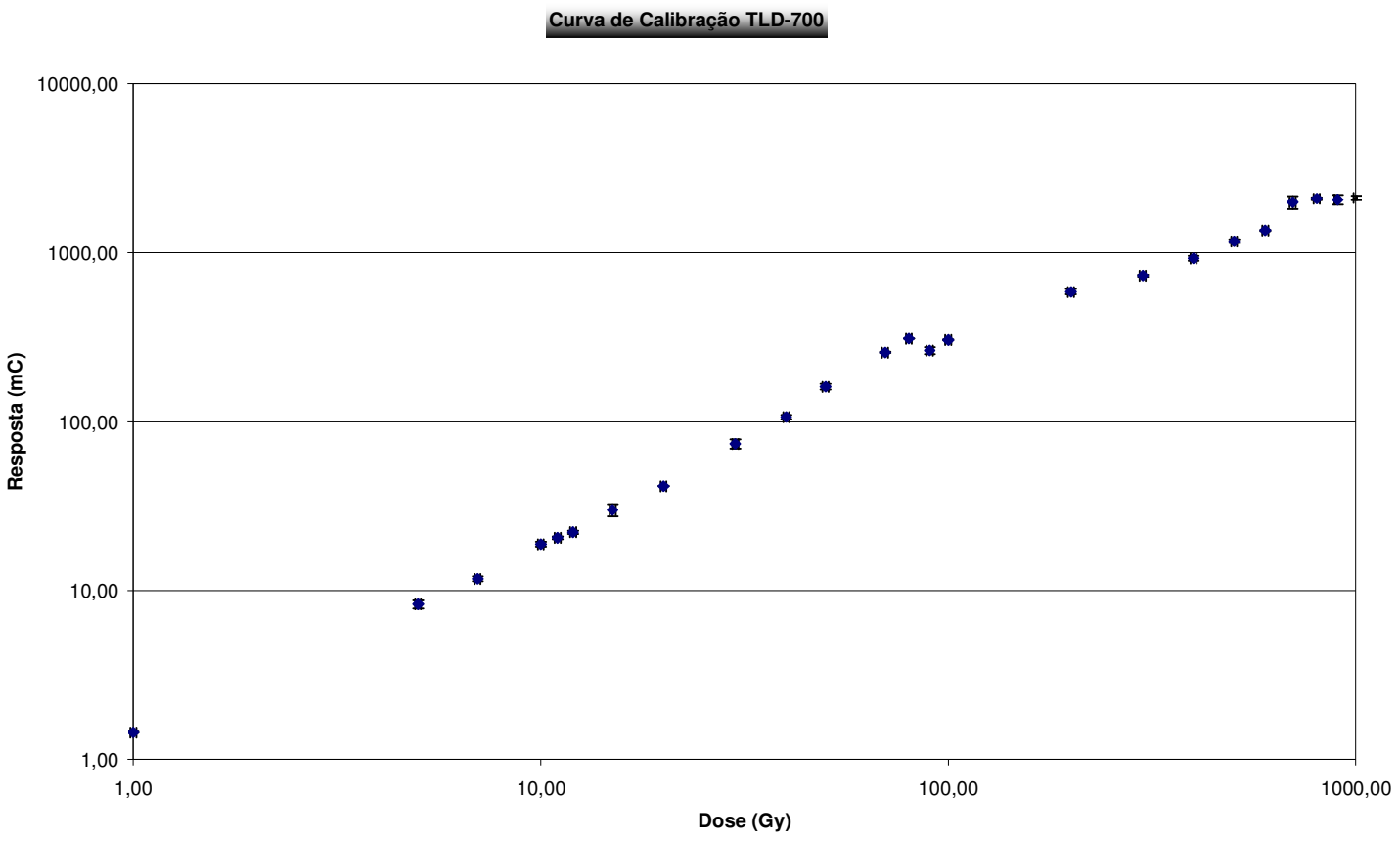

Figura 45 - Pontos experimentais obtidos para os TLDs-700 para o intervalo de dose de 0,5 até $1000 \mathrm{~Gy}$. 


\subsection{Calibração dos TLDs-600}

A curva de calibração deste dosímetros abrange um curto intervalo de dose de 0,005Gy até 0,100Gy, pois, até agora, não foi encontrada uma fonte de nêutrons calibrada com intensidade suficiente intensa para estender este intervalo de calibração. A figura 46 apresenta a curva de calibração do TLD-600 apenas para uma pequena faixa da região linear destes TLDs. Esta calibração pode ser extrapolada até 10Gy, pois segundo o fabricante o TLD-600 apresenta linearidade até 10Gy.

Apesar destes dosímetros não serem selecionados é possível ver que este fato não tem grande influência na construção da curva de calibração destes dosímetros.

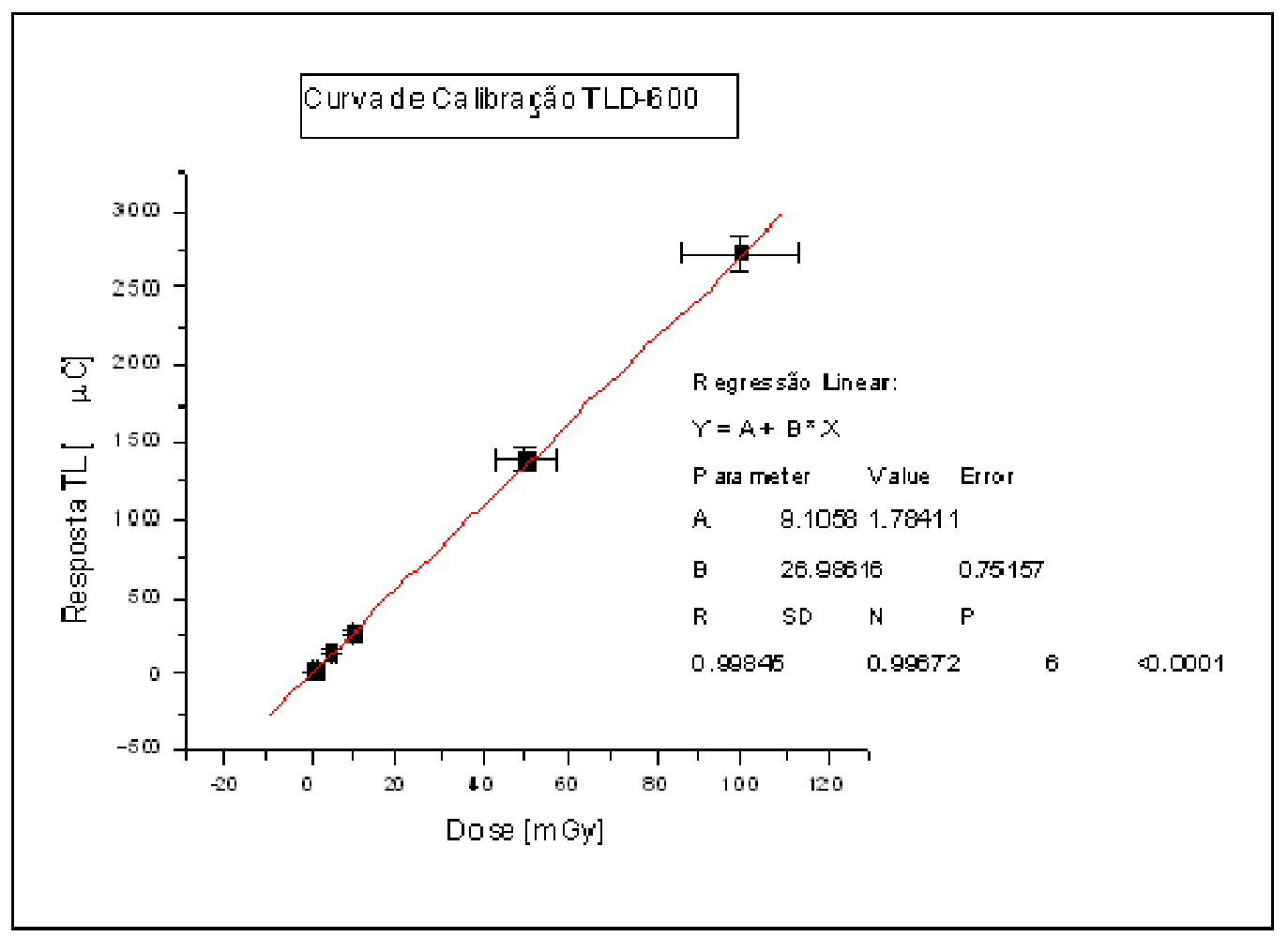

Figura 46 - Curva de calibração para os TLDs-600 para o intervalo de dose de 0,5 até 100m Gy.

\subsection{Medidas na Instalação para Pesquisas em BNCT}

Os dados referentes às medidas dos TLDs-600 e 700 na posição de irradiação de amostras, com o conjunto completo de filtros e moderadores posicionados na instalação, são 
apresentas nas tabelas 14, 15 e 16. As medidas foram tomadas na cestinha na posição de amostra com um desvio padrão de tempos de irradiação de 45 segundos.

Tabela 14 - Dados da irradiação.

\begin{tabular}{c|c}
\hline \hline \multicolumn{2}{c}{ Dados da irradiação } \\
\hline \hline Data de irradiação & $17 / 10 / 06$ \\
\hline Tempo de irradiação & $00: 10: 00$ \\
\hline Potência do reator & $3,5 \mathrm{MW}$ \\
\hline$\sigma_{\text {tempo de irradiação }}$ & 45 segundos \\
\hline \hline
\end{tabular}

Tabela 15 - Condições iniciais e finais de Leitura.

\begin{tabular}{c|c|c}
\hline \hline Condições de leitura & Iniciais & Finais \\
\hline \hline Temperatura $\left({ }^{\circ} \mathrm{C}\right)$ & 21,8 & 21,8 \\
\hline Umidade $(\%)$ & 39 & 39 \\
\hline Janela aberta $(\mathrm{nC})$ & 251,5 & 251,0 \\
\hline Janela fechada $(\mathrm{nC})$ & 0,747 & 0,918 \\
\hline Testes & OK & OK \\
\hline \hline
\end{tabular}

Tabela 16 - Dados da leitura, dos TLDs-600 e 700, efetuadas no dia 24/10/06.

\begin{tabular}{|c|c|c|c|c|c|c|c|}
\hline \multicolumn{8}{|c|}{ TLD-700 } \\
\hline Posição & Pastilha & Resp. $(\mu \mathrm{C})$ & Resp. méd. $(\mu \mathrm{C})$ & $\sigma_{\text {resp. }}(\mu C)$ & Dose (Gy) & $\mathrm{d}_{\text {méd }}(\mathrm{Gy})$ & $\sigma_{\text {dose }}(\mathrm{Gy})$ \\
\hline $1 \mathrm{C}$ & 1L1 & 1,92 & \multirow{3}{*}{2,1} & \multirow{3}{*}{0,2} & 1,67 & \multirow{3}{*}{1,8} & \multirow{3}{*}{0,1} \\
\hline $2 \mathrm{C}$ & $2 \mathrm{~L} 1$ & 2,13 & & & 1,77 & & \\
\hline $3 \mathrm{C}$ & $3 \mathrm{~L} 1$ & 2,24 & & & 1,83 & & \\
\hline \multicolumn{8}{|c|}{ TLD-600 } \\
\hline Posição & Pastilha & Resp. $(\mu \mathrm{C})$ & Resp. méd. $(\mu \mathrm{C})$ & $\sigma_{\text {resp. }}(\mu \mathrm{C})$ & Dose (Gy) & $\mathrm{d}_{\text {méd }}(\mathrm{Gy})$ & $\sigma_{\text {dose }}(\mathrm{Gy})$ \\
\hline $1 \mathrm{C}$ & $1 \mathrm{G} 1$ & 147 & \multirow{3}{*}{146,7} & \multirow{3}{*}{0,6} & 5,4 & \multirow{3}{*}{5,37} & \multirow{3}{*}{0,02} \\
\hline $2 \mathrm{C}$ & $2 \mathrm{G} 1$ & 146 & & & 5,3 & & \\
\hline $3 \mathrm{C}$ & $3 \mathrm{G} 1$ & 147 & & & 5,4 & & \\
\hline
\end{tabular}

Foram irradiados 3 Tlds-700 e 3 TLDs-600 na posição da cestinha. Os TLDs-700 apresentam uma resposta média que está dentro do intervalo de calibração. Já os TLDs-600 apresentam uma resposta média que está fora do intervalo de calibração, mas está contida no seu intervalo de linearidade.

Os dados referentes às medidas dos TLDs-400, 600 e 700, utilizando apenas 4cm de espessura chumbo como conjunto de filtro-moderador, são apresentados nas tabelas 17, 18 e 19. As medidas foram tomadas na cestinha na posição de amostra, para a irradiação com filtros retirados e com um desvio padrão de tempos de irradiação de 45 segundos. 
Tabela 17 - Dados da irradiação.

\begin{tabular}{c|c}
\hline \hline \multicolumn{2}{c}{ Dados da irradiação } \\
\hline \hline Data de irradiação & $06 / 12 / 06$ \\
\hline Tempo de irradiação & $00: 10: 00$ \\
\hline Potência do reator & $3,5 \mathrm{MW}$ \\
\hline$\sigma_{\text {tempo de irradiação }}$ & 45 segundos \\
\hline \hline
\end{tabular}

Tabela 18 - Condições iniciais e finais de Leitura.

\begin{tabular}{c|c|c}
\hline \hline Condições de leitura & Iniciais & Finais \\
\hline \hline Temperatura $\left({ }^{\circ} \mathrm{C}\right)$ & 22,8 & 23 \\
\hline Umidade $(\%)$ & 45 & 46 \\
\hline Janela aberta $(\mathrm{nC})$ & 257,4 & 253,3 \\
\hline Janela fechada $(\mathrm{nC})$ & 0,991 & 1,148 \\
\hline Testes & OK & OK \\
\hline \hline
\end{tabular}

Tabela 19 - Dados da leitura, dos TLDs 400, 600 e 700, efetuadas no dia 12/12/06.

\begin{tabular}{|c|c|c|c|c|c|c|c|}
\hline \multicolumn{8}{|c|}{ TLD - 700} \\
\hline Posição & Pastilha & Resp. $(\mu \mathrm{C})$ & Resp. méd. $(\mu \mathrm{C})$ & $\sigma_{\text {resp. }}(\mu C)$ & Dose (Gy) & $\mathrm{d}_{\text {méd }}(\mathrm{Gy})$ & $\sigma_{\text {dose }}(\mathrm{Gy})$ \\
\hline $1 \mathrm{C}$ & $7 \mathrm{G} 1$ & 34,55 & \multirow{3}{*}{32} & \multirow{3}{*}{3} & 17,41 & \multirow{3}{*}{16} & \multirow{3}{*}{1} \\
\hline $2 \mathrm{C}$ & $8 \mathrm{G} 1$ & 31,02 & & & 15,71 & & \\
\hline $3 \mathrm{C}$ & 9G1 & 29,54 & & & 14,99 & & \\
\hline \multicolumn{8}{|c|}{ TLD - 600} \\
\hline Posição & Pastilha & Resp. $(\mu \mathrm{C})$ & Resp. méd. $(\mu \mathrm{C})$ & $\sigma_{\text {resp. }}(\mu \mathrm{C})$ & Dose (Gy) & $\mathrm{d}_{\text {méd }}(\mathrm{Gy})$ & $\sigma_{\text {dose }}(\mathrm{Gy})$ \\
\hline $1 \mathrm{C}$ & 7G1 & 734 & \multirow{3}{*}{709} & \multirow{3}{*}{22} & 26,9 & \multirow{3}{*}{25,9} & \multirow{3}{*}{0,8} \\
\hline $2 \mathrm{C}$ & $8 \mathrm{G} 1$ & 696 & & & 25,5 & & \\
\hline $3 \mathrm{C}$ & 9G1 & 696 & & & 25,5 & & \\
\hline \multicolumn{8}{|c|}{ TLD - 400} \\
\hline Posição & Pastilha & Resp. $(\mu \mathrm{C})$ & Resp. méd. $(\mu \mathrm{C})$ & $\sigma_{\text {resp. }}(\mu \mathrm{C})$ & Dose (Gy) & $\mathrm{d}_{\text {méd }}(\mathrm{Gy})$ & $\sigma_{\text {dose }}(\mathrm{Gy})$ \\
\hline $1 \mathrm{C}$ & $1 \mathrm{G} 12$ & 85,41 & \multirow{3}{*}{82} & \multirow{3}{*}{4} & 8,5 & \multirow{3}{*}{8,2} & \multirow{3}{*}{0,4} \\
\hline $2 \mathrm{C}$ & $2 \mathrm{G} 12$ & 83,73 & & & 8,4 & & \\
\hline $3 \mathrm{C}$ & $3 \mathrm{G} 12$ & 77,96 & & & 7,8 & & \\
\hline
\end{tabular}

Foram irradiados 3 TLDs-700, 3 TLDs-600 e 3 TLDs na posição central da cestinha. A dose medida com os TLDs-700 está dentro do intervalo de calibração dos mesmos. Já para os TLDs-600 o mesmo não ocorreu a dose estimada com esses TLDs está fora do seu intervalo de calibração, que vai até $0,1 \mathrm{~Gy}$, e também fora do seu intevalo de linearidade, que vai até $10 \mathrm{~Gy}$.

Comparando com as medidas realizadas no dia 17/10/06, onde foram irradiados TLDs700 e 600 na mesma posição, com o reator operando a 3,5 MW as doses encontradas nesta medida são maiores. No dia 17/10 foram medidas doses devido a nêutrons e gama de 5,37 e 1,8 Gy respectivamente, e os filtros ainda estavam no $\mathrm{BH}$, isso explica o aumento na doses. 
Contudo, a dose devido aos nêutrons continuou sendo maior do que a dose devido aos raios gama.

Os dados referentes às medidas dos TLDs-400, 600 e 700, após a retirada de $4 \mathrm{~cm}$ de espessura de chumbo do conjunto completo de filtro-moderador, são apresentas nas tabelas 20, 21 e 22. As medidas foram tomadas na cestinha, na posição de amostra e com um desvio padrão de tempos de irradiação de 45 segundos. 
Tabela 20 - Dados da irradiação.

\begin{tabular}{c|c}
\hline \hline \multicolumn{2}{c}{ Dados da irradiação } \\
\hline \hline Data de irradiação & $19 / 12 / 06$ \\
\hline Tempo de irradiação & $00: 10: 00$ \\
\hline Potência do reator & $3,5 \mathrm{MW}$ \\
\hline$\sigma_{\text {tempo de irradiação }}$ & 45 segundos \\
\hline \hline
\end{tabular}

Tabela 21 - Condições iniciais e finais de Leitura.

\begin{tabular}{c|c|c}
\hline \hline Condições de leitura & Iniciais & Finais \\
\hline \hline Temperatura $\left({ }^{\circ} \mathrm{C}\right)$ & 23,6 & 23,3 \\
\hline Umidade $(\%)$ & 44 & 39 \\
\hline Janela aberta $(\mathrm{nC})$ & 255,9 & 251,9 \\
\hline Janela fechada $(\mathrm{nC})$ & 1,287 & 1,114 \\
\hline Testes & OK & OK \\
\hline \hline
\end{tabular}

Tabela 22 - Dados da leitura, dos TLDs-400, 600 e 700, efetuadas no dia 19/12/06.

\begin{tabular}{|c|c|c|c|c|c|c|c|c|c|c|c|}
\hline \multicolumn{12}{|c|}{ TLD - 700} \\
\hline Posição & Pastilha & Resp. $(\mu \mathrm{C})$ & Resp. méd. $(\mu \mathrm{C})$ & $\sigma_{\text {resp. }}(\mu \mathrm{C})$ & Dose (Gy) & $\mathrm{d}_{\text {méd }}(\mathrm{Gy})$ & $\sigma_{\text {dose }}(\mathrm{Gy})$ & Dose média (Gy) & $\sigma_{\text {dose med }}(\mathrm{Gy})$ & Resp. méd. $(\mu \mathrm{C})$ & $\sigma_{\text {resp. }}(\mu \mathrm{C})$ \\
\hline $1 \mathrm{C}$ & L1 & 4,02 & \multirow{3}{*}{3,78} & \multirow{3}{*}{0,02} & 2,69 & \multirow{3}{*}{2,57} & \multirow{3}{*}{0,11} & \multirow{5}{*}{2,27} & \multirow{5}{*}{0,05} & \multirow{5}{*}{3,15} & \multirow{5}{*}{0,14} \\
\hline $2 \mathrm{C}$ & L1 & 3,73 & & & 2,55 & & & & & & \\
\hline $3 \mathrm{C}$ & L1 & 3,59 & & & 2,48 & & & & & & \\
\hline $4 \mathrm{C}$ & L2 & 2,48 & \multirow{2}{*}{2,52} & \multirow{2}{*}{0,06} & 1,94 & \multirow{2}{*}{1,96} & \multirow{2}{*}{0,03} & & & & \\
\hline $5 \mathrm{C}$ & $\mathrm{L} 2$ & 2,57 & & & 1,99 & & & & & & \\
\hline \multicolumn{12}{|c|}{ TLD - 600} \\
\hline Posição & Pastilha & Resp. $(\mu \mathrm{C})$ & Resp. méd. $(\mu \mathrm{C})$ & $\sigma_{\text {resp. }}(\mu \mathrm{C})$ & Dose (Gy) & $\mathrm{d}_{\text {méd }}(\mathrm{Gy})$ & $\sigma_{\text {dose }}(\mathrm{Gy})$ & Dose média (Gy) & $\sigma_{\text {dose med }}(\mathrm{Gy})$ & Resp. méd. $(\mu \mathrm{C})$ & $\sigma_{\text {resp. }}(\mu \mathrm{C})$ \\
\hline $1 \mathrm{C}$ & 4G1 & 340 & \multirow{3}{*}{325,7} & \multirow{3}{*}{12,4} & 12,4 & \multirow{3}{*}{11,9} & \multirow{3}{*}{0,45} & \multirow{5}{*}{8,4} & \multirow{5}{*}{0,3} & \multirow{5}{*}{229} & \multirow{5}{*}{6} \\
\hline $2 \mathrm{C}$ & $5 \mathrm{G} 1$ & 318 & & & 11,6 & & & & & & \\
\hline $3 \mathrm{C}$ & $6 \mathrm{G} 1$ & 319 & & & 11,7 & & & & & & \\
\hline $4 \mathrm{C}$ & $7 \mathrm{G} 1$ & 133 & \multirow{2}{*}{133,0} & \multirow{2}{*}{-} & 4,9 & \multirow{2}{*}{4,9} & \multirow{2}{*}{-} & & & & \\
\hline $5 \mathrm{C}$ & $8 \mathrm{G} 1$ & 133 & & & 4,9 & & & & & & \\
\hline \multicolumn{12}{|c|}{ TLD - 400} \\
\hline Posição & Pastilha & Resp. $(\mu \mathrm{C})$ & Resp. méd. $(\mu \mathrm{C})$ & $\sigma_{\text {resp. }}(\mu \mathrm{C})$ & Dose (Gy) & $\mathrm{d}_{\text {méd }}(\mathrm{Gy})$ & $\sigma_{\text {dose }}(\mathrm{Gy})$ & Dose média (Gy) & $\sigma_{\text {dose med }}(\mathrm{Gy})$ & Resp. méd. $(\mu \mathrm{C})$ & $\sigma_{\text {resp. }}(\mu \mathrm{C})$ \\
\hline $2 \mathrm{C}$ & $5 \mathrm{G} 11$ & 9,24 & \multirow[t]{2}{*}{9,0} & \multirow[t]{2}{*}{1,1} & 0,9 & \multirow[t]{2}{*}{0,90} & \multirow[t]{2}{*}{0,11} & \multirow{4}{*}{0,92} & \multirow{4}{*}{0,02} & & \\
\hline $3 \mathrm{C}$ & $6 \mathrm{G} 11$ & 7,76 & & & 0,8 & & & & & 9,2 & 0,9 \\
\hline $4 \mathrm{C}$ & 7G11 & 8,91 & 9.4 & 0.7 & 0,9 & 0.94 & 0.08 & & & & \\
\hline $5 \mathrm{C}$ & $8 \mathrm{G} 11$ & 9,97 & . & , & 1,0 & דול, &, 00 & & & & \\
\hline
\end{tabular}


Foram irradiados 5 TLDs-700, 5 TLDs-600 e 5 TLDs-400 na posição central da cestinha. Sendo que, os TLDs-400 foram dispostos em um semi-circulo de $11 \mathrm{~mm}$ de raio, os TLDs-600 e os TLDs-700 foram colocados juntos em um semi-circulo de $15 \mathrm{~mm}$ de raio, sendo que, foram colocadas cinco pastilhas de cada tipo em cada metade do mesmo.

A dose medida com os TLDs-700 está dentro do intervalo de calibração dos mesmos. Já para os TLDs-600 o mesmo não ocorreu, dose estimada para esses TLDs está além do seu intervalo de calibração, porém dentro do seu intervalo de linearidade. A irradiação foi feita na presença dos filtros e moderadores, porém sem dois discos de chumbo, o equivalente a $4 \mathrm{~cm}$ de $\mathrm{Pb}$.

Os dados referentes às medidas dos TLDs-400, 600 e 700 , após a retirada de $4 \mathrm{~cm}$ de espessura de chumbo do conjunto completo de filtro-moderador, são apresentas nas tabelas 23, 24 e 25. Foram irradiados 3 TLDs-400, 3 TLDs-600 e 3 TLDs-700 após a blindagem de chumbo e com um desvio padrão de tempo de irradiação de 45 segundos.

Tabela 23 - Dados da irradiação.

\begin{tabular}{c|c}
\hline \hline \multicolumn{2}{c}{ Dados da irradiação } \\
\hline \hline Data de irradiação & $27 / 11 / 06$ \\
\hline Tempo de irradiação & $01: 48: 17$ \\
\hline Potência do reator & $3,5 \mathrm{MW}$ \\
\hline$\sigma_{\text {tempo de irradiação }}$ & 45 segundos \\
\hline \hline
\end{tabular}

Tabela 24 - Condições iniciais e finais de Leitura.

\begin{tabular}{c|c|c}
\hline \hline Condições de leitura & Iniciais & Finais \\
\hline \hline Temperatura $\left({ }^{\circ} \mathrm{C}\right)$ & 23,3 & 21,4 \\
\hline Umidade $(\%)$ & 38 & 37 \\
\hline Janela aberta $(\mathrm{nC})$ & 256,23 & 255,0 \\
\hline Janela fechada $(\mathrm{nC})$ & 0,925 & 0,910 \\
\hline Testes & OK & OK \\
\hline \hline
\end{tabular}


Tabela 25 - Dados da leitura, dos TLDs-400, 600 e 700, efetuadas no dia 04/12/06.

\begin{tabular}{|c|c|c|c|c|c|c|c|}
\hline \multicolumn{8}{|c|}{ TLD - 700} \\
\hline Posição & Pastilha & Resp. $(\mu \mathrm{C})$ & Resp. méd. $(\mu \mathrm{C})$ & $\sigma_{\text {resp. }}(\mu \mathrm{C})$ & Dose (Gy) & $\mathrm{d}_{\text {méd }}(\mathrm{Gy})$ & $\sigma_{\text {dose }}(\mathrm{Gy})$ \\
\hline \multirow{3}{*}{ Após blind. } & 1L2 & 0,2627 & \multirow{3}{*}{0,27} & \multirow{3}{*}{0,02} & 0,87 & \multirow{3}{*}{0,88} & \multirow{3}{*}{0,01} \\
\hline & $2 \mathrm{~L} 2$ & 0,2895 & & & 0,89 & & \\
\hline & $3 \mathrm{~L} 2$ & 0,2450 & & & 0,87 & & \\
\hline \multicolumn{8}{|c|}{ TLD - 600} \\
\hline Posição & Pastilha & Resp. $(\mu \mathrm{C})$ & Resp. méd. $(\mu \mathrm{C})$ & $\sigma_{\text {resp. }}(\mu \mathrm{C})$ & Dose (Gy) & $\mathrm{d}_{\text {méd }}(\mathrm{Gy})$ & $\sigma_{\text {dose }}(\mathrm{Gy})$ \\
\hline \multirow{3}{*}{ Após blind. } & 4G1 & 41,36 & \multirow{3}{*}{39} & \multirow{3}{*}{3} & 1,5 & \multirow{3}{*}{1,4} & \multirow{3}{*}{0,1} \\
\hline & $5 \mathrm{G} 1$ & 36,00 & & & 1,3 & & \\
\hline & $6 \mathrm{G} 1$ & 40,00 & & & 1,5 & & \\
\hline \multicolumn{8}{|c|}{ TLD - 400} \\
\hline Posição & Pastilha & Resp. $(\mu \mathrm{C})$ & Resp. méd. $(\mu \mathrm{C})$ & $\sigma_{\text {resp. }}(\mu \mathrm{C})$ & Dose (Gy) & $\mathrm{d}_{\text {méd }}(\mathrm{Gy})$ & $\sigma_{\text {dose }}(\mathrm{Gy})$ \\
\hline \multirow{3}{*}{ Após blind. } & 4G11 & 0,4604 & \multirow{3}{*}{0,49} & \multirow{3}{*}{0,04} & 0,0461 & \multirow{3}{*}{0,050} & \multirow{3}{*}{0,004} \\
\hline & $5 \mathrm{G} 11$ & 0,4939 & & & 0,0494 & & \\
\hline & 6G11 & 0,5304 & & & 0,0531 & & \\
\hline
\end{tabular}

Foram irradiados 3 TLDs-700, 3 TLDs-600 e 3 TLDs-400 após os discos de chumbo. Os TLDs-700 apresentaram uma resposta média que está dentro do intervalo de calibração. Já os TLDs-600 apresentaram uma resposta média que está fora do intervalo de calibração, mas, está contida no seu intervalo de linearidade. As pastilhas foram fixadas após a blindagem no dia 24/11/06 (sexta-feira) e irradiadas no dia 27/11/06 (segunda-feira).

Os dados referentes às medidas de TLDs-400, 600 e 700, na posição de irradiação de amostra com o conjunto completo de filtro-moderador e com o reator operando com $2 \mathrm{MW}$, são apresentas nas tabelas 26, 27 e 28. As medidas foram tomadas na cestinha na posição central de amostra, foram irradiados 3 TLDs-400, 3 TLDs-600 e 3 TLDs-700 e com um desvio padrão de tempos de irradiação de 45 segundos.

Tabela 26 - Dados da irradiação.

\begin{tabular}{c|c}
\hline \hline \multicolumn{2}{c}{ Dados da irradiação } \\
\hline \hline Data de irradiação & $31 / 10 / 06$ \\
\hline Tempo de irradiação & $00: 10: 00$ \\
\hline Potência do reator & $2,0 \mathrm{MW}$ \\
\hline$\sigma_{\text {tempo de irradiação }}$ & 45 segundos \\
\hline \hline
\end{tabular}


Tabela 27 - Condições iniciais e finais de Leitura.

\begin{tabular}{c|c|c}
\hline \hline Condições de leitura & Iniciais & Finais \\
\hline \hline Temperatura $\left({ }^{\circ} \mathrm{C}\right)$ & 21,2 & 21,4 \\
\hline Umidade $(\%)$ & 37 & 37 \\
\hline Janela aberta $(\mathrm{nC})$ & 254,3 & 255,0 \\
\hline Janela fechada $(\mathrm{nC})$ & 0,736 & 0,910 \\
\hline Testes & OK & OK \\
\hline \hline
\end{tabular}

Tabela 28 - Dados da leitura, dos TLDs-400, 600 e 700, efetuadas no dia 09/12/06.

\begin{tabular}{|c|c|c|c|c|c|c|c|}
\hline \multicolumn{8}{|c|}{ TLD - 700} \\
\hline Posição & Pastilha & Resp. $(\mu \mathrm{C})$ & Resp. méd. $(\mu \mathrm{C})$ & $\sigma_{\text {resp. }}(\mu \mathrm{C})$ & Dose (Gy) & $\mathrm{d}_{\text {méd }}(\mathrm{Gy})$ & $\sigma_{\text {dose }}(\mathrm{Gy})$ \\
\hline $1 \mathrm{C}$ & 1L2 & 0,0683 & \multirow{3}{*}{0,062} & \multirow{3}{*}{0,008} & 0,78 & \multirow{3}{*}{0,78} & \multirow{3}{*}{0,004} \\
\hline $2 \mathrm{C}$ & $2 \mathrm{~L} 2$ & 0,0642 & & & 0,78 & & \\
\hline $3 \mathrm{C}$ & $3 \mathrm{~L} 2$ & 0,0522 & & & 0,77 & & \\
\hline \multicolumn{8}{|c|}{ TLD - 600} \\
\hline Posição & Pastilha & Resp. $(\mu \mathrm{C})$ & Resp. méd. $(\mu \mathrm{C})$ & $\sigma_{\text {resp. }}(\mu \mathrm{C})$ & Dose (Gy) & $\mathrm{d}_{\text {méd }}(\mathrm{Gy})$ & $\sigma_{\text {dose }}(\mathrm{Gy})$ \\
\hline $1 \mathrm{C}$ & $1 \mathrm{G} 1$ & 19,69 & \multirow{3}{*}{18} & \multirow{3}{*}{2} & 0,7 & \multirow{3}{*}{0,64} & \multirow{3}{*}{0,08} \\
\hline $2 \mathrm{C}$ & $2 \mathrm{G} 1$ & 17,67 & & & 0,6 & & \\
\hline $3 \mathrm{C}$ & $3 \mathrm{G} 1$ & 15,13 & & & 0,6 & & \\
\hline \multicolumn{8}{|c|}{ TLD - 400} \\
\hline Posição & Pastilha & Resp. $(\mu \mathrm{C})$ & Resp. méd. $(\mu \mathrm{C})$ & $\sigma_{\text {resp. }}(\mu \mathrm{C})$ & Dose (Gy) & $\mathrm{d}_{\text {méd }}(\mathrm{Gy})$ & $\sigma_{\text {dose }}(\mathrm{Gy})$ \\
\hline $1 \mathrm{C}$ & $1 \mathrm{G} 1$ & 2,38 & \multirow{3}{*}{2,7} & \multirow{3}{*}{0,3} & 0,2 & \multirow{3}{*}{0,27} & \multirow{3}{*}{0,03} \\
\hline $2 \mathrm{C}$ & $2 \mathrm{G} 1$ & 2,82 & & & 0,3 & & \\
\hline $3 \mathrm{C}$ & $3 \mathrm{G} 1$ & 3,03 & & & 0,3 & & \\
\hline
\end{tabular}

Foram irradiados 3 TLDs-700, 3 TLDs-600 e 3 TLDs-400 na posição central a cestinha. Os TLDs-700 apresentaram uma resposta média que está dentro do intervalo de calibração. Já os TLDs-600 apresentaram uma resposta média que está fora do intervalo de calibração, mas está contida no seu intervalo de linearidade. $\mathrm{Na}$ medida anterior, foi encontrada uma dose devido aos nêutrons maior do que a dose devido aos gama, nessa, a dose devido aos gama foi ligeiramente maior do que a dose devido aos nêutrons. A potencia do reator foi o único parâmetro que variou nas duas medidas, foi de 3,5 MW para 2,0 MW. 


\subsection{Resultados e Discussões - Folhas}

\subsubsection{Resultados e Análise}

A tabela 29 contém os valores de fluxo térmico na posição de irradiação de amostra, medidos em dias diferentes. Na tabela 30 são encontrados os valores para o fluxo epitérmico.

Tabela 29 - Fluxo Térmico.

\begin{tabular}{|c|c|c|}
\hline \multicolumn{3}{|c|}{ Fluxo Térmico } \\
\hline Dia & $\phi_{\text {térmico }}\left(\mathrm{n} / \mathrm{cm}^{2} \mathrm{~s}\right)$ & $* \sigma_{\phi \text { térmico }}\left(\mathrm{n} / \mathrm{cm}^{2} \mathrm{~s}\right)$ \\
\hline $20 / 12 / 05$ & $1.39 \mathrm{E}+08$ & $1.2 \mathrm{E}+07$ \\
\hline $07 / 03 / 06$ & $1.39 \mathrm{E}+08$ & $1.7 \mathrm{E}+07$ \\
\hline
\end{tabular}

Tabela 30 - Fluxo Epitérmico.

\begin{tabular}{ccc}
\hline \hline \multicolumn{3}{c}{ Fluxo Epitérmico } \\
\hline \hline Dia & $\begin{array}{l}\phi_{\text {epitérmico }} \\
\left(\mathrm{n} / \mathrm{cm}^{2} \mathrm{~s}\right)\end{array}$ & $\sigma_{\text {申epitérmico }}\left(\mathrm{n} / \mathrm{cm}^{2} \mathrm{~s}\right)$ \\
\hline $20 / 12 / 05$ & $2.8 \mathrm{E}+06$ & $5 \mathrm{E}+05$ \\
$07 / 03 / 06$ & $4.0 \mathrm{E}+06$ & $8 \mathrm{E}+05$ \\
\hline \hline
\end{tabular}

As tabelas 31 e 32 são referentes às irradiações dos dias 19/12/05 e 20/03/06, respectivamente, para determinação do fluxo rápido.

Tabela 31 - Fluxo Rápido 19/12/05.

\begin{tabular}{cccc}
\hline \hline \multicolumn{4}{c}{ Fluxo Rápido 19/12/05 } \\
\hline \hline Folha & $* \mathrm{E}_{\text {eff }}(\mathrm{MeV})$ & $\begin{array}{c}* * \phi_{(\mathrm{E}>\text { Eeff })} \\
\left(\mathrm{n} / \mathrm{cm}^{2} \mathrm{~s}\right)\end{array}$ & $\sigma_{\phi(\mathrm{E}>\text { Eeff })} \quad\left(\mathrm{n} / \mathrm{cm}^{2} \mathrm{~s}\right)$ \\
\hline \hline $\mathrm{Ni}$ & 2.8 & $1.32 \mathrm{E}+08$ & $1.6 \mathrm{E}+07$ \\
$\mathrm{Al}$ & 7.2 & $7.9 \mathrm{E}+06$ & $8 \mathrm{E}+05$ \\
$\mathrm{Ni}$ & 13.5 & $1.0 \mathrm{E}+05$ & $2.0 \mathrm{E}+04$ \\
\hline \hline \multicolumn{4}{c}{$*$ energia limiar efetiva } \\
& $* *$ fluxo acima da energia limiar efetiva
\end{tabular}


Tabela 32 - Fluxo Rápido 20/03/06.

\begin{tabular}{cccc}
\hline \hline \multicolumn{4}{c}{ Fluxo Rápido 20/03/06 } \\
\hline \hline Folha & $\mathrm{E}_{\text {eff }}(\mathrm{MeV})$ & $\begin{array}{c}\phi_{(\mathrm{E}>\mathrm{Eeff})} \\
\left(\mathrm{n} / \mathrm{cm}^{2} \mathrm{~s}\right)\end{array}$ & $\sigma_{\phi(\mathrm{E}>\mathrm{Eeff})}\left(\mathrm{n} / \mathrm{cm}^{2} \mathrm{~s}\right)$ \\
\hline \hline $\mathrm{Ni}$ & 2.8 & $1.15 \mathrm{E}+08$ & $1.5 \mathrm{E}+07$ \\
$\mathrm{Al}$ & 7.2 & $6.6 \mathrm{E}+06$ & $7 \mathrm{E}+05$ \\
$\mathrm{Ni}$ & 13.5 & $6.6 \mathrm{E}+04$ & $1.2 \mathrm{E}+04$ \\
\hline \hline
\end{tabular}

Na segunda determinação do fluxo epitérmico a incerteza variou devido a necessidade de utilizar outro detector para a contagem da folha, visto uma indisponibilidade de utilização do detector principal. Então, contou-se uma folha no detector principal e a mesma folha no outro detector e encontrou-se um fator de equivalência entre os detectores e devido a isso houve um aumento na incerteza que ficou evidente no fluxo epitérmico.

Para a reação de energia limiar do níquel (acima de $13.5 \mathrm{MeV}$ ), têm-se uma incerteza porcentual maior que as demais devido ao fluxo de nêutrons na posição de irradiação de amostra acima dessa energia ser baixo, o que causa uma estatística de contagem ruim para essa reação.

$\mathrm{Na}$ figura 47, a seguir, é mostrado o espectro de entrada obtido por simulações com o DOT 3.5, para a posição de irradiação de amostra.

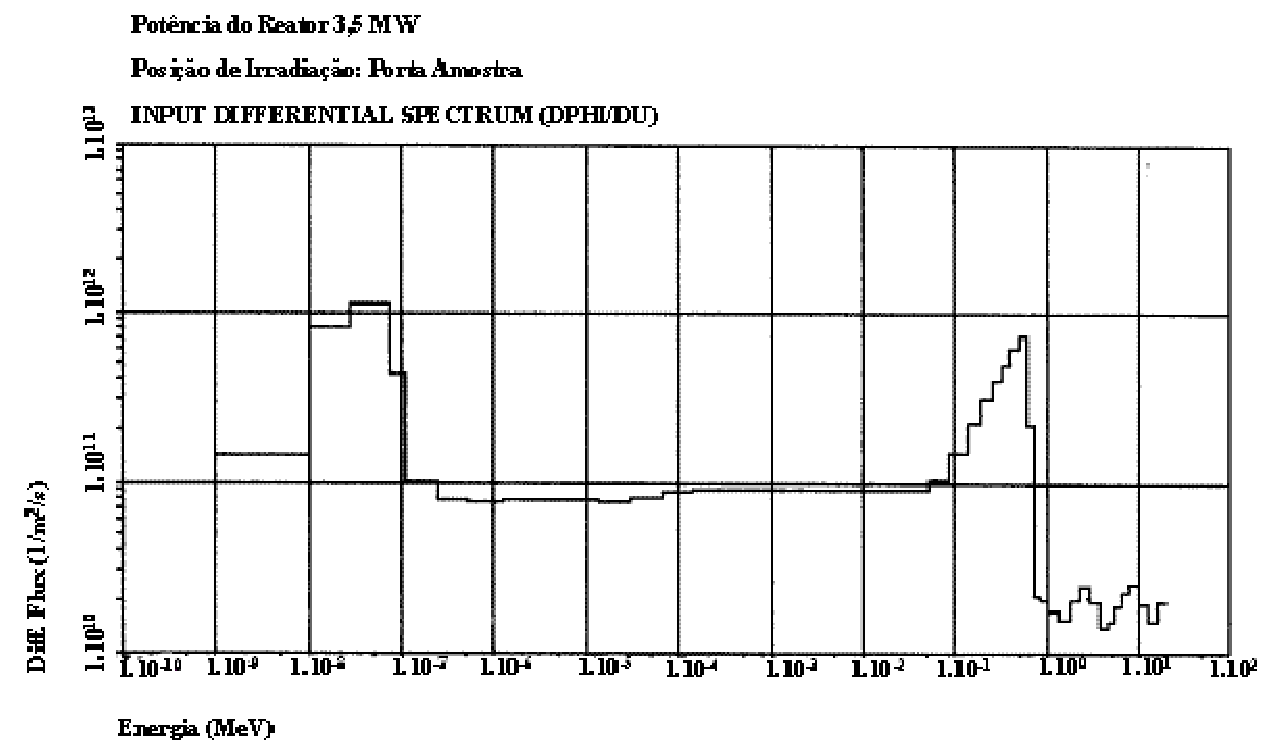

Figura 47 - Espectro de energia de nêutrons utilizado como dado de entrada para o programa SAND-BP. 
Utilizando-se as atividades de saturação por núcleo alvo dos detectores irradiados em 19/12/05 e 20/12/05 (folhas de ouro), e o espectro de entrada, após 5 interações (determinado nos dados de entrada) obteve-se o espectro abaixo (figura 48).

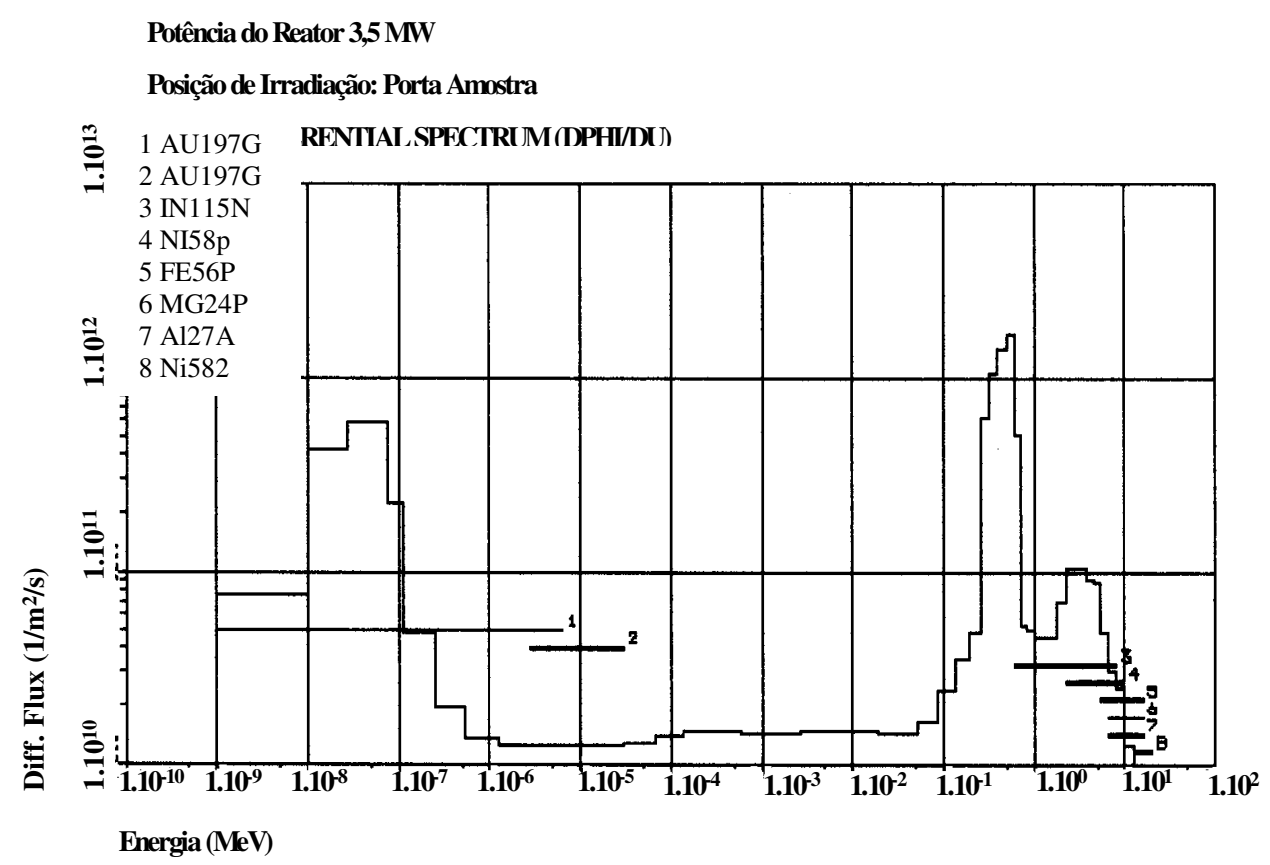

Figura 48 - Espectro de saída do programa SAND-BP após 5 interações.

As linhas numeradas no espectro indicam as regiões de energia onde cada folha foi importante para o ajuste do espectro. Neste espectro observa-se a modificação em relação ao espectro de entrada, as mais significativas são:

a) Menor intensidade, principalmente na região entre $1.10^{-7}$ e $1.10^{-1} \mathrm{MeV}$.

b) Formação de dois "picos" a partir da energia de $0,1 \mathrm{MeV}$. 


\section{CONCLUSÕES}

A calibração dos TLDs-400 evidenciou as três regiões de comportamentos deste dosímetro. Para o intervalo linear foi possível um ajuste até 90Gy; para o intervalo supralinear foi possível um ajuste até 500Gy; a partir desta dose começa a saturação. Sendo assim as doses no interior da instalação poderão ser medidas até valores de 500Gy com estes TLDs. Utilizando função linear até 90Gy e polinomial de 90 à 500Gy.

Para os TLDs-700 foi possível um ajuste linear até 20Gy sendo que a literatura mostra que os mesmos são lineares até $10 \mathrm{~Gy}$; essa extrapolação foi feita para facilitar a determinação da dose. Para doses superiores a 20Gy o ajuste linear não foi possível. O intervalo de supralinearidade começa em 20Gy e vai até 600Gy; com isso a determinação da dose devido a gama com esses dosímetros é possível até 600Gy usando uma função polinomial.

Para os TLDs-600 só foi possível calibrá-los de $0,5 \mathrm{mGy}$ até $0,1 \mathrm{~Gy}$, ou seja, a dose devido aos nêutrons só pode ser determinada até $0,1 \mathrm{~Gy}$. Esse intervalo de calibração não pode ser estendido no momento, pois, até agora não dispomos de uma fonte de nêutrons calibrada mais intensa que a fonte de ${ }^{252} \mathrm{Cf}+\mathrm{D}_{2} \mathrm{O}$ administrada pelo IRD/CNEN. No entanto considerando a informação do fabricante do TLD-600, Thermal Electron-Eberline, pode-se utilizar por extrapolação este ajuste linear até 10Gy.

No dia 06/12 foram obtidas as maiores doses, tanto para nêutrons quanto para gama. Isso porque neste dia a irradiação foi feita na ausência dos filtros e moderadores. A dose devido aos raios gama é confiável segundo a curva de calibração destes dosímetros, já a dose devido aos nêutrons esta fora do intervalo de calibração dos TLDs-600 e também fora do intervalo onde os mesmos apresentam comportamento linear.

Foi possível verificar que mesmo em condições distintas de irradiação a dose devido aos nêutrons é maior que a dose devido aos raios gama. Esta verificação é importante para a técnica da BNCT, pois, esta requer uma dose de nêutrons sempre maior que dose de radiação gama.

Novas medidas estão sendo realizadas para auxiliar a determinação de uma configuração de filtros e moderadores que minimizem a dose devido aos raios gama e maximizem a dose devido aos nêutrons térmicos. 
É necessário ampliar o intervalo de calibração do TLD-600 para determinar doses maiores em pontos da instalação para pesquisas em BNCT com a mesma confiabilidade que as apresentadas nas curvas já construídas para os TLDS-700 e os TLDS-400. Para os TLDs 600 é necessário dispor de uma fonte de nêutrons calibrada e intensa o suficiente para estender seu intervalo de medida de linearidade.

Todas as irradiações as medições feitas com os TLDs-400 apresentaram doses inferiores às feitas com os TLDs-700, isso se deve ao fato de que estes dosímetros, apesar de apresentarem baixa sensibilidade para nêutrons térmicos e rápidos, contem uma pequena quantidade de ${ }^{6} \mathrm{Li}$, um elemento com alta secção de choque para nêutrons térmicos. Essa pequena quantidade de ${ }^{6} \mathrm{Li}$ fez com que a dose medida por esses dosímetros fosse maior do que a dose medida com os TLDs-400 que não contém este elemento. Portanto, as medidas realizadas com os TLDs-400 são mais confiáveis que as medidas feitas com os TLDs-700.

Foram obtidos fluxos: térmico, epitérmico e rápido na posição de irradiação de amostra, utilizando-se detectores de ativação tipo folha. As repetições das medidas em dias diferentes comprovam a consistência dos resultados experimentais obtidos.

O espectro de energia de nêutrons na posição de irradiação de amostras, foi obtido com o código SAND-BP a partir dos valores dos fluxos citados acima.

A realização deste trabalho permitiu a caracterização do campo na instalação para estudo em BNCT. Os resultados das medidas permitiram ao grupo de BNCT a avaliação das simulações computacionais realizadas durante o projeto da instalação para estudo na área de BNCT, no que se refere ao projeto da instalação. Também permitirá avanço no desenvolvimento dos estudos de filtros para adequação do campo de radiação na posição de irradiação de amostras para a pesquisa da técnica em BNCT, bem como outras áreas de pesquisa, que vem sendo objeto de utilização desta instalação do IPEN. 


\section{REFERÊNCIAS BIBLIOGRÁFICAS}

[1] KANDA, K. Experience of boron neutron capture therapy in Japan.Advances in Neutrons Capture Therapy, Volume I, medicine and physics, ELSEVIER ed. 71-76,1997.

[2] P.R.P COELHO, A .C.HERNANDES AND P.T.D. SIQUEIRA, Neutron Flux Calculation in a BNCT Research Facility Implemeted in IEA-R1 Reactor "Research and Development in Neutron Capture Therapy", Monduzzi Editore, September 2002, p.197-2001.

[3] G.S. DE A E SILVA, P.R.P COELHO AND P.DE T. SIQUEIRA. Shielding Desing For Research Facility in the IEA-R1 Reator. PHYSOR 2002, Seoul, Korea, October 7-10, 2002

[4] ANTONIO C. HERNANDES, Caracterização do Campo de Radiação Numa Instalação Para Pesquisa Em BNCT Utilizando o Método de Monte Carlo CódigoMCNP-4B, Dissertação de mestrado, IPEN, 2002.

[5] HATANAKA, H. Boron Nêutron Capture Therapy for Tumor. Ed. Nigata: Nishimura, 1986.

[ 6] GASPAR, P.F., Considerações Sobre o Estudo da BNCT ( Terapia de Captura Neutrônica por Boro). Dissertação de mestrado, IPEN, 1994.

[7] ROLF F. BARTH, M. D, ALBERT H. SOLOWAY and ROBERT M. BRUGGER, Boron Neutron Capture Therapy of Brain Tumors: Past History, Current Status, and Future Potential (Clinical Science Reviews), Cancer Investigation, 14(6), 534-550(1996).

[8] WOLFGANG SAUERWEIN, KATALIN HIDEGHÉTY, DETLEF GABEL and RAYMOND L. MOSS, European Clinical Trials of Boron Neutron Capture Therapy for Gliobastoma, Nuclear News, 54-56, february 1998.

[9] S. W. S. MCKEEVER, MARKO MOSCOVITCH, P. D. TOWNSEND, Thermoluminescence Dosimetry Material: Properties and Uses, Nuclear Technology Publishing England.

[10] Certificado 03.042 IDAS/IAEA.

[11] Absorved Dose Determination in Photon and Electron Beams. Agência Internacional de Energia Atômica (1987)

[12] G.S.A. SILVA, P.T.D. SIQUEIRA, P.R.P COELHO , Projeto da Blindagem de Uma instalação Para Estudo em BNCT, PHYSOR 2002, Seoul, Korea, October 7-10,2002

[13] BOYLE R, Experiments and considerations Touching Colours, Royal Society, 413(1664).

[14] ROSA L.A.R. Dosimetria Termoluminescente Aplicada à Física Médica.: Departamento de Física médica. 2000.IRD.

[15] CAMERON, J. R. SUNTHARALINGAM, N.; KENNEY, G. N. Termoluminescentry Dosimetry Madison, Univ. Wisconsin Press,. 1968 
[16] MCKEEVER, S. W. S; MOSCOVITCH, M; TOWNSEND, P. D. thermoluminescence Dosimetry: Properties and Uses. London, Nuclear Technology Publishing, 1995.

[17] CURIE, D. - Luminescence Crystalline. Dunod, Paris. (1960)

[18] GARLICK, G. F. J. AND GIBSON, A. F., The Electron Trap Mechanism of Luminescence in Sulphide and Silicate Phosphors. Proc. Phys. Soc. London. 60: 574-590 (1948) Grossweiner, L. I. - A Note on the Analysis of First Order Curves. J. Appl. Phys. 24, $1306(1953)$

[19] HALPERIN, A. AND BRANER, A. A., Evaluation of Thermal Activation Energies from Glow Curves. Phys. Rev. 117, 408 (1960)

[20] LADELL, J., Redetermination of the Crystal Structure of Topaz: A Preliminary Account, Norelco Rep., 12, 34-39 (1965).

[21] ADIROWITCH, E. I., La Formule de Becquerel et la loi Élementaire du Déclin de la Luminescence de Phosphores Cristallins. J. Phys. Rad. 17-705 (1956).

[22]OBERHOFER, M.; SCHARMAMN. A. Applied Thermoluminescence Dosimetry. Published for the Commission of the European Comunities. Adam Hilger, Italy. 1979.

[23] LIMA, C. A. F., ROSA, L. A. R. AND CUNHA, P. G. - The Thermoluminescent Properties of Brazilian Topaz. Appl. Radiat. Isot., 37, 135-137 (1986)

[24]S.W.S. MCKEEVER,M. MOSCOVITCH, P.D. TOWNSEND, "Termoluninescence Dosimetry Materials: Properties and Uses", Nuclear Tecnology Publishing, Ashford, Kent, England 1995.

[25] MESTINIK, F. J. A Distribuição Espacial do Fluxo de Nêutrons no Núcleo do Reator IEA-R1, Obtida por Meio da Ativação de Folhas. São Paulo, 1978, Dissertação (Mestrado) - Escola Politécnica, Universidade de São Paulo.

[26] BECKURTZ, K. H.; WIRTZ, K. Neutron Physics. New York: 1964

[27] BITELli, U. D’U. Medida e Cálculo da Distribuiçãa Espacial e Energéticas de Nêutrons no Núcleo do Reator IEA - R1. São Paulo: 1988. Dissertação(Mestrado)Instituto de Pesquisas Energéticas e Nucleares.

[28] SZONDI, E. J.; ZSOLNAY, E. M. Regional Training Course on Calculation and Measurement of Neutron Flux Spectrum for Research Reactors. Serpong, Indonésia: September 27 - October 15: 1993. 
ANEXO 1 
RESULTADO DO SELECIONAMENTO DOS TLDS - 400 E TLDS - 700.

Resultado do selecionamento dos TLDs-400

\begin{tabular}{|c|c|c|c|c|c|c|c|c|c|c|}
\hline past. & $\begin{array}{l}1{ }^{1} \text { rod. } \\
\text { (nC) }\end{array}$ & $2^{\circ}$ resp. (nC) & $3^{\circ}$ resp. (nC) & média & desvio & divisão & des & $\begin{array}{c}\text { Cond. } \\
1\end{array}$ & $\begin{array}{c}\text { Cond. } \\
2\end{array}$ & $\begin{array}{c}\text { Cond. } \\
3\end{array}$ \\
\hline 1 & 50,8 & 49,9 & 49,8 & 50,17 & 0,55 & 0,01 & 1,10 & aprov. & aprov. & reprov. \\
\hline 2 & 52,1 & 52,6 & 51,8 & 52,17 & 0,40 & 0,01 & 0,77 & prov. & aprov. & reprov. \\
\hline 3 & 51,4 & 52,5 & 49,4 & 51,10 & 1,57 & 0,03 & 3,08 & aprov. & aprov. & reprov. \\
\hline 4 & 46,7 & 48,7 & 46,2 & 47,20 & 1,32 & 0,03 & 2,80 & aprov. & reprov. & reprov. \\
\hline 5 & 48,2 & 49,3 & 45,8 & 47,77 & 1,79 & 0,04 & 3,75 & aprov. & reprov. & reprov. \\
\hline 6 & 47,2 & 49,1 & 46,9 & 47,73 & 1,19 & 0,02 & 2,50 & aprov. & reprov. & reprov. \\
\hline 7 & 43,7 & 47,4 & 43,6 & 44,90 & 2,17 & 0,05 & 4,82 & aprov. & reprov. & reprov. \\
\hline 8 & 45,5 & 47,3 & 47,4 & 46,73 & 1,07 & 0,02 & 2,29 & aprov. & reprov. & reprov. \\
\hline 9 & 49 & 49,2 & 48,8 & 49,00 & 0,20 & 0,00 & 0,41 & aprov. & reprov. & reprov. \\
\hline 10 & 52,2 & 49,4 & 48,9 & 50,17 & 1,78 & 0,04 & 3,55 & aprov. & aprov. & reprov. \\
\hline 11 & 51,4 & 51 & 49,4 & 50,60 & 1,06 & 0,02 & 2,09 & aprov. & aprov. & reprov. \\
\hline 12 & 56,1 & 52,8 & 51,1 & 53,33 & 2,54 & 0,05 & 4,77 & aprov. & aprov. & aprov. \\
\hline 13 & 52,7 & 52 & 51,2 & 51,97 & 0,75 & 0,01 & 1,44 & aprov. & aprov. & reprov. \\
\hline 14 & 52,4 & 50,8 & 49,1 & 50,77 & 1,65 & 0,03 & 3,25 & aprov. & aprov. & reprov. \\
\hline 15 & 53,2 & 52 & 51,5 & 52,23 & 0,87 & 0,02 & 1,67 & aprov. & aprov. & reprov. \\
\hline 16 & 51,9 & 51,7 & 51,1 & 51,57 & 0,42 & 0,01 & 0,81 & aprov. & aprov. & reprov. \\
\hline 17 & 52,4 & 51,4 & 51,5 & 51,77 & 0,55 & 0,01 & 1,06 & aprov. & aprov. & reprov. \\
\hline 18 & 52,1 & 49,8 & 51 & 50,97 & 1,15 & 0,02 & 2,26 & aprov. & aprov. & reprov. \\
\hline 19 & 54,8 & 53,9 & 53,1 & 53,93 & 0,85 & 0,02 & 1,58 & aprov. & aprov. & aprov. \\
\hline 20 & 54,1 & 50,3 & 50,4 & 51,60 & 2,17 & 0,04 & 4,20 & aprov. & aprov. & reprov. \\
\hline 21 & 56,9 & 55,5 & 53,7 & 55,37 & 1,60 & 0,03 & 2,90 & aprov. & aprov. & aprov. \\
\hline 22 & 55,1 & 54,6 & 52,2 & 53,97 & 1,55 & 0,03 & 2,87 & aprov. & aprov. & aprov. \\
\hline 23 & 51,4 & 48,1 & 47,4 & 48,97 & 2,14 & 0,04 & 4,36 & aprov. & reprov. & reprov. \\
\hline 24 & 53,3 & 49,4 & 50,6 & 51,10 & 2,00 & 0,04 & 3,91 & aprov. & aprov. & reprov. \\
\hline 25 & 57,9 & 54,5 & 53,2 & 55,20 & 2,43 & 0,04 & 4,40 & aprov. & aprov. & aprov. \\
\hline 26 & 56,8 & 52,1 & 56,8 & 55,23 & 2,71 & 0,05 & 4,91 & aprov. & aprov. & aprov. \\
\hline 27 & 57 & 51,8 & 54,5 & 54,43 & 2,60 & 0,05 & 4,78 & aprov. & aprov. & aprov. \\
\hline 28 & 56,4 & 49,6 & 57,4 & 54,47 & 4,24 & 0,08 & 7,79 & reprov. & aprov. & aprov. \\
\hline 29 & 52,5 & 48,1 & 49,3 & 49,97 & 2,27 & 0,05 & 4,55 & aprov. & aprov. & reprov. \\
\hline 30 & 58,4 & 54,8 & 53,2 & 55,47 & 2,66 & 0,05 & 4,80 & aprov. & aprov. & reprov \\
\hline
\end{tabular}


Resultado do selecionamento dos TLDs-400 (continuação)

past. ${ }^{1}$ rod. ${ }^{2}$ resp. (nC) $3^{\circ}$ resp. (nC) média desvio divisão desv. \% Cond. Cond. Cond.

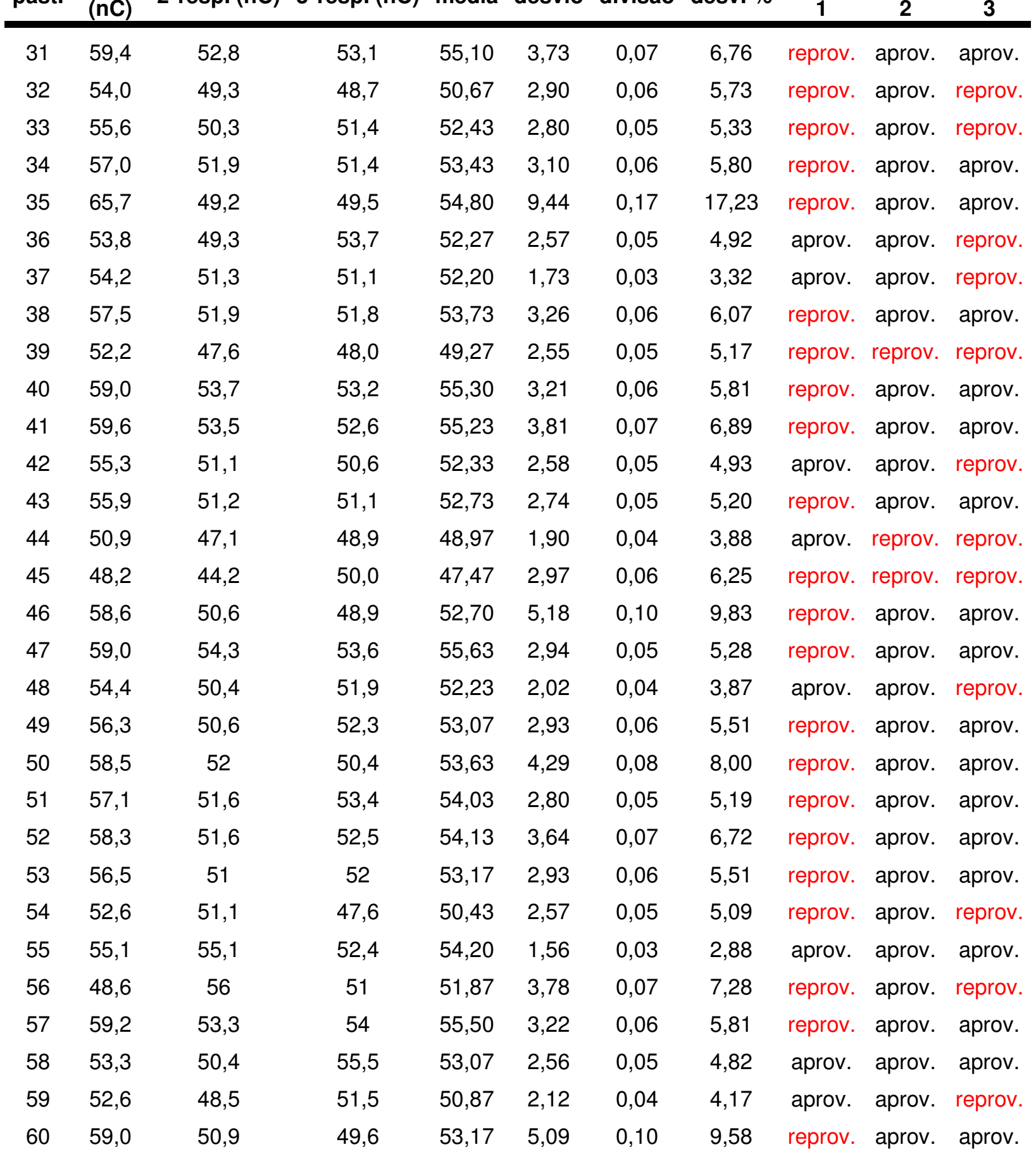


Resultado do selecionamento dos TLDs-400 (continuação) past. ${ }^{1}$ rod. $2^{\circ}$ resp. (nC) $3^{\circ}$ resp. (nC) média desvio divisão desv. \% Cond. Cond. Cond.

\begin{tabular}{|c|c|c|c|c|c|c|c|c|c|}
\hline 61 & 52,7 & 50,0 & 48,4 & 50,37 & 2,17 & 0,04 & 4,32 & aprov. aprov. & reprov. \\
\hline 62 & 58,9 & 51,6 & 51,6 & 54,03 & 4,21 & 0,08 & 7,80 & reprov. aprov. & aprov. \\
\hline 63 & 57,5 & 55,6 & 62,2 & 58,43 & 3,40 & 0,06 & 5,81 & reprov. aprov. & aprov. \\
\hline 64 & 52,4 & 49,1 & 52,1 & 51,20 & 1,82 & 0,04 & 3,56 & aprov. aprov. & reprov. \\
\hline 65 & 51,6 & 47,7 & 48,6 & 49,30 & 2,04 & 0,04 & 4,14 & aprov. reprov. & reprov. \\
\hline 66 & 49,3 & 47,2 & 48,2 & 48,23 & 1,05 & 0,02 & 2,18 & aprov. reprov. & reprov. \\
\hline 67 & 54,3 & 51,7 & 51,5 & 52,50 & 1,56 & 0,03 & 2,98 & aprov. aprov. & reprov. \\
\hline 68 & 51,4 & 47,4 & 47,2 & 48,67 & 2,37 & 0,05 & 4,87 & aprov. reprov. & reprov. \\
\hline 69 & 51,8 & 51,5 & 50,9 & 51,40 & 0,46 & 0,01 & 0,89 & aprov. & reprov. \\
\hline 70 & 49,3 & 48,9 & 46,5 & 48,23 & 1,51 & 0,03 & 3,14 & reprov. & reprov. \\
\hline 71 & 53,5 & 50,8 & 51,5 & 51,93 & 1,40 & 0,03 & 2,70 & aprov. aprov. & reprov. \\
\hline 72 & 50,2 & 46,0 & 53,5 & 49,90 & 3,76 & 0,08 & 7,53 & reprov. aprov. & reprov. \\
\hline 73 & 49,5 & 48,2 & 51,6 & 49,77 & 1,72 & 0,03 & 3,45 & aprov. aprov. & reprov. \\
\hline 74 & 48,9 & 47,2 & 47,9 & 48,00 & 0,85 & 0,02 & 1,78 & aprov. reprov. & reprov. \\
\hline 75 & 50,1 & 47,4 & 47,7 & 48,40 & 1,48 & 0,03 & 3,06 & aprov. reprov. & reprov. \\
\hline 76 & 54,2 & 47,3 & 48,4 & 49,97 & 3,71 & 0,07 & 7,42 & reprov. aprov. & reprov. \\
\hline 77 & 50,6 & 44,7 & 45,5 & 46,93 & 3,20 & 0,07 & 6,82 & reprov. reprov. & reprov. \\
\hline 78 & 52,9 & 43,9 & 46,7 & 47,83 & 4,61 & 0,10 & 9,63 & reprov. reprov. & reprov. \\
\hline 79 & 50,5 & 42,8 & 46,9 & 46,73 & 3,85 & 0,08 & 8,24 & reprov. reprov. & reprov. \\
\hline 80 & 51,0 & 44,0 & 45,8 & 46,93 & 3,64 & 0,08 & 7,75 & reprov. reprov. & reprov. \\
\hline 81 & 47,2 & 43,0 & 45,4 & 45,20 & 2,11 & 0,05 & 4,66 & aprov. reprov. & reprov. \\
\hline 82 & 50,4 & 43,1 & 47,3 & 46,93 & 3,66 & 0,08 & 7,81 & reprov. reprov. & reprov. \\
\hline 83 & 49,4 & 43,2 & 46,0 & 46,20 & 3,10 & 0,07 & 6,72 & reprov. reprov. & reprov. \\
\hline 84 & 53,5 & 45,0 & 48,4 & 48,97 & 4,28 & 0,09 & 8,74 & reprov. reprov. & reprov. \\
\hline 85 & 47,8 & 48,6 & 43,1 & 46,50 & 2,97 & 0,06 & 6,39 & reprov. reprov. & reprov. \\
\hline 86 & 50,5 & 44,7 & 46,9 & 47,37 & 2,93 & 0,06 & 6,18 & reprov. reprov. & reprov. \\
\hline 87 & 51,7 & 46,2 & 46,6 & 48,17 & 3,07 & 0,06 & 6,37 & reprov. reprov. & reprov. \\
\hline 88 & 60,2 & 44,1 & 48,9 & 51,07 & 8,27 & 0,16 & 16,19 & reprov. aprov. & reprov. \\
\hline 89 & 59,9 & 44,1 & 43,0 & 49,00 & 9,46 & 0,19 & 19,30 & reprov. reprov. & reprov. \\
\hline 90 & 49,0 & 44,1 & 45,5 & 46,20 & 2,52 & 0,05 & 5,46 & reprov. reprov. & reprov. \\
\hline
\end{tabular}


Resultado do selecionamento dos TLDs-700

past. ${ }^{1}$ rod. $2^{\circ}$ resp. (nC) $3^{\circ}$ resp. (nC) média desvio divisão desv. \% Cond. Cond. Cond.

\begin{tabular}{|c|c|c|c|c|c|c|c|c|c|}
\hline 9,4 & 8,990 & 9,400 & 9,26 & 0,24 & 0,026 & 2,555 & aprov. & aprov. & aprov. \\
\hline 8,784 & 8,311 & 8,521 & 8,54 & 0,24 & 0,028 & 2,777 & aprov. & reprov. & aprov. \\
\hline 8,808 & 8,860 & 8,546 & 8,74 & 0,17 & 0,019 & 1,926 & aprov. & reprov. & aprov. \\
\hline 8,825 & 8,551 & 8,443 & 8,61 & 0,20 & 0,023 & 2,287 & aprov. & reprov. & aprov. \\
\hline 8,868 & 8,705 & 8,516 & 8,70 & 0,18 & 0,020 & 2,024 & aprov. & reprov. & aprov. \\
\hline 8,891 & 9,137 & 9,100 & 9,04 & 0,13 & 0,015 & 1,467 & aprov. & reprov. & aprov. \\
\hline 8,896 & 9,164 & 8,579 & 8,88 & 0,29 & 0,033 & 3,302 & aprov. & reprov. & aprov. \\
\hline 8,898 & 9,210 & 8,692 & 8,93 & 0,26 & 0,029 & 2,919 & aprov. & reprov. & aprov. \\
\hline 8,949 & 9,300 & 8,891 & 9,05 & 0,22 & 0,024 & 2,447 & aprov. & reprov. & aprov. \\
\hline 8,996 & 9,340 & 8,970 & 9,10 & 0,21 & 0,023 & 2,266 & aprov. & reprov. & aprov. \\
\hline 9,003 & 9,354 & 9,023 & 9,13 & 0,20 & 0,022 & 2,159 & aprov. & reprov. & aprov. \\
\hline 9,106 & 9,110 & 9,039 & 9,09 & 0,04 & 0,004 & 0,438 & aprov. & reprov. & aprov. \\
\hline 9,11 & 9,000 & 9,043 & 9,05 & 0,06 & 0,006 & 0,612 & aprov. & reprov. & aprov. \\
\hline 9,13 & 9,200 & 9,080 & 9,14 & 0,06 & 0,007 & 0,662 & aprov. & reprov. & aprov. \\
\hline 9,138 & 9,490 & 9,170 & 9,27 & 0,19 & 0,021 & 2,098 & aprov. & aprov. & aprov. \\
\hline 9,152 & 9,533 & 9,500 & 9,39 & 0,21 & 0,022 & 2,245 & aprov. & aprov. & aprov. \\
\hline 9,186 & 9,566 & 9,249 & 9,33 & 0,20 & 0,022 & 2,182 & aprov. & aprov. & aprov. \\
\hline 9,188 & 9,575 & 9,460 & 9,41 & 0,20 & 0,021 & 2,114 & aprov. & aprov. & aprov. \\
\hline 9,194 & 9,577 & 9,286 & 9,35 & 0,20 & 0,021 & 2,136 & aprov. & aprov. & aprov. \\
\hline 9,209 & 9,619 & 9,292 & 9,37 & 0,22 & 0,023 & 2,311 & aprov. & reprov. & aprov. \\
\hline 9,237 & 9,630 & 9,299 & 9,39 & 0,21 & 0,023 & 2,253 & aprov. & aprov. & aprov. \\
\hline 9,33 & 9,655 & 9,334 & 9,44 & 0,19 & 0,020 & 1,976 & aprov. & aprov. & aprov. \\
\hline 9,35 & 9,703 & 9,393 & 9,48 & 0,19 & 0,020 & 2,032 & aprov. & aprov. & aprov. \\
\hline 9,354 & 9,786 & 9,422 & 9,52 & 0,23 & 0,024 & 2,439 & aprov. & aprov. & aprov. \\
\hline 9,364 & 9,788 & 9,423 & 9,52 & 0,23 & 0,024 & 2,410 & aprov. & aprov. & aprov. \\
\hline 9,385 & 9,801 & 9,428 & 9,54 & 0,23 & 0,024 & 2,401 & aprov. & aprov. & aprov. \\
\hline 9,393 & 9,803 & 9,440 & 9,55 & 0,22 & 0,024 & 2,351 & aprov. & aprov. & aprov. \\
\hline 9,397 & 9,860 & 9,466 & 9,57 & 0,25 & 0,026 & 2,610 & aprov. & aprov. & aprov. \\
\hline 9,397 & 9,885 & 9,460 & 9,58 & 0,27 & 0,028 & 2,768 & aprov. & aprov. & aprov. \\
\hline 9,401 & 9,927 & 9,517 & 9,62 & 0,28 & 0,029 & 2,877 & aprov. & aprov. & aprov. \\
\hline 9,415 & 9,958 & 9,526 & 9,63 & 0,29 & 0,030 & 2,979 & aprov. & aprov. & aprov. \\
\hline 9,423 & 10,002 & 9,542 & 9,66 & 0,31 & 0,032 & 3,170 & aprov. & aprov. & aprov. \\
\hline
\end{tabular}




\section{Resultado do selecionamento dos TLDs-700 (continuação)}

\begin{tabular}{|c|c|c|c|c|c|c|c|c|c|c|}
\hline ast. & $\begin{array}{c}1 \text { rod. } \\
\text { (nC) }\end{array}$ & $2^{\circ}$ resp. (nC) & 3 resp. (nC) & média & desvio & divisão & desv. $\%$ & $\begin{array}{c}\text { Cond. } \\
1 \\
\end{array}$ & $\begin{array}{c}\text { Cond. } \\
2 \\
\end{array}$ & $\begin{array}{c}\text { Cond. } \\
3 \\
\end{array}$ \\
\hline 34 & 9,424 & 10,078 & 9,575 & 9,69 & 0,34 & 0,035 & 3,535 & aprov. & aprov. & aprov. \\
\hline 35 & 9,433 & 10,134 & 9,581 & 9,72 & 0,37 & 0,038 & 3,801 & aprov. & aprov. & aprov. \\
\hline 36 & 9,453 & 10,188 & 9,586 & 9,74 & 0,39 & 0,040 & 4,019 & aprov. & aprov. & aprov. \\
\hline 37 & 9,458 & 10,204 & 9,596 & 9,75 & 0,40 & 0,041 & 4,070 & aprov. & aprov. & aprov. \\
\hline 38 & 9,468 & 10,214 & 9,605 & 9,76 & 0,40 & 0,041 & 4,066 & aprov. & aprov. & aprov. \\
\hline 39 & 9,505 & 10,290 & 9,644 & 9,81 & 0,42 & 0,043 & 4,269 & aprov. & aprov. & aprov. \\
\hline 40 & 9,507 & 10,306 & 9,655 & 9,82 & 0,43 & 0,043 & 4,328 & aprov. & aprov. & aprov. \\
\hline 41 & 9,516 & 10,306 & 9,657 & 9,83 & 0,42 & 0,043 & 4,288 & aprov. & aprov. & aprov. \\
\hline 42 & 9,519 & 10,314 & 9,781 & 9,87 & 0,41 & 0,041 & 4,104 & aprov. & aprov. & aprov. \\
\hline 43 & 9,521 & 10,391 & 9,793 & 9,90 & 0,45 & 0,045 & 4,495 & aprov. & aprov. & aprov. \\
\hline 44 & 9,523 & 10,391 & 9,801 & 9,90 & 0,44 & 0,045 & 4,475 & aprov. & aprov. & aprov. \\
\hline 45 & 9,543 & 564 & 9,535 & 9,55 & 0,01 & 0,002 & 0,157 & & prov. & prov. \\
\hline 46 & 9,564 & 10,408 & 9,815 & 9,93 & 0,43 & 0,044 & 4,365 & & prov. & prov. \\
\hline 47 & 9,577 & & ,829 & 9,94 & 0,43 & & 4,287 & & & aprov. \\
\hline 48 & 9,587 & & 9,851 & & 0,47 & & & & & aprov. \\
\hline 49 & 9,613 & & 9,868 & & 0,45 & & & & aprov. & aprov. \\
\hline 50 & 9,7 & & & 10, & 0,43 & & & aprov. & aprov. & aprov. \\
\hline 51 & 9,728 & 10,514 & & 0,06 & 0,41 & & & aprov. & rov. & aprov. \\
\hline 52 & 9,731 & 10,514 & & 0,06 & 0,41 & & & aprov. & rov. & aprov. \\
\hline 53 & 9,735 & 10 & & & 0,45 & & 4,424 & aprov. & ov. & aprov. \\
\hline 54 & 9,754 & 10,612 & ,985 & 10,12 & 0,44 & 044 & 4,390 & aprov. & aprov. & aprov. \\
\hline 55 & 9,769 & 10,614 & 10,011 & 10,13 & 0,44 & 0,043 & 4,296 & aprov. & aprov. & aprov. \\
\hline 56 & 9,771 & 10,120 & 10,500 & 10,13 & 0,36 & 0,036 & 3,599 & aprov. & aprov. & aprov. \\
\hline 57 & 9,802 & 10,714 & 10,059 & 10,19 & 0,47 & 0,046 & 4,615 & aprov. & aprov. & aprov. \\
\hline 58 & 9,805 & 10,714 & 10,081 & 10,20 & 0,47 & 0,046 & 4,571 & aprov. & aprov. & aprov. \\
\hline 59 & 9,811 & 10,714 & 10,114 & 10,21 & 0,46 & 0,045 & 4,501 & aprov. & aprov. & aprov. \\
\hline 60 & 9,822 & 10,714 & 10,151 & 10,23 & 0,45 & 0,044 & 4,412 & aprov. & aprov. & aprov. \\
\hline 61 & 9,843 & 10,714 & 10,560 & 10,37 & 0,46 & 0,045 & 4,483 & aprov. & aprov. & aprov. \\
\hline 62 & 9,879 & 10,714 & 10,204 & 10,27 & 0,42 & 0,041 & 4,102 & aprov. & aprov. & aprov. \\
\hline 63 & 9,904 & 10,714 & 10,204 & 10,27 & 0,41 & 0,040 & 3,988 & aprov. & aprov. & aprov. \\
\hline 64 & 9,905 & 10,230 & 10,204 & 10,11 & 0,18 & 0,018 & 1,786 & aprov. & aprov. & aprov. \\
\hline 65 & 9,937 & 10,815 & 10,204 & 10,32 & 0,45 & 0,044 & 4,360 & aprov. & aprov. & aprov. \\
\hline 66 & 9,967 & 10,000 & 10,204 & 10,06 & 0,13 & 0,013 & 1,276 & aprov. & aprov. & aprov. \\
\hline 67 & 9,988 & 10,996 & 10,290 & 10,42 & 0,52 & 0,050 & 4,964 & aprov. & aprov. & aprov. \\
\hline
\end{tabular}




\section{Resultado do selecionamento dos TLDs-700 (continuação)}

past. $\begin{gathered}{ }^{\circ} \text { rod. } \\ \text { (nC) }\end{gathered}{ }^{\circ}$ resp. (nC) $3^{\circ}$ resp. (nC) média desvio divisão desv. \% $\begin{gathered}\text { Cond. } \\ \mathbf{1}\end{gathered} \begin{gathered}\text { Cond. } \\ \mathbf{2}\end{gathered} \begin{gathered}\text { Cond. } \\ \mathbf{3}\end{gathered}$

\begin{tabular}{|c|c|c|c|c|c|c|c|c|c|c|}
\hline 68 & 10,00 & 10,996 & 10,391 & 10,46 & 0,50 & 0,048 & 4,798 & aprov. & aprov. & aprov. \\
\hline 69 & 10,00 & 11,097 & 10,492 & 10,53 & 0,55 & 0,052 & 5,219 & reprov. & aprov. & aprov. \\
\hline 70 & 10,10 & 10,000 & 10,510 & 10,20 & 0,27 & 0,026 & 2,649 & aprov. & aprov. & aprov. \\
\hline 71 & 10,10 & 11,115 & 10,510 & 10,58 & 0,51 & 0,048 & 4,828 & aprov. & aprov. & aprov. \\
\hline 72 & 10,10 & 11,198 & 10,514 & 10,60 & 0,55 & 0,052 & 5,230 & reprov. & aprov. & aprov. \\
\hline 73 & 10,20 & 11,198 & 10,514 & 10,64 & 0,51 & 0,048 & 4,798 & aprov. & aprov. & aprov. \\
\hline 74 & 10,20 & 11,198 & 10,612 & 10,67 & 0,50 & 0,047 & 4,701 & aprov. & aprov. & aprov. \\
\hline 75 & 10,30 & 11,215 & 10,694 & 10,74 & 0,46 & 0,043 & 4,276 & aprov. & aprov. & aprov. \\
\hline 76 & 10,30 & 11,215 & 10,714 & 10,74 & 0,46 & 0,043 & 4,265 & aprov. & aprov. & aprov. \\
\hline 77 & 10,30 & 11,224 & 10,714 & 10,75 & 0,46 & 0,043 & 4,309 & aprov. & aprov. & reprov. \\
\hline 78 & 10,30 & 11,299 & 10,795 & 10,80 & 0,50 & 0,046 & 4,626 & aprov. & aprov. & reprov. \\
\hline 79 & 10,40 & 11,315 & 10,918 & 10,88 & 0,46 & 0,042 & 4,219 & aprov. & aprov. & reprov. \\
\hline 80 & 10,40 & 11,315 & 10,996 & 10,90 & 0,46 & 0,043 & 4,261 & aprov. & aprov. & reprov. \\
\hline 81 & 10,40 & 10,500 & 10,996 & 10,63 & 0,32 & 0,030 & 3,004 & aprov. & aprov. & reprov. \\
\hline 82 & 10,40 & 11,400 & 11,115 & 10,97 & 0,52 & 0,047 & 4,695 & aprov. & aprov. & reprov. \\
\hline 83 & 10,50 & 11,415 & 11,198 & 11,04 & 0,48 & 0,043 & 4,333 & aprov. & aprov. & aprov. \\
\hline 84 & 10,60 & 11,428 & 11,315 & 11,11 & 0,45 & 0,040 & 4,042 & aprov. & aprov. & reprov. \\
\hline 85 & 10,70 & 11,516 & 11,326 & 11,18 & 0,43 & 0,038 & 3,818 & aprov. & aprov. & reprov. \\
\hline 86 & 10,80 & 12,016 & 11,501 & 11,44 & 0,61 & 0,053 & 5,337 & reprov. & aprov. & reprov. \\
\hline 87 & 10,90 & 12,016 & 11,531 & 11,48 & 0,56 & 0,049 & 4,874 & aprov. & aprov. & reprov. \\
\hline 88 & 11,00 & 12,317 & 11,602 & 11,64 & 0,66 & 0,057 & 5,663 & reprov. & aprov. & reprov. \\
\hline 89 & 11,30 & 12,510 & 11,616 & 11,81 & 0,63 & 0,053 & 5,313 & reprov. & aprov. & reprov. \\
\hline 90 & 11,40 & 13,418 & 12,245 & 12,35 & 1,01 & 0,082 & 8,201 & reprov. & aprov. & reprov. \\
\hline
\end{tabular}


ANEXO 2 


\section{CALIBRAÇÃO TLD-400 e TLD-700 CTR CALIBRAÇÃO TLD-600 IRD.}

resp. méd. $(\boldsymbol{\mu C})$
3,04
6,12
34,81
48,86
73,55
81,76
91,21
115,33
144,67
242,33
335,00
440,67
743,67
855,00
926,33
3,38
13,86
21,85
25,31
31,89
21,45
21,91
21,34
27,50
21,97
4,05
0,16
2,18
0,31
3,42

\section{TLD-400/Calibração CTR}

\begin{tabular}{crrr}
$\boldsymbol{\sigma}_{\text {resp. }}(\boldsymbol{\mu C})$ & $\boldsymbol{\sigma} \%$ & dose $(\mathbf{G y})$ & \multicolumn{1}{c}{$\boldsymbol{\sigma}_{\text {dose }}(\mathbf{G y})$} \\
0,12 & 3,79 & 0,500 & 0,025 \\
0,28 & 4,50 & 1,000 & 0,050 \\
1,87 & 5,38 & 5,000 & 0,250 \\
2,19 & 4,49 & 7,000 & 0,350 \\
3,95 & 5,37 & 10,000 & 0,500 \\
0,64 & 0,79 & 11,000 & 0,550 \\
2,65 & 2,90 & 12,000 & 0,600 \\
2,08 & 1,80 & 15,000 & 0,750 \\
6,03 & 4,17 & 20,000 & 1,000 \\
18,50 & 7,64 & 30,000 & 1,500 \\
10,54 & 3,14 & 40,000 & 2,000 \\
14,01 & 3,18 & 50,000 & 2,500 \\
26,58 & 3,57 & 70,000 & 3,500 \\
24,25 & 2,84 & 80,000 & 4,000 \\
41,43 & 4,47 & 90,000 & 4,500 \\
1,33 & 39,18 & 100,000 & 5,000 \\
0,83 & 5,97 & 200,000 & 10,000 \\
1,06 & 4,87 & 300,000 & 15,000 \\
0,55 & 2,18 & 400,000 & 20,000 \\
1,15 & 3,59 & 502,000 & 25,100 \\
1,48 & 6,88 & 604,000 & 30,200 \\
0,99 & 4,50 & 703,000 & 35,150 \\
1,90 & 8,92 & 803,000 & 40,150 \\
0,47 & 1,70 & 902,000 & 45,100 \\
1,86 & 8,47 & 1001,000 & 50,050 \\
0,25 & 6,26 & 100,000 & 5,000 \\
0,01 & 5,29 & 5,000 & 0,250 \\
0,08 & 3,57 & 50,000 & 2,500 \\
0,03 & 9,76 & 10 & 0,500 \\
0,18 & 5,40 & 800 & 4,000 \\
& & &
\end{tabular}


TLD-700/Calibração CTR

\begin{tabular}{rrrr} 
dose $(\mathbf{G y})$ & $\boldsymbol{\sigma}_{\text {dose }}(\mathbf{G y})$ & resp. méd. $(\mu \mathbf{C})$ & $\boldsymbol{\sigma}_{\text {resp. }}(\mu \mathbf{C})$ \\
\hline 0,500 & 0,025 & 0,746 & 0,061 \\
1,000 & 0,050 & 1,447 & 0,012 \\
5,000 & 0,250 & 8,297 & 0,472 \\
7,000 & 0,350 & 11,743 & 0,420 \\
10,000 & 0,500 & 18,817 & 0,580 \\
11,000 & 0,550 & 20,510 & 0,410 \\
12,000 & 0,600 & 22,125 & 0,502 \\
15,000 & 0,750 & 29,937 & 2,560 \\
20,000 & 1,000 & 41,457 & 0,226 \\
30,000 & 1,500 & 73,733 & 4,702 \\
40,000 & 2,000 & 106,333 & 3,055 \\
50,000 & 2,500 & 160,667 & 6,110 \\
70,000 & 3,500 & 256,000 & 2,000 \\
80,000 & 4,000 & 309,000 & 0,000 \\
90,000 & 4,500 & 263,000 & 12,166 \\
100,000 & 5,000 & 303,667 & 1,155 \\
200,000 & 10,000 & 586,333 & 22,008 \\
300,000 & 15,000 & 729,667 & 8,622 \\
400,000 & 20,000 & 923,667 & 32,593 \\
503,000 & 25,150 & 11,395 & 0,276 \\
600,000 & 30,000 & 13,195 & 0,106 \\
700,000 & 35,000 & 19,387 & 1,701 \\
802,000 & 40,100 & 20,667 & 0,376 \\
903,000 & 45,150 & 21,133 & 1,308 \\
1005,000 & 50,250 & 20,570 & 0,632
\end{tabular}

TLD-600/Calibração IRD

\begin{tabular}{rrrr} 
dose $(\mathbf{m G y})$ & $\boldsymbol{\sigma}_{\text {dose }}(\mathbf{m G y})$ & resp. media $(\mathbf{n C})$ & \multicolumn{2}{c}{$\boldsymbol{\sigma}_{\text {resp. }}(\mathbf{n C})$} \\
\hline 0,0005 & 0,0001 & 0,0243 & 0,0019 \\
0,0010 & 0,0001 & 0,0299 & 0,0038 \\
0,0050 & 0,0002 & 0,1415 & 0,0090 \\
0,0100 & 0,0003 & 0,2725 & 0,0178 \\
0,0500 & 0,0070 & 1,3933 & 0,0680 \\
0,1000 & 0,0140 & 2,7317 & 0,1165
\end{tabular}

